\title{
Advanced Coal-Fueled \\ Gas Turbine Systems
}

\author{
Final Report
}

Work Performed Under Contract No.: DE-AC21-86MC23167

\author{
For \\ U.S. Department of Energy \\ Office of Fossil Energy \\ Morgantown Energy Technology Center \\ P.O. Box 880 \\ Morgantown, West Virginia 26507-0880
}

\author{
By \\ Westinghouse Electric Corporation \\ Power Generation Business Unit \\ 4400 Alafaya Trail \\ Orlando, Florida 32826-2399
}

August 1993 


\section{TABLE OF CONTENTS}

LIST OF FIGURES

LIST OF TABLES

iv

1. EXECUTIVE SUMMARY 1-1

2. INTRODUCTION 2-1

2.1 SCOPE OF REPORT 2-1

2.2 PROGRAM OBJECTIVES 2-1

2.3 COMBUSTOR CONCEPT DEVELOPMENT $2-2$

3. REFERENCE SYSTEM DEFINITION 3-1

4. SUBSCALE SLAGGNG COMBUSTOR APPARATUS, 4-1 PLAN AND METHOD

5. SUBSCALE SLAGGING COMBUSTOR TEST RESULTS 5-1 AND DISCUSSION

6. ANCILLARY STUDIES 6-1

6.1 COLD-FLOW CYCLONE TESTS 6-1

6.2 SUBSCALE CASCADE DESIGN 6-4

6.3 SULFUR STUDIES

6.4 AMES ALKALI MEASUREMENTS 6-7

6.5 GENERIC TURBDE DESIGN STUDY 6-7

6.6 SUBBITUMNOUS COAL TESTING FOR 6-13 NORTHERN STATES POWER

6.7 ADVANCED TURBINE SYSTEMS - SCOPING 6-14 AND FEASIBILITY STUDIES

7. CONCLUSIONS AND RECOMMENDATIONS 7-1

$\begin{array}{ll}\text { PROJECT BIBLIOGRAPHY PB-1 } & \text { PBY }\end{array}$ 


\section{LIST OF FIGURES}

Fig. Title

Page

2-1 Artist's Rendering of Combustor

2-2 Schematic of Subscale Slagging Combustor Test Rig with

Real-Time Slag-Tapping Capability and Slagging Cyclone

3-1 Comparison of COE for Conventional Power Plants and PC and CWM CFCTCC Reference Plants

4-1 Overall Test System Schematic

4-2 Schematic of Original Subscale Slagging Combustor Test Rig 4-2

4-3 Schematic of Subscale Slagging Combustor Test Rig as Utilized 4-8

4-4 Actual Picture of Subscale Slagging Combustor

Test Rig with Slagging Cyclone

4-5 Curved Body Impact Separator with Slag Tap and Collection Vesse!

5-1 Uniformly Distributed Slag on the Dome of Primary Combustion Chamber

Uniformly Distributed Residual Slag on the Wall of the Primary Combustion Chamber Looking Towards the Exit Nozale

Uniformly Distributed Residual Slag on the Impact Separator

Following a Typical Run

Comparison of Primary Zone Carbon Conversion for CWM and PC; Primary Zone Exit Data

(Dorchester and Pittsburgh No. 8) and Subbituminous

(Wyoming Rosebud) Pulverized Coals 


\section{LIST OF FIGURES}

(continued)

Fig. Title

Page

5-8 Slag Rejection Data for Subscale Slagging Combustor Test

5-9 Measured Exhaust Gas Particulate Loadings as a Function of Particle Size for Dorchester and Pittsburgh No. 8 Pulverized Coal with and without Limestone Sorbent

5-10 Primary Zone Flame Temperature as a Function of Equivalence Ratio Profiles at Several Average Exit Temperatures

Particle Size Distributions from Cyclone Bucket, Measured Size Distributions for: (1) 200 Mesh Dorchester Coal;

(2) Sample from Cyclone Bucket, Cl-1; (3) Sample No. 1 Test from Cyclone Bucket, Test Cl-2; (4) Sample No. 2 from Cyclone Bucket, Test Cl-2

5-13 Sulfur Capture with Pittsburgh No. 8 Coal

6-1 Cyclone Separator Experimental Arrangement 


\section{EXECUTIVE SUMMARY}

This is the final report on the Advanced Coal-Fueled Gas Turbine Systems Program of the Westinghouse Electric Corporation under the U.S. Department of Energy Morgantown Energy Technology Center Contract DE-AC21-86MC23167. This program was initiated by the Department of Energy in 1986 as an R\&D effort to establish the technology base for the commercial application of direct coal-fired gas turbines.

The combustion system under consideration incorporates a modular staged, rich-lean-quench, slagging combustor concept. The primary zone is based on 25 years of Textron experience on the development of a slagging Toroidal Vortex Combustor (TVC) which was originally designed for magnetohydrodynamics (MHD) applications. Fuel-rich conditions in the first stage inhibit $\mathrm{NO}_{\mathbf{x}}$ formation from fuel-bound nitrogen; molten coal ash and sulfated sorbent are removed, tapped and quenched from the combustion gases by inertial separation in the second stage. Final oxidation of the fuel-rich gases and dilution to achieve the desired turbine inlet conditions are accomplished in the third stage which is maintained sufficiently lean so that here, too, $\mathrm{NO}_{\mathrm{x}}$ formation is inhibited.

The configuration of the subscale combustor has evolved during the six years of this prngram from a system using only an impact separator to remove particulates to a system which also included a slagging cyclone separator before the lean-quench combustor. The system also now includes active slag tapping after the impact separator rather than a bucket to collect the slag.

The subscale $12 \mathrm{MM}$ Btu/hr (higher heating value, HHV) slagging combustor has demonstrated excellent coal-fired operation at $6 \mathrm{~atm}$. The combustor has fired both coal-water mixtures (CWM) and pulverized coal (PC). Three Wyoming subbituminous coals and two castern bituminous coals have been successfully fired in the TVC. As a result of this active testing, the following conclusions may be drawn:

- It was possible to achieve the full design thermal capacity of $12 \mathrm{MM}$ Btu/hr with the subscale slagging combustor, while burning $100 \%$ pulverized coal and operating at the design pressure of 6 atm.

- Because of the separate-chamber, rich-lean design of the subscale slagging combustor, NOx emissions that easily meet the New Source Performance Standards (NSPS) limits were achieved.

- Carbon burnout efficiency was in excess of $99 \%$ when $100 \%$ coal-fired.

- Ninety percent of the ash can be separated as slag in the impact separator, and a total 98 to $99 \%$ removed with the addition of the slagging cyclone separator.

- Objectives for third-stage $e$ it temperature $\left(1850^{\circ} \mathrm{F}\right)$, and exit temperature pattern factor (14\%) were readily achieved.

- Overall pressure loss is currently an acceptable 5 to $6 \%$ without cyclone separator and 7 to $9 \%$ with the cyclone.

- Feeding pulverized coal or sorbent into the combustor against 6 atm pressure is achievable. 
- New Source Performance Standard (NSPS) requirement in the area of particulate removal indicated an additional cleanup stage, over-and-above the impact separator is needed. A slagging cyclone was designed, manufactured and tested successfully. Based on the results of this testing, the NSPS levels can be approached. The size distribution of the particulates entering the Westinghouse combustion turbine would be small enough to prevent erosion damage to the blades.

- Sulfur reductions at the third-stage exhaust of up to $50 \%$ have been achieved. The NSPS goal is 70 to $90 \%$ reduction, depending on coal sulfur content. To meet the new Environmental Protection Agency (EPA) goals based on acid rain legislation will require additional sulfur capture.

- Vapor alkali measurements done with the Ames alkali monitor indicated that slag tapping and slagging cyclone separating reduce vapor $\mathrm{Na}$ and $\mathrm{K}$ levels down to around the 20 parts per billion by weight (ppbw) levels as recommended by combustion turbine manufacturers. This could eliminate the need for additional alkali removal and simplify the commercial combined cycle approach.

- Technical accomplishments of the program verify the feasibility of integrating a direct coal-fired combustion system into a combined cycle application. Advantages of the concept are small sizeto-Btu heat release ratio, production of inert high-density glass-type slag, production of trace quantities of very fine relatively nonabrasive ash particulates, potential for minimum $\mathrm{NO}_{\mathrm{X}}$ emissions through the destruction of the fuel $\mathrm{NO}_{\mathrm{x}}$ and the prevention of thermal $\mathrm{NO}_{\mathrm{x}}$ generation, and nonequilibrium, sulfur capture of approximately $90 \%$ with calcia-based sorbents.

In addition to the development of a TVC system there were several ancillary studies performed under this contract which are supportive to the development of a direct coal-fired combustion turbine system. Tasks performed in this area included: reference system definition, generic turbine design, and advanced turbine systems. Some achievements accomplished include:

- Developing comparative economic data for the coal-fueled combustion turbine combined cycle and three conventional fossil-fueled plants (a $220 \mathrm{MW}$ pulverized coal plant with flue gas desulfurization and oil and gas-fired combustion turbine combined cycles).

- Performing economic sensitivity studies to determine the impact of various parameters on the cost of electricity (COE) margin of pulverized coal coal-water mixture direct coal-fired combined cycles.

- Development of a conceptual design for a combustion turbine system that will perform in a pressurized fluidized bed combustor application.

- Defining a coal-fueled advanced gas turbine cycle utilizing the slagging combustor concept.

- Establishing the technical concepts required to achisve natural gas fired combined cycle efficiencies of $60 \%$ (lower heating value basis, LHV) or higher.

- Defining an intercooled, recuperative combined cycle that has the combustion turbine and steam turbine directly coupled to form a single shaft operating at 3600 RPM. 


\section{INTRODUCTION}

This is the final report for the Advanced Coal-Fueled Gas Turbine Systems Program of the Westinghouse Electric Corporation. This program was initiated by the U.S. Department of Energy (DOE) in 1986 as an R\&D effort to establish the technology base for the commercial application of direct coal-fired gas turbines (DCFGT). The combustion system under consideration incorporates a modular staged, richlean-quench, Toroidal Vortex Slagging Combustor (TVC) concept. Fuel-rich conditions in the first stage inhibit NOx formation from fuel-bound nitrogen; molten coal ash and sulfated sorbent are removed, tapped and quenched from the combustion gases by inertial separation in the second stage. Final oxidation of the fuel-rich gases, and dilution to achieve the desired turbine inlet conditions are accomplished in the third stage, which is maintained sufficiently lean so that here, too, NOx formation is inhibited.

\subsection{SCOPE OF REPORT}

This report covers work associated with the subscale combustion testing performed under DOE Morgantown Energy Technology Center (METC) Contract DE-AC21-86MC23167, Advanced CoalFueled Gas Turbine Systems, for the period July 1986 through August 1993. Major tasks of the program included:

- Design, fabrication, testing and evaluation of a $12 \mathrm{MM}$ Btu/hr (HHV) toroidal vortex slagging combustor for utility gas turbine applications. (All heat consumptions and heating values in this report are based on the higher heating values, HHV, of the fuel, unless noted otherwise.)

- Bench-scale sulfur control experiments in separate facilities.

- Design, fabrication, and testing of a stationary turbine cascade rig. (Following completion of the design during the 1988-1989 period this subtask was put on hold until it was officially deleted from the work scope by METC in 1991.)

- Development of a direct coal-fired combined cycle reference plant

- Generic turbine design study.

- Advanced turbine systems - scoping and feasibility studies.

\subsection{PROGRAM OBJECTIVES}

The primary objective of this work was to verify the feasibility of a direct coal-fueled combustion system for combustion turbine applications. This was accomplished by the design, fabrication, testing and operation of a subscale development-type coal-fired combustor. Because this was a complete departure from present-day turbine combustors and fuels, it was considered necessary to make a thorough evaluation of this design, and its operation in subscale, before applying it in commercial combustion turbine power systems.

Another objective was to keep fuel costs acceptably low by burning raw or moderately cleaned coal, as is normal utility practice. Both bituminous and subbituminous coals have been tested. Coal grinding has 
been, and, is to be, consistent with that considered practical and economical for electric utility utilization. The coal was burned exclusively as dried pulverized coal (PC) during the 1988-1989 reporting period and then burned as coal-water mixture (CWM) during much of the 1989-1990 period. Testing revealed PC to be the preferred fuel both from performance and economic standpoints. Therefore, the slagging combustor system was reconfigured to bum PC for the balance of the program.

The ultimate goal for the coal combustion system was to attain efficient combustion of the coal, and simultaneously to satisfy all of the current environmental emission regulations, such as the NSPS, for coal-fired steam generators and combustion turbine power system requirements.

\section{Program Objectives}

1. Attain high efficiency with emphasis on effective fuel utilization (burn-out) and low pressure and heat losses.

2. Achieve stable and reliable operation.

3. Control and limit $\mathrm{NO}_{\mathrm{x}}$ formation in the gas to meet or exceed NSPS.

4. Remove sulfur to meet or exceed NSPS.

5. Demonstrate efficient removal of slag and all particulates in the gas with the ultimate objective to meet or exceed NSPS.

6. Retain alkali in ash/slag removed from the combustor.

\section{Specific Performance Goals}

1. Demonstrate self-sustaining coal combustion at the thermal design rating of $12 \mathrm{MMBtu} / \mathrm{hr}$.

2. Burn utility grade bituminous and subbituminous coal, both in the pulverized form, and as coalwater mixture.

3. Produce a lean-zone exit gas stream having an average temperature of at least $1850^{\circ} \mathrm{F}$, and having a uniformity such that the exit temperature pattern factor will be $20 \%$ or less.

4. Achieve combustion efficiency greater than $98 \%$.

5. Demonstrate stable and reliable operation and acceptable refractory performance.

6. Acceptable heat and pressure losses.

7. NO $\mathrm{x}$ emissions less than the NSPS limit of $0.6 \mathrm{lb} / \mathrm{MMM}$ Btu.

8. Limit $\mathrm{SO}_{x}$ per the NSPS to a maximum of $1.2 \mathrm{lb} / \mathrm{MM}$ Btu, where $90 \%$ reduction is required for $\mathrm{SO}_{\mathrm{x}}$ greater than $0.6 \mathrm{lb} / \mathrm{MM}$ Btu, and $70 \%$ reduction is required for $\mathrm{SO}_{\mathrm{x}}$ less than $0.6 \mathrm{lb} / \mathrm{MM}$ Btu.

\subsection{COMBUSTOR CONCEPT DEVELOPMENT}

As shown in Fig. 2-1, the original slagging combustor is a modular unit with three stages. The first stage is the primary combustion zone. Coal and preheated air enter the primary zone coaxially through four injection nozzles which are equally spaced around the combustion chamber. This coaxial injection promotes intense air/coal mixing and rapid particle heat-up/devolatilization, which minimizes carbon burnout time.

The four incoming coal-air jets coverage at the combustor centerline that forms one vertical jet which impacts the combustor dome. This forms a toroidal vortex which provides the mechanisms for: (1) flame stabilization; and, (2) centrifugal separation of larger ash/slag particles. The separated ash/slag forms a stable flowing layer on the combustor walls. The vertical geometry of this stage allows gravity to assist in the removal of the molten slag. 


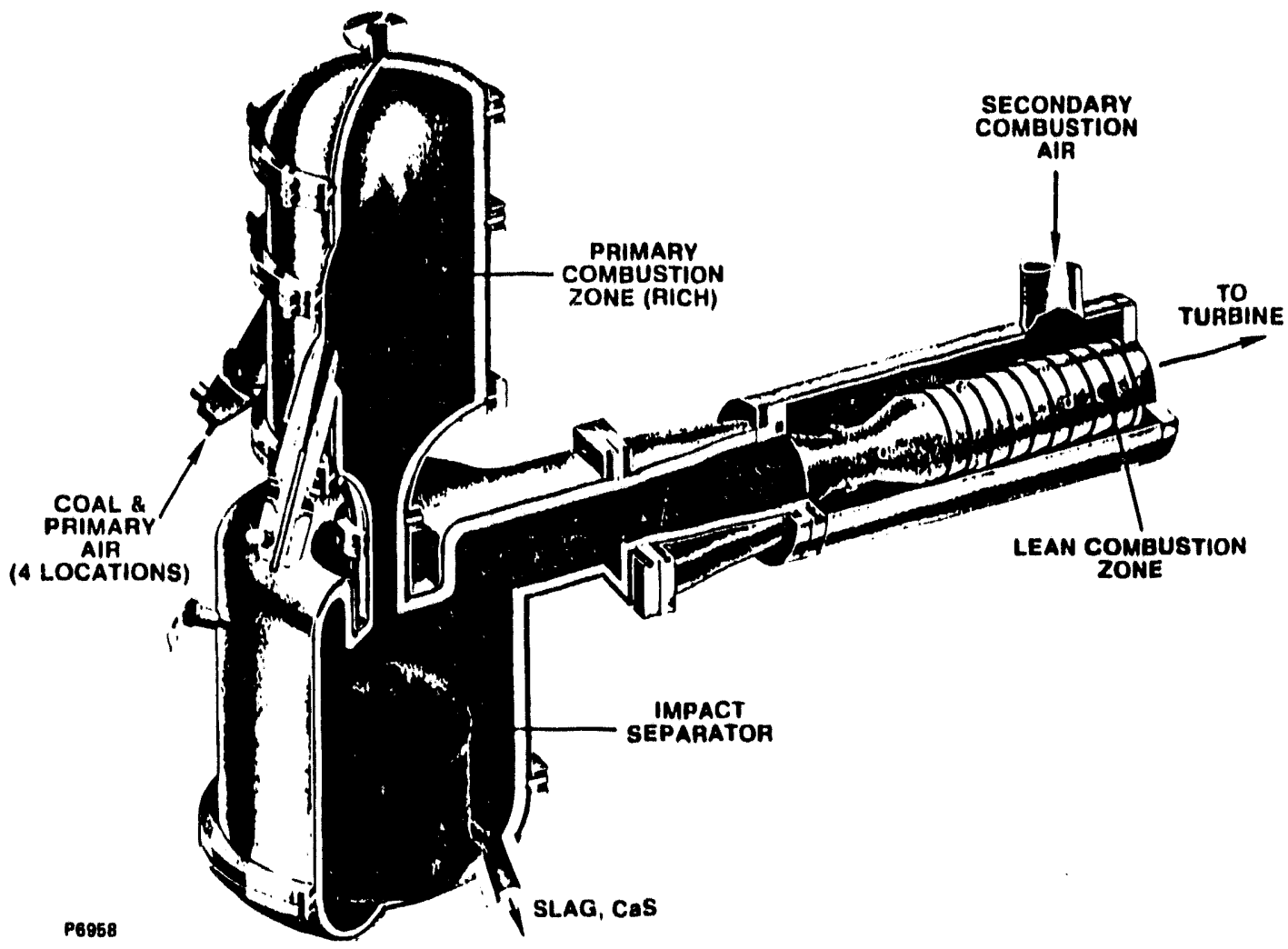

Fig. 2-1. Artist's Rendering of Combustor

Fuel-rich conditions in this stage inhibit $\mathrm{NO}_{\mathrm{x}}$ formation from fuel-bound nitrogen. It also provides the necessary reducing conditions for removal and capture of sulfur. The sulfur sorbent, limestone or dolomite, is counter-flow injected (dry) into the downstream end of the primary zone. The first stage was designed for a coal particle residence time of about $100 \mathrm{~ms}$ (for 75 micron sized particles).

The second stage is an efficient impact separator which is closely coupled to the first stage. The impact separator removes particulates carried over with the gas from the primary zone, whether they are sorbent or fine particles of ash. Additional gas cleanup was required to meet NSPS particulate standards; therefore, a slagging cyclone separator was considered in addition to the impact separator.

The third stage is used to complete combustion and to temper the products to meet turbine inlet requirements. The rapid mixing between gases coming from the second stage and secondary air insures that the peak gas temperatures, and hence, thermal $\mathrm{NO}_{\mathrm{x}}$ formation is minimized. This stage is designed based on conventional gas turbine combustor practices.

Based on experimental results acquired prior to 1990, the current concept now includes a slagging cyclone separator as an integral part of the slagging combustor system, as seen in Fig. 2-2. 


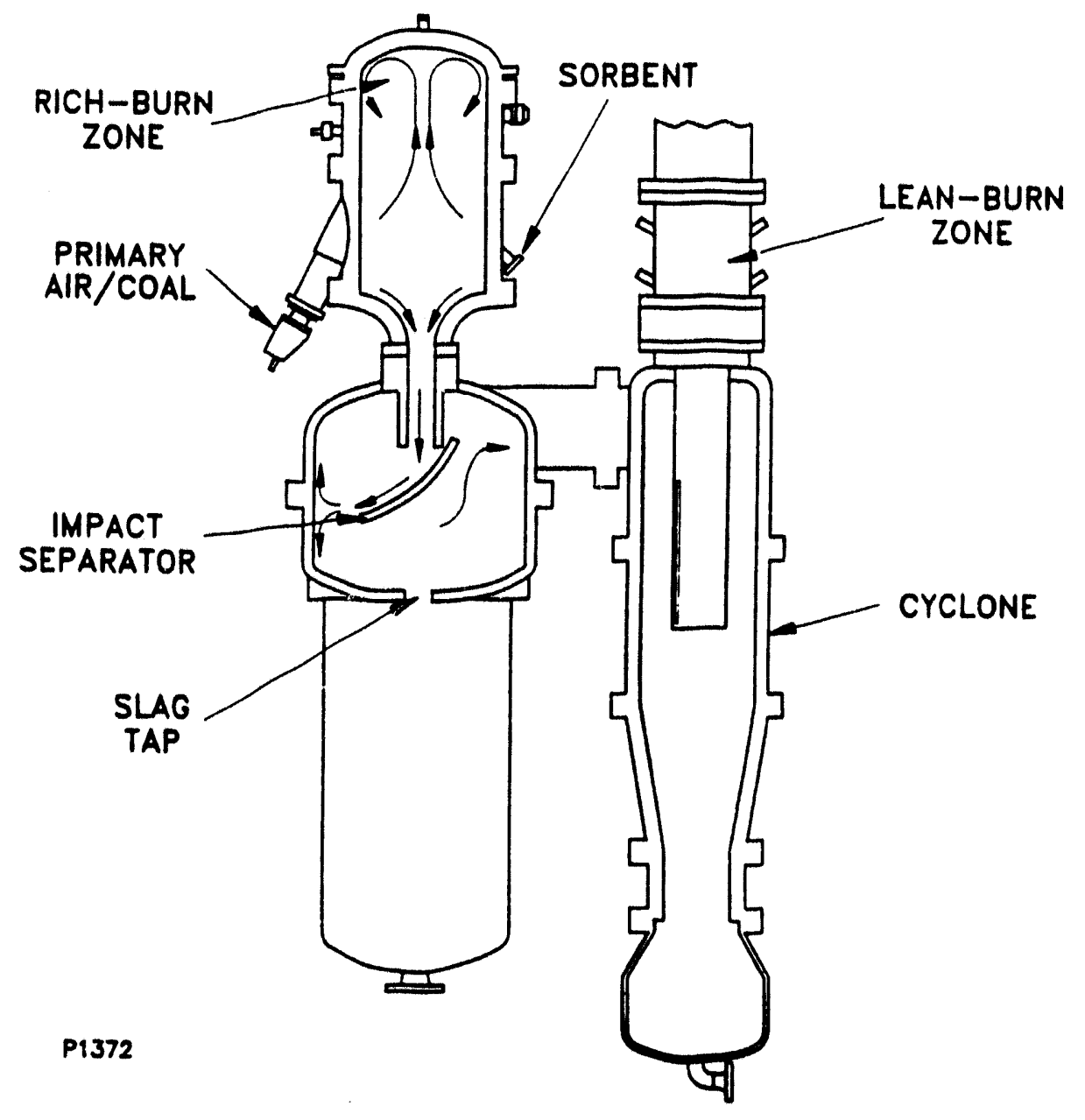

Fig. 2-2. Schematic of Subscale Slageing Combustor Test Rig with Real-Time Slag Tapping Capabiltty and Slagging Cyclone

The hot gases, once leaving the impact separator, enter into a water-cooled and refractory-lined slagging cyclone separator where particulate emissions are further recuced. The cleaned fuel-rich gases then pass into the third stage, the lean-quench combustor. The secondary combustor is a cylindrical wi-cooled section having two circumferential rings of air jets, each ring containing 16 jets. The first ring of jets bring in secondary air to oxidize the fuel-rich gases, which burn spontaneously. The second ring of jets admit dilution (quench) air, which drops the burning gases to a turbine inlet temperatures of $1850^{\circ}$ to $2000^{\circ} \mathrm{F}$.

Following the lean-quench zone, the hot gases pass through a water-cooled instrumentation section, and then through a water-cooled orifice plate which drops the pressure to near atmospheric pressure. Emissions, pressure and temperature profile are detected in the instrumentation section. Following the orifice plate, the gases pass through a water spray quench and then to an exhaust stack. 


\section{REFERENCE SYSTEM DEFINITION}

The reference power system definition used as the basis for this contract is a coal-fueled gas turbine combined cycle with a slagging combustor. Its operating conditions are based on the recommended system proposed in the "Gas Turbine Systems Research and Development Study" final report, dated February 1986, and submitted to DOE/METC. This reference system was the starting point of the work performed for the Advanced Coal-Fueled Gas Turbine Systems program and was fully described in the "Reference System Definition" report dated December 1986.

The cost and performance model developed for the base reference system was eventually modified to reflect the technical data that was obtained during the testing phase of the slagging combustor and subsequently reported in the "Reference System Definition Update" dated September 1991.

The original "Reference System Definition" report provided the following information with regards to definition of the reference system:

- An overview of the base reference system.

- Thermal and environmental performance of the reference system, including assumptions of ambient conditions, fuel, and operation.

- Economic assumptions and described the economic evaluation method. (The capital cost, operating cost, and cost of electricity for the reference system were itemized.)

- Description of the slagging combustor.

- Development alternatives to cover the areas of technical uncertainty, and assessed their economic impacts.

- Detailed description of the entire power plant.

- Overview of institutional idiosyncrasies that could inhibit the commercialization of this concept.

- Steps needed to bring this concept to the marketplace,

Testing of the slagging combustor, which began in September 1988, yielded valuable technical data that impacted the original cost and performance model for the base system. As a result of this testing data it became appropriate to update and expand the previous conceptual design studies.

The "Reference System Definition Update" report dated September 1991 was the effort performed to evaluate the relative economic benefits of various design and process options for the direct coal-fueled combustion turbine combined cycle. In general the report updatnd and expanded the earlier report:

- The assumptions, performance and emission goals of the two reference coal-fueled combustion turbine systems which burn either PC or CWM were discussed

- The plant economics including the assumptions made, cost of electricity calculations (COE), estimates for operation and maintenance, consumables and $C O E$, and the COE of a mature plant were either expanded or added.

- The description of the slagging combustor which included the concept and how particulates, sulfur, nitrogen oxide and alkali are controlled was updated.

- Economic sensitivity studies; an assessment of the influence of different parameters on the COE margin of the CWM-fueled plant were added.

- A complete description of the coal-fueled combustion turbine combined cycle power plant was provided. 
A power system computer model was used to compare the proposed design alternatives with a conventional coal-fired steam turbine power plant and conventional combustion turbine combined cycles in terms of performance, capital cost, and cost of electricity. All performance data was based on the higher heating value (HHV) of the fuel and all costs were in 1989 dollars.

The technical assumptions on which the current standard Westinghous: coal-fueled combustion turbine combined cycle (CFCTCC) was based included: using Pittsburgh No. 8 coal (standard utility grade); ambient conditions of 14.7 psia, $59^{\circ} \mathrm{F}$, and a relative humidity of $60 \%$; NSPS emissions criteria; use of a slagging combustor whose rich/lean zone reduces $\mathrm{NO}$ formation; use of limestone as a sorbent to capture sulfur $(\mathrm{Ca} / \mathrm{S}=2)$; use of slagging cyclone separators to reduce particulate matter and solid alkali; combustor outlet temperature of $1850^{\circ} \mathrm{F}$; maximum turbine metal temperature of $1650^{\circ} \mathrm{F}$; pressure drop of $7 \%$ through the slagging combustor system; and, partial recovery of $8 \%$ combustor heat loss.

The economics and performance of the CFCTCC reference plants were compared to three convention plants: a $220 \mathrm{MW}$ conventional pulverized coal-fired (PC) steam turbine generator plant with flue gas desulfurization (FGD) (this plant, PC-FGD, is fueled with Pittsburgh No. 8 coal), and two combustion turbine combined cycles (CTCC) plants, one fueled with distillate oil and the other plant fueled with natural gas. The sizes of the comparison plants were chosen to appioximate the generating capacity of the CFCTCC reference systems.

The design values on which the costs were based reflected generic design conditions for the conventional plants. Table 3-1 summarizes the design conditions of each plant. Pittsburgh No. 8 coal was purchased at $\$ 1.80 / \mathrm{MMBtu}$ and gas and oil were priced at $\$ 4.00 / \mathrm{MMB}$ (u) delivered to the power plants studied. These prices were based on the HHV of the fuels.

Capital costs for the PC-FGD plant were developed consistent with the cost basis of the reference CFCTCC. The concepturil cost estimate for the PC-FGD plant was intended to cover a complete plant, including all equipment, materials, labor and construction support.

The costing bases for the two combined cycle plants were also consistent with the reference CFCTCC plants. Power is produced by two combustion turbines and one steam turbine with a combined output of around $260 \mathrm{MW}$.

The 30-year levelized costs of electricity (S/MWh) for the three conventional plants and the two CFCTCC reforence plants was: 94.4 (PC-FOD), 84.1 (CTCC, gas), 85.2 (CTCC, oil), 84.05 (CWMCFCTCC), and 77.51 (PC-CFCTCC). The COE's of the CFCTCC are lower than the PC-FGD, by 11\% and $17.9 \%$ for the CWM and PC plants respectively, and comparable to the gas and oil-fired combined cycles. 
Table 3-1.

\section{Conventional Plants - Design Conditions}

\author{
Plant Type \\ Plant Output, MW \\ Fuel Type \\ Fuel HHV, Btu per \\ Plant Heat Rate, Btu/kWh \\ Boiler \\ Steam Turbine Generator [1] \\ Cooling Tower [2] \\ Sulfur Control System \\ Fuel Cost, S/MMBtu \\ Construction Time, yrs \\ Book Life, yrs \\ Total Plant Cost Year \\ Total Plant Investment Year \\ Capacity Factor
}

$\begin{array}{rrr}\text { PC-FGD } & \text { CTCC, gas } & \text { CTCC, oil } \\ 220 & 262 & 258 \\ \text { Pgh. 8 Coal } & \text { Nat Gas } & \text { No. 2 Oil } \\ 13,555 / 1 b & 1,0.35 / \text { SCF } & 138,690 / \text { gal } \\ 9,960 & 8.208 & 8,227 \\ \text { Subcrit } & \text { Subcrit } & \text { Subcrit } \\ \text { TC/2F } & \text { TC/2F } & \text { TC/2F } \\ \text { MD, Wet } & \text { MD, Wet } & \text { MD, Wet } \\ \text { Limestone FGD } & \text { none } & \text { none } \\ \text { S1.80 } & \text { S4.00 } & \text { S4.00 } \\ 3.5 & 2.0 & 2.0 \\ 30 & 30 & 30 \\ \text { Dec } 1989 & \text { Dec } 1989 & \text { Dec } 1989 \\ \text { Jan } 1990 & \text { Jan } 1990 & \text { Jan } 1990 \\ 70 \% & 70 \% & 70 \%\end{array}$

[1] Tandem Compound, Double Flow

[2] Mechanical Draft, Wet

In Fig. 3-1, the COE for the PC-FGD plant, and the two conventional and two ccal-fueled combined cycles studied is divided into the cost areas of capital and maintenance, consumables, and fuel. Capital and maintenance costs dominate the PC-FGD COE, while the COE of the oil and gas-fired combined cycles is set and controlled by the fuel costs.

As would be expected, the COE of the coal-fueled combined cycles has a large capital and maintenance cost and also a large consumable cost when compared to a gas or oil-fired combined cycle plant. The CWM plant consumable costs are higher than for a PC combined cycle plant due to the costs associated with making the slurry.

The CFCTCC power plant performance is summarized in Table 3-2. The CWM plant generates 9.5 MWs more power than the PC plant, but has a plant cycle efficiency which is lower by 1.8 percentage points. Evaporation of the water contained in the CWM causes this phenomenon to occur.

Sensitivity studies were also performed using the reference system computer model to assess the influence of certain parameters on the COE margin of the CWM and PC CFCTCC plants. Some of the parameters studied included: Combustor outlet temperature, combustion turbine blading interval, $\mathrm{Ca} / \mathrm{S}$ ratio and possible FGD installation, combustor pressure loss, combustor heat rejection, and slurry chemical expense and coal beneficiation. 


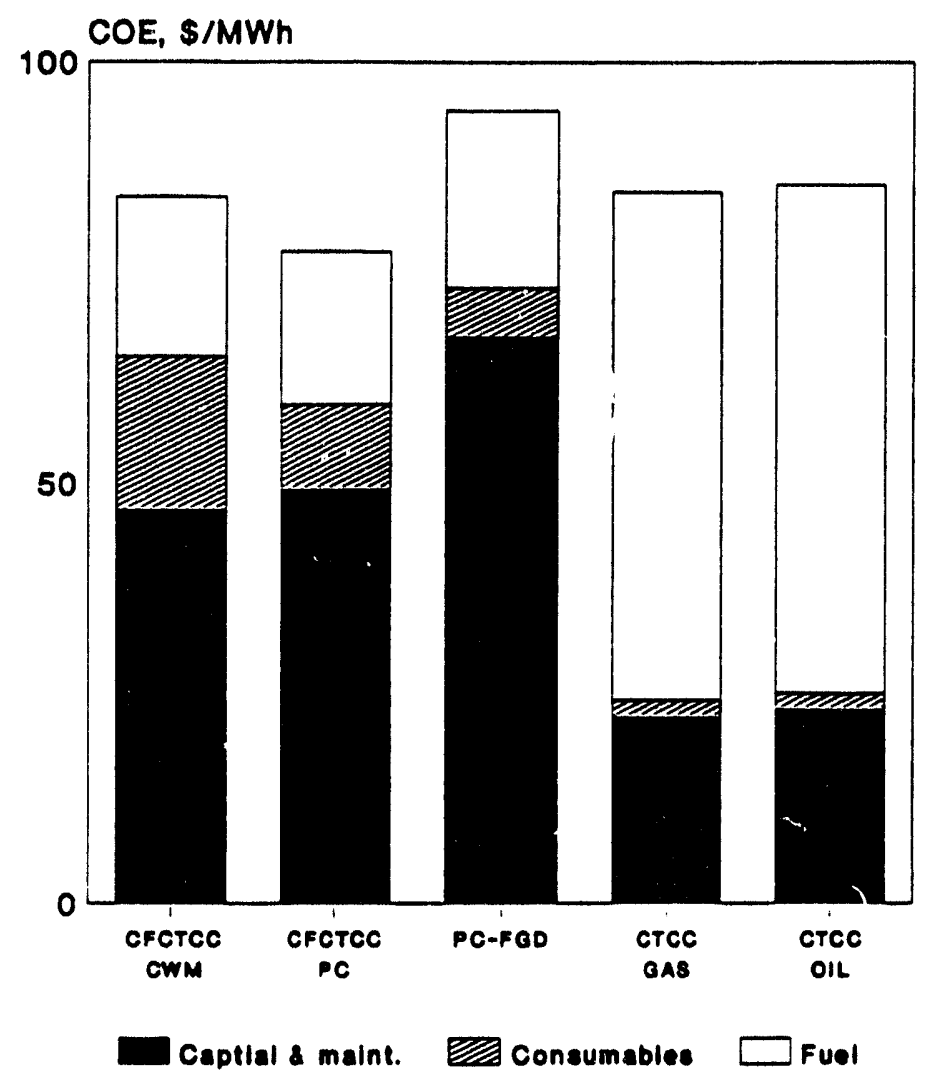

Fig. 3-1. Comparison of COE for Conventional Power Plants and PC and CWM CFCTCC Reference Plants

Table 3-2.

\section{Summary of CFCTCC Power Plant Performance}

\section{Plant Type}

Combustion Turbine Net Power (MW)

Steam Turbine Net Power (MW)

Fuel Processing \& Auxiliary Power (MW)

Net Power Generation (MW)

Net Heat Rate (Btu/kWh)

Efficiency (Percent)
CWM

172.1

63.9

(4.7)

231.3

8924.0

38.2
PC

161.3

62.6

(2.0)

221.8

8536.0

40.0

When compared against the PC-FGD plant, the economics today show COE margins for combined cycle plants fueled with PC, CWM, gas and oil of 17.9, 11.0, 10.9 and $9.7 \%$, respectively. When coal prices are compared against a rising price in gas or oil (>\$4.00/MMBtu), the economics immediately become more favorable to a coal-fueled based power process. 


\section{4 \\ SUBSCALE SLAGGING COMBUSTOR APPARATUS, PLAN AND METHOD}

All combustion tests were conducted at the Textron Defense Systems (TDS), formerly known as Avco Research Laboratories, facility located in Haverhill, MA. Fig. 4-1 is an overall test system schematic sbowing the major component parts of the original setup.

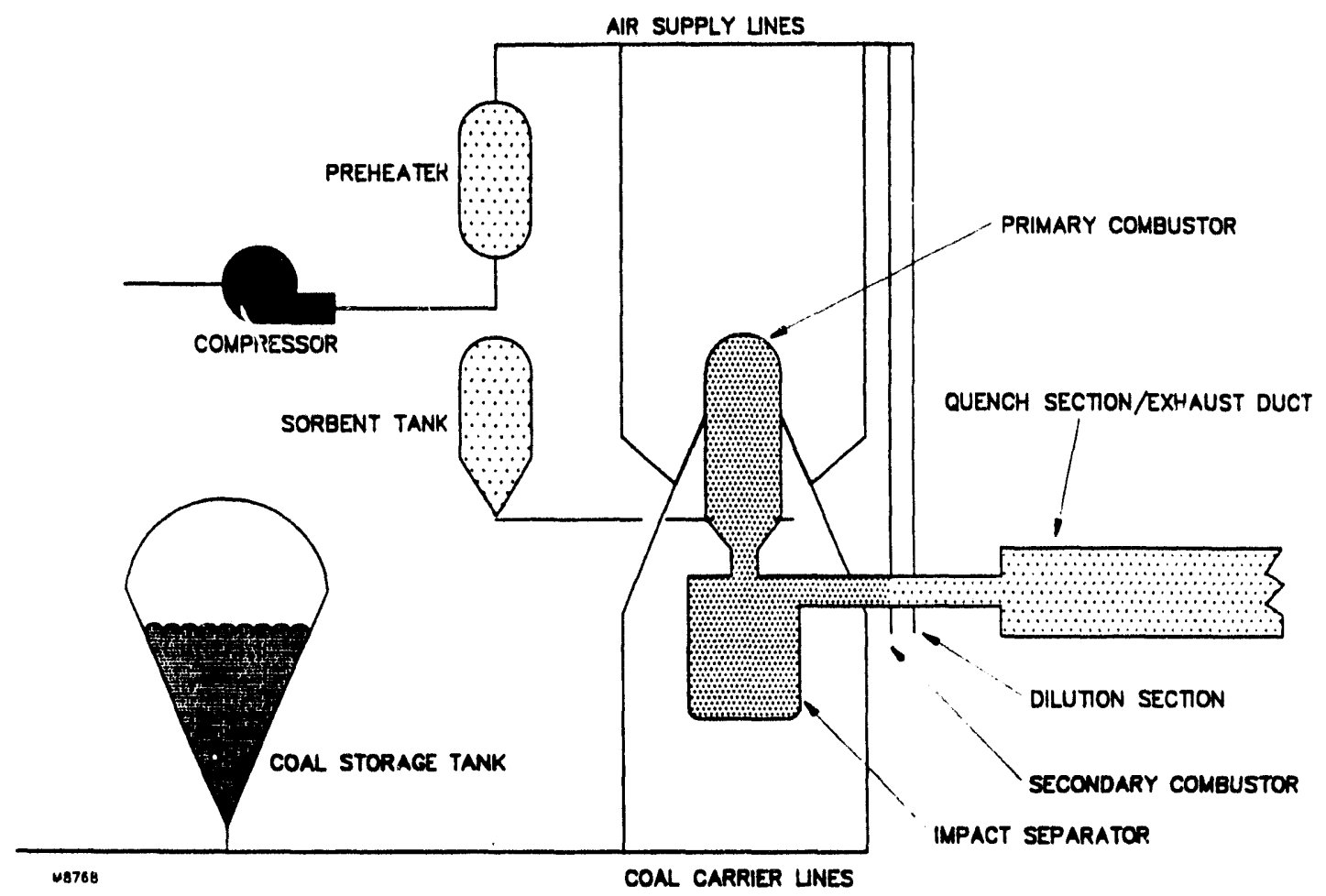

Fie. 41. Overall Test System Schematic

Details relative to the layout of the facility and the design and operation of the test facility support apparatus is provided in the Topical Report - Task 3.1, titled, "Advanced Coal-Fueled Gas Turbine Systems: Subscale Combustion Testing," dated May 1993. Discussed are the following subsystems:

- Preheated air supply system

- Cooling and quench water systems

- Fuel feed systems, pulverized coal and coal-water mixture

- Instrumentation and control system, and

- Sorbent feed systems.

Fig. 4-2 shows the original configuration of the combustor test rig prior to the inclusion of the slagging cyclone separator in late 1990. 


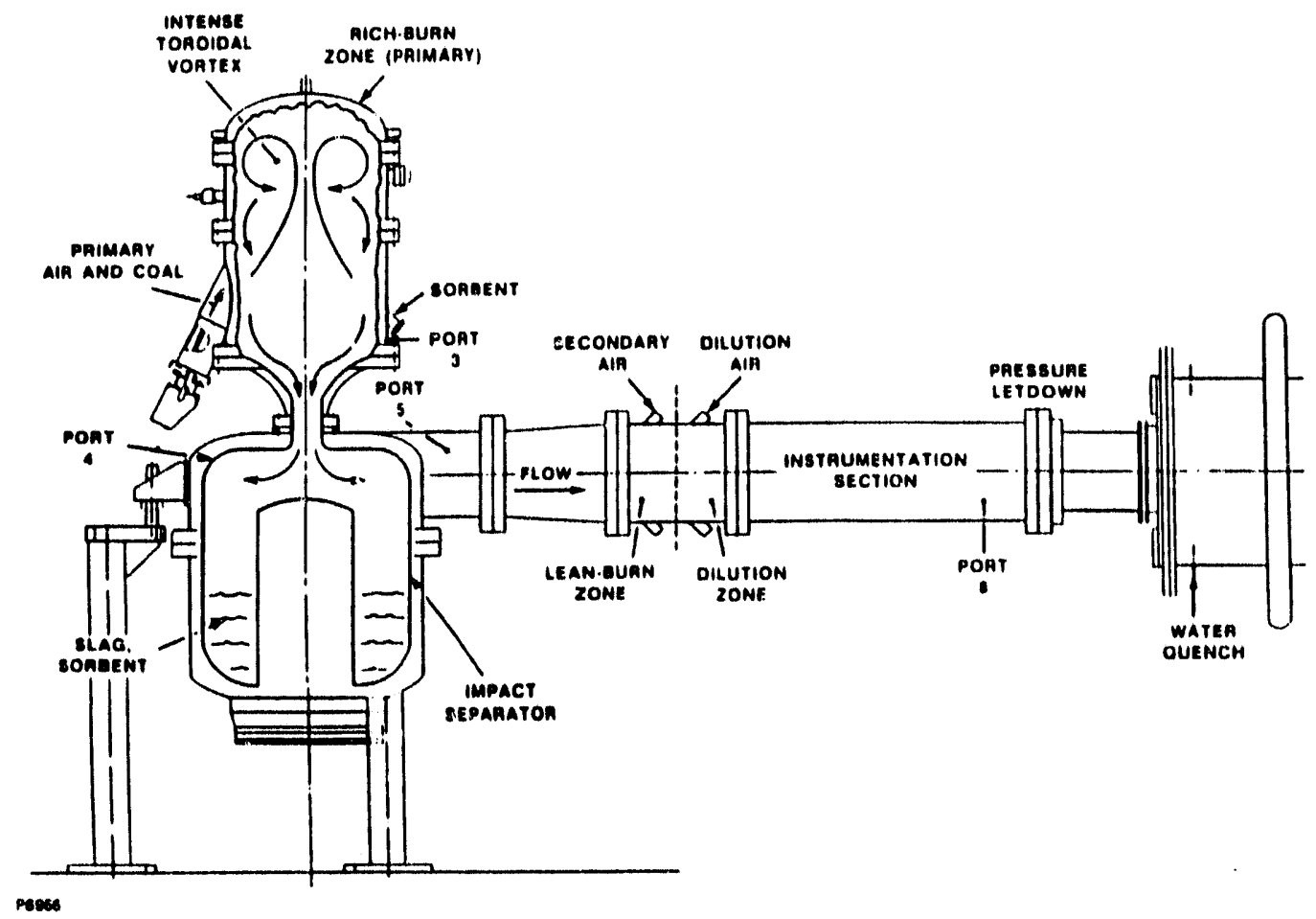

Fig. 4-2. Schematic of Original Subscale Slagging Combustor Test Rig

Air and PC or CWM are injected upward into this primary zone through four angled fuel injectors, equally spaced around the zone. For simplicity, only one is shown in this Fig. When needed, pulverized sorbent, with carrier air, is also injected into the primary zone. Four smaller injectors (one is shown) handled this task

Rich combustion occurs in the primary zone, and melted coal ash (slag) and hot, fuel-rich gases exit downward out of the zone through the small diameter nozale shown. The nozzle leads the rich gases into the impact separator, the large vessel shown, at the lower left. A sudden change of direction, and gravity, separate slag and particles. Leaving the liquid and solid matter behind, the cleaned, hot fuel-rich gases move out of the top right-hand side of the impact separator. The primary zone, the impact separator, the internals of the impact separator, and the connecting passages are water-cooled, high-pressure, steel vessels, lined with refractory.

Having left the impact separator, the hot, fuel-rich gases pass to the right, through the diffusing section, to the lean-burn zone. The lean-burn zone is a cylindrical water-cooled section having 32 inclined air jet inlets. The first 16 of these bring combustion air in, to oxidize the fuel-rich gases. The second 16 inlet jets admit dilution air, which drops the burning gases to a $1850^{\circ}$ to $2000^{\circ} \mathrm{F}$.

Following the lean-burn zone, the hot gases pass through a water-cooled instrunaentation section, and then through a water-cooled orifice plate which drops them to near atmospheric pressure. Emissions, pressure, and temperature profile are detected in the instrumentation section. Following the orifice plate, the gases pass through a water spray, and to the exhaust. 
Table 4-1 lists both the parameters to be measured and the necessary information to be obtained during the subscale combustor testing and evaluation. The parameters in Table 4-1 may be divided between three categories: 1) material properties; 2) parameters to be measured on-line during a combustor test (Table 4-2); and, 3) parameters to be measured off-line, after a combustor test.

Table 4-1.

\section{Required Measurements and Data in Combustor Testing}

\section{Eirst Combustor Stage}

Coal fuel and ash specifications

Sorbent specifications

Fuel mass flow rate

Sorbent mass flow rate

Primary air mass flow rate, temperature and pressure

Combustor pressure

Gas temperature

Coolant mass flow rate, inlet and outlet temperature metal skin temperatures

\section{Second Combustor Stage}

Particle loading, size and size distribution, inlet and exit

Slag (including sorbent) removed

Gas pressure, inlet and exit

Gas temperature

Gas exit composition $\left(\mathrm{CO}_{2}, \mathrm{CO}, \mathrm{O}_{2}, \mathrm{H}_{2} \mathrm{~S}, \mathrm{COS}, \mathrm{HCN}, \mathrm{NH}_{3}, \mathrm{NO}, \mathrm{HC}\right)$

Vaporized alkali in gas

Coolant mass flow rate, inlet and outlet temperature

Metal temperatures

Composition and characteristics of slag removed and particles collected (C, S, N, alkali, etc.)

\section{Third Combustor Stage}

Secondary air mass tlow rate, pressure and temperature

Dilution air mass flow rate, pressure and temperature

Products of combustion pressure and temperature (including pattern factor)

Products of combustion composition $\left(\mathrm{CO}_{2}, \mathrm{CO}, \mathrm{O}_{2}, \mathrm{NO}_{\mathrm{x}}, \mathrm{HC}\right)$

Vaporized alkali

Products of combustion particle loading, size and size distribution

Coolant mass flow rate, inlet and outlet temperature

Metal temperatures

Composition and characteristics of particles removed 
Table 4-2.

\section{Parameters to be Measured On-Line and Transducer Types}

Burameter

Coal Flow Rate

Sorbent Flow Rate

Primary Air Mass Flow Rate

Secondary Air Mass Flow Rate

Dilution Air Mass Flow Rate

Coal Carrier Air Flow Rate

Sorbent Carrier N2 Flow Rate

Coolant Mass Flow Rate

Quench Water Mass Flow Rate

Coolent Inlet Temperatures

Coolant Outlet Temperatures

Metal Temperatures

Primary Air Inlet Temp

Secondary Air Inlet Temp

Dilution Air Inlet Temp

Combustor Gas Temperature

Products of Combustion

Temp. Pattem Factor

Combustor Pressure

Products of Combustion

Velocity Partern Factor

Gas Composition
Transducer Type

Load Cell

Triboelectric Probes

Load Cell

Pressure Transducer

Thermocouple

Pressure Transducer Thermocouple

Pressure Transclucer

Thermocouple

Pressure Transducer

Thermocouple

Pressure Transducer Thermocouple

Flowmeter

Flowmeter

RTD

RTD

Thermocouple

Thermocouple

Thermocouple

Thermocouple

Optic Fiber Thermometer

Optical Pyrometer 2

High Temp. Thermocouple

Thermocouples 25

Pressure Transducer 5

Pressure Transducers 25

Gas Analyzers 5

4

5

5

4

0

4


In suminary, the subscale combustor data acquisition and processing system:

- Acquires and stores data on more than 150 channels from a variety of transducers at rates which vary from a few samples per second to a few thousand samples per second.

- Computes and displays in real-time important combustor parameters, in order to facilitate combustor control.

- Monitors combustnr health and generates appropriate alarms in the event that a specified parameter exceeds a specified limit.

- Further processes the test data after the combustor test and generates output (including graphical output) to enable assessment of combustor performance.

- Provides a means and medium for storage of the combustor test data generated.

\section{CCALS TESTED}

Based on a coal fuel specification study (issued January 1987) by the Amax Corporation, it was decided to look at minimally cleaned pulverized coal as the target fuel for the Direct Coal-Fired Gas Turbine (DCFGT) system. High volatility bituminous coals were recommended for the TVC because these coals have high heating values and relatively high volatile contents. High flame temperatures and rapid cornbustion can be achieved using these coals. Amax suggested alkali and sulfur contents from environmental and corrosion standpoints. Alkali in the form of sodium and potassium should be minimized. Sulfur content should be below $1.0 \%$ to minimize sorbent additions.

Combustor testing was docided by Westinghouse and Textron to be conducted with three different test coals:

\section{Bituminous $P C$ and $C W M$ with S-content $<1 \%$}

\section{Bituminous $P C$ and CWM with S-content $>2-3 \%$}

3. Subbituminous PC with S-content $<1 \%$.

The coals actually selected and tested in this program were:

\section{Dorchester seam coal from Virginia}

\section{Pittsburgh No. 8 seam coal from West Virginia}

3. Hanna Rosebud from Wyoming.

All coals were used as utility grind, with a particle size such that $95 \%$ would pass through a 200 mesh screen. Table 4-3 shows the ultimate and proximate analysis for the coals tested. Again, detailed analysis of the coals tested, i.e., ash fusion and ash analysis for each coal is given in "Topical Report Task 3.1, Advanced Coal-Fueled Gas Turbine Systems: Subscale Combustion Testing," dated May 1993. 
Table 4-3.

Ultimate and Proximate Analyses of Coals Tested - (Dry Basis)

Percent

\begin{tabular}{ccc} 
& Coal Type & \\
Eastern & Eastern & Westem \\
Bituminous & Bituminous & Subbituminous \\
& & \\
\hline Dorchester, & Pittsburgh, & Hanna, \\
Virginia & No.8 & Wyoming
\end{tabular}

Ash

6.49

34.02

59.49

Fixed Carbon

100.00

7.71

5.91

38.86

42.16

53.43

51.93

100.00

100.00

Sulfur

1.04

0.04

2.39

0.62

80.80

0.14

77.89

0.05

Carbon

5.37

Hydrozen

1.43

5.29

73.79

Nitrogen

4.83

1.36

Oxygen *

6.49

5.22

5.57

1.59

12.47

Ash

7.71

5.91

\section{- By Difference}

Heating Value, Btu/lb

14,390

14.031

15,389

15.203

12,962

Ash Free Htg. Value, Btu/lb

6.13

1.49

13.776

Percent Moisture in the

9.09

\section{SORBENTS TESTED}

Both calcia and iron oxide based sorbents were tested during this program. Sorbent feed methods used during this program included mixing as dry powder with the coal, mixing with CWM before firing, and injecting as dry sorbent into the primary zone of the combustor:

\section{NOMINAL TEST CONDITIONS}

The nominal test conditions in the subscale slagging combustor were set to essentially the same values for each test during this program, and are summarized in Table 4-4. Parameters associated with fuel delivery were, of course, affected by the change from PC fuel to CWM, and therefore two separate columns have been provided in the table. 


\section{Table 4-4.}

\section{Nominal Test Conditions}

Euel Type

Compressor Delivery Pressure, psia

Combustion Air Pressure, psia

Combustion Air Temperature, ' $F$

Primary Air Mass Flow Rate, Ib/s

Secondary Air Mass Flow Rate, lb/s

Dilution Air Mass Flow Rate, lb/s

Fuel Mass Flow Rate, lb/min

Coal Carrier Gas Mass Flow. lb/s

Sorbent Mass Flow Rate, lb/min

Primary Zone Equivalence Ratio

Molar Ratio, $\mathrm{Ca} / \mathrm{S}$ or $\mathrm{Fe} / \mathrm{S}$
PC

130

87

650

1.8 to 2.2

2.1 to 2.3

2.1 to 2.3

12 to 16

0.03

1 to 5

1.2 to 1.7

2 to 4
CWM

130

87 to 92

610 to 650

1.8 to 2.2

2.1 to 2.3

2.1 to 2.3

12 to 27

0.20 to $0.40 *$

0.5 to 1.5

1.0 to 1.4

1.5 to 3.0

-Actually not coal carrier gas, but atomizing air.

\section{HISTORY OF COMBUSTOR TEST CONFIGURATIONS}

The overall layout of the initial combustor test rig is shown on Fig. 4-2. All the initial testing of the three PC's and the two CWM's was performed with this configuration.

In 1990, a hardware modification was made on the test rig so as to include the slagging cyclone separator as shown in the schematic of Fig. 4-3 and in the actual photograph of Fig. 4.4.

Following the successful slagging cyclone separator tests a further bardware change was made with the redesign of the impact separator section and the inclusion of a slag tap and water quench for the molten slag as illustrated previously in Fig. 2-2. 


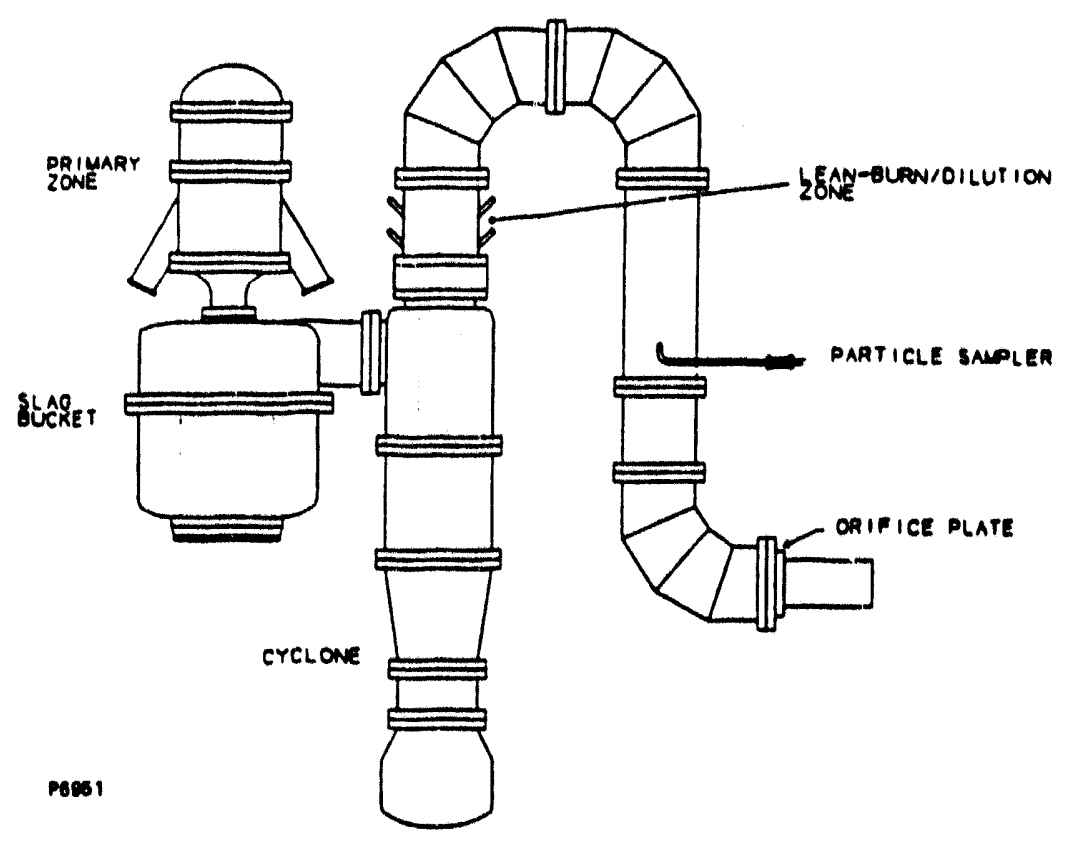

Fig. 4-3. Schematic of Subseale Slageing Combustor Teat Rig as Uttlized During Slageing Cyclone Teating

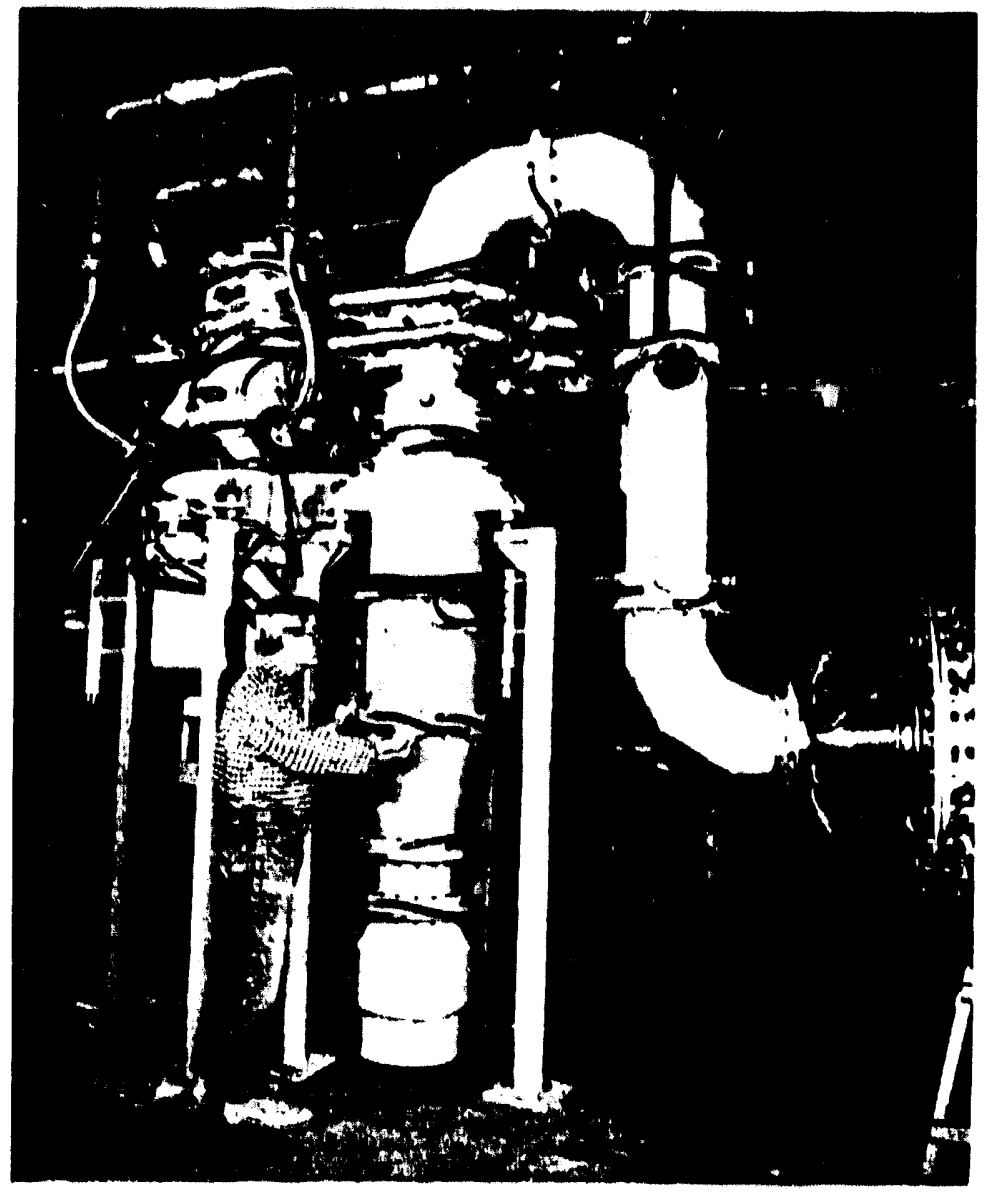

Fig. 4-4. Actual Picture of Subscale Slagging Combustor Test Rig with Slagging Cyclone 
The curved body impact separator was designed to minimize slag droplet re-entrainment, to better control the bucket wall slag flow and also to reduce heat losses. Illustrated schematically in Fig. 4-5, the curved body impact separator also includes a slag tap. Separated slag flows out of the bucket, via the centrally located slag tap hole, and is collected in a water bath below the tap. The exhaust housing has been redesighed to reduce the exit gas velocities and also to reduce heat losses by reducing surface area. Also, with the slag now being collected in a separate slag vessel, the slag bucket itself has been reduced in size considerably, again reducing heat losses.

The problem of slag flow out of the bucket exit has been addressed by both recontouring the exit duct and by re-designing the centerbody to be asymmetric. The intention here was to direct the high momentum inlet jet away from the bucket exit. Inertial separation of slag will take place both on the asymmetric centerbody and on the bucket walls in the region of jet impingement. By intent, the slag is separated onto the wall opposite the exit, and the upper part of the asymmetric centerbody acts as a shield to prevent slag being directed towards the exit. The strong re-circulation in the vicinity of the slag tap also belps to keep the slag tap clear by increasing the heat flux in that region.

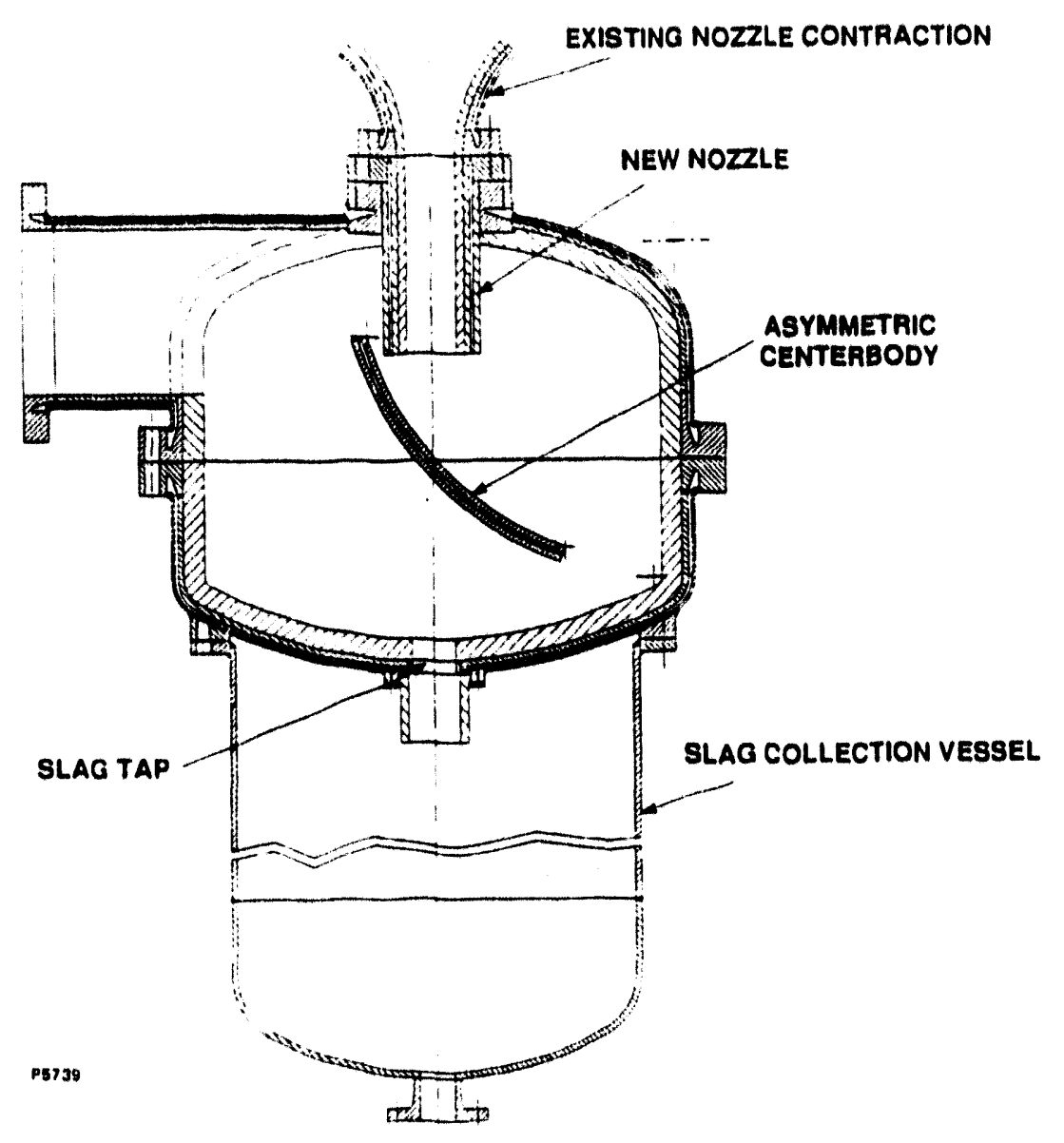

Fig. 4-5. Curved Body Impact Separator with Slag Tap and Collection Vessel 
(This page intentionally left blank) 


\section{SUBSCALE SLAGGING COMBUSTOR TEST RESULTS AND DISCUSSION}

Shakedown testing of the subscale slagging combustor system was conducted during August 1988 and PC combustion tests commenced the following month. Some difficulties were experienced with PC coal flow during early tests, however, these difficulties were overcome by relatively simple modifications of the geometries and flow conditions in the pneumatic feeding and conveying system.

From the onset of combustion testing, a stable flowing slag layer was formed on the primary zone dome and walls as shown in Figs. 5-1 and 5-2, respectively. Some dissolution of the refractory layer was observed in the early runs, but after a few hours of operation an equilibrium insulation layer of slag and refractory was formed. No obstruction or fouling of any of the primary zone coal/air injectors or of the relatively small diameter primary zone exit nozzle with slag was observed. The impact separator worked as planned, and a flowing slag layer, as shown in Fig. 5-3, was obtained on the top and sides of the impact or center body and on the slag bucket walls.

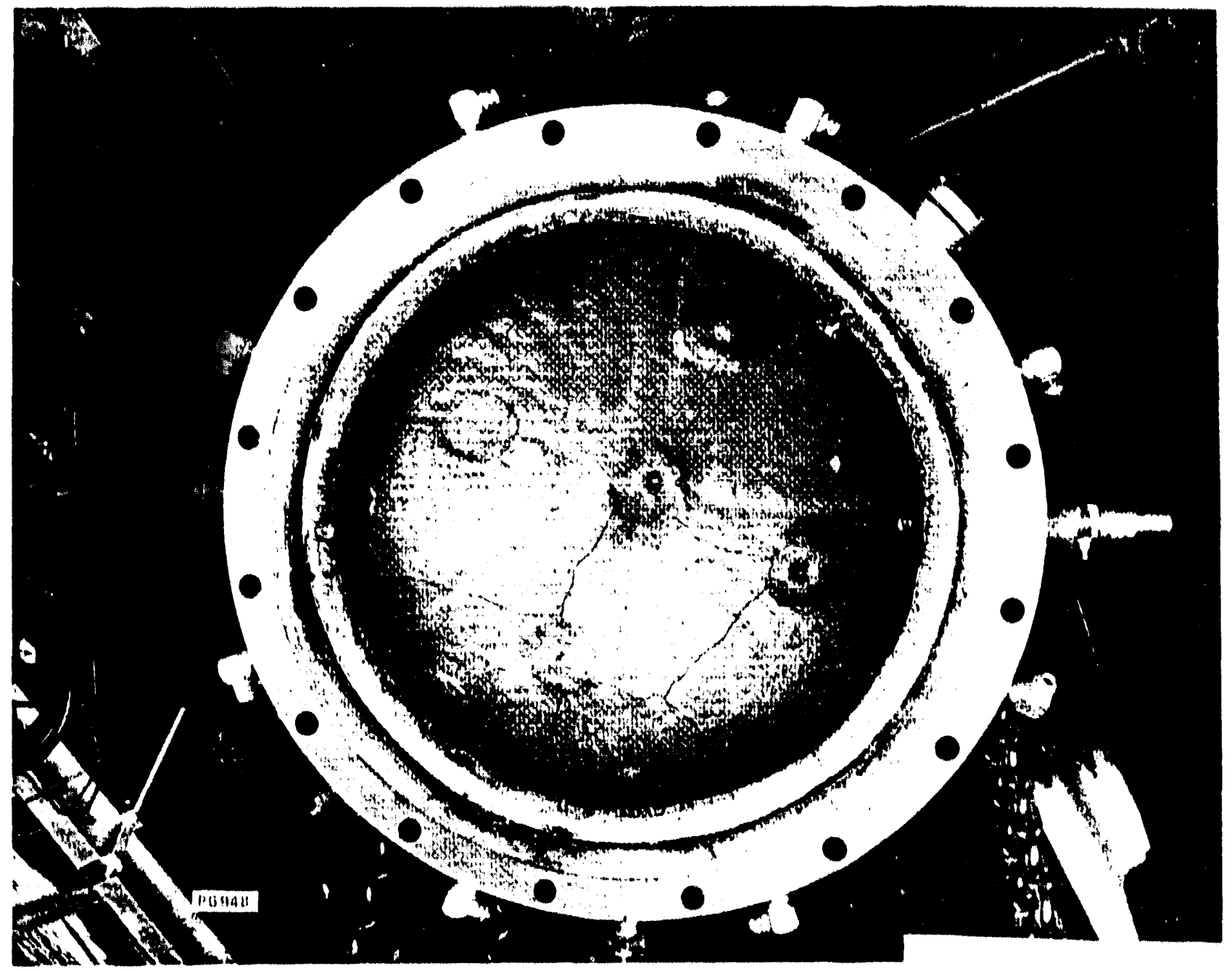

Fig. 5-1. Uniformly Distributed Slag on the Dome of Primary Combustion Chamber 


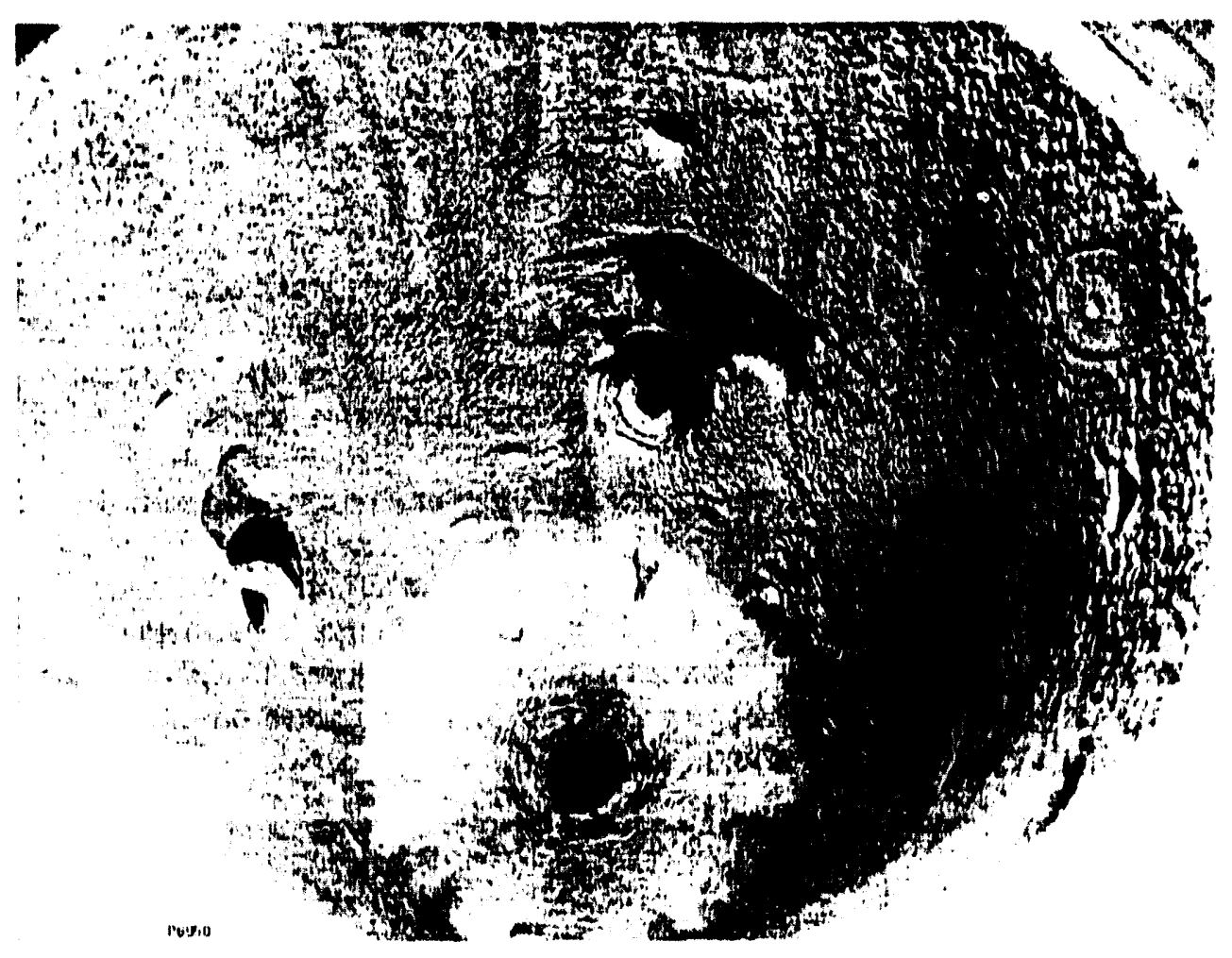

Fig. 5-2. Uniformly Diatributed Residual Slag on the Wall of the Primary Combustion Chamber Looking Towards the Extt Nozede

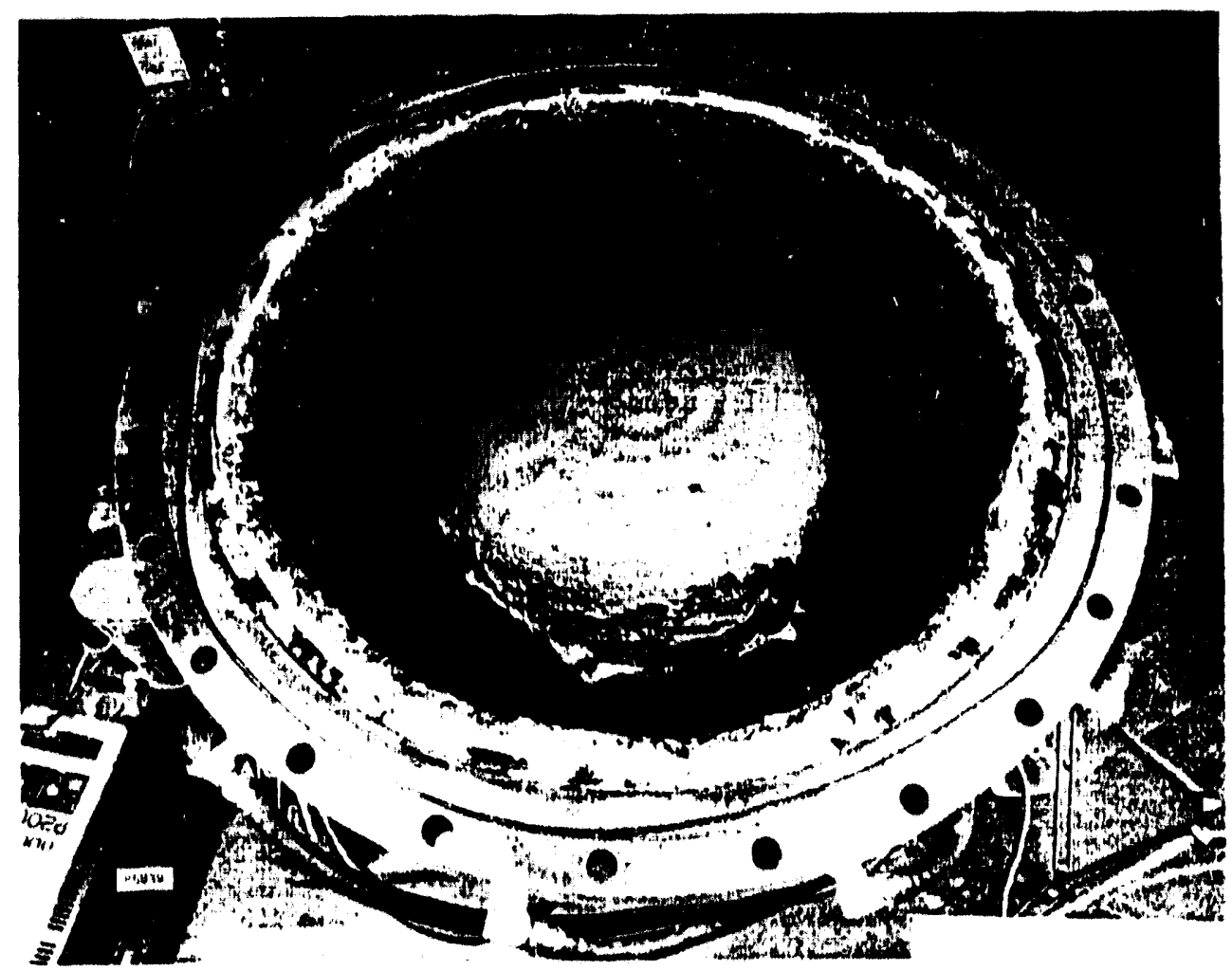

Fig. 5-3. Uniformly Distributed Residual Slag on the Impact Separator Following a Typical Run 
The subscale slagging combustor demonstrated excellent combustion performance when burning PC. Primary zone carbon conversion was typically $98-99 \%$ at equivalence ratios up to approximately 1.5 . There is a moderate reduction in primary zone conversion as the equivalence ratio is increased, as expected. However, even at a primary zone equivalence ratio of 1.7 , the carbon conversion is still very good. When testing was switched to CWM for the same coals, carbon burnout efficiency decreased. By lengthening the primary zone from a length-to-diameter ratio $(L / D)$ of 1.2 to 1.5 and a repositioning of the CWM nozzles to avoid spray/wall impingement and heating, the CWM carbon conversion was increased to $98 \%$ as illustrated in Fig. 5-4.

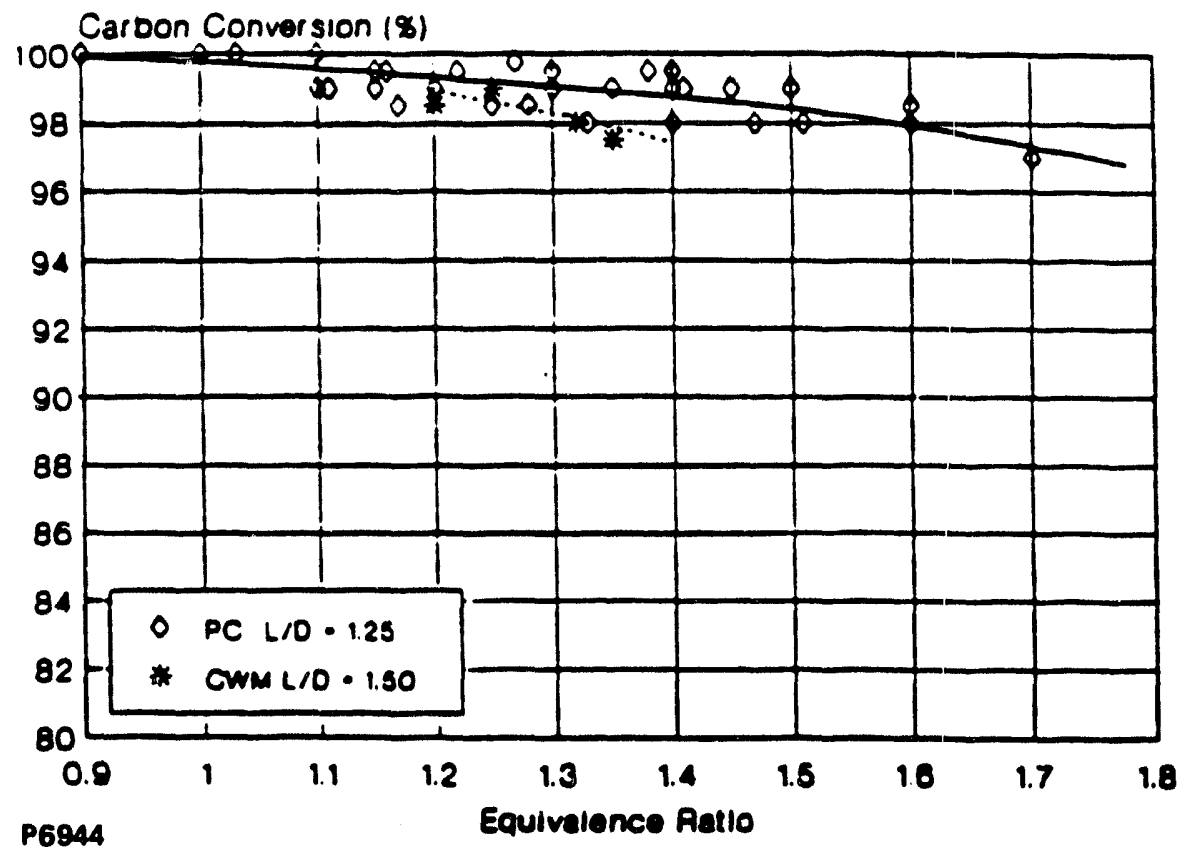

Fig. 5-4. Comparison of Primary Zone Carbon Conversion for CWM and PC; Primary Zone Exit Data

The coals evaluated in this program contained from 1.4 to $1.6 \%$ chemically-bound nitrogen. If converted in the combustor, this nitrogen would produce hundreds of parts per million $\mathrm{NO}_{\mathrm{x}}$ in the exhaust. However, by operating the primary zone at equivalence ratios of 1.2 to 1.4 , it was possible to suppress $\mathrm{NO}_{\mathrm{x}}$ formation. Measured $\mathrm{NO}_{\mathrm{x}}$ emissions from the combustor are showna as a function of the three PCs burned and liumer outlet temperature in Fig. 5-5. The measurements were made at the combustor exit, downstream of the lean burner/dilution zone. When primary zone equivalence ratio is held in the normal range of 1.2 to 1.6, the NOx levels of 35 to $55 \mathrm{ppmv}$ are well below what would be required to meet the EPA's NSPS for a coal-fired plant, which in this case would be approximately $165 \mathrm{ppmv}$. $\mathrm{NO}_{\mathrm{x}}$ levels when testing with CWM are slightly higher than with $\mathrm{PC}$, as opposed to what would be expected. It was expected that the water contained in $\mathrm{CWM}$ would act to reduce thermally generation $\mathrm{NO}_{\mathrm{x}}$ and lower these emissions. 


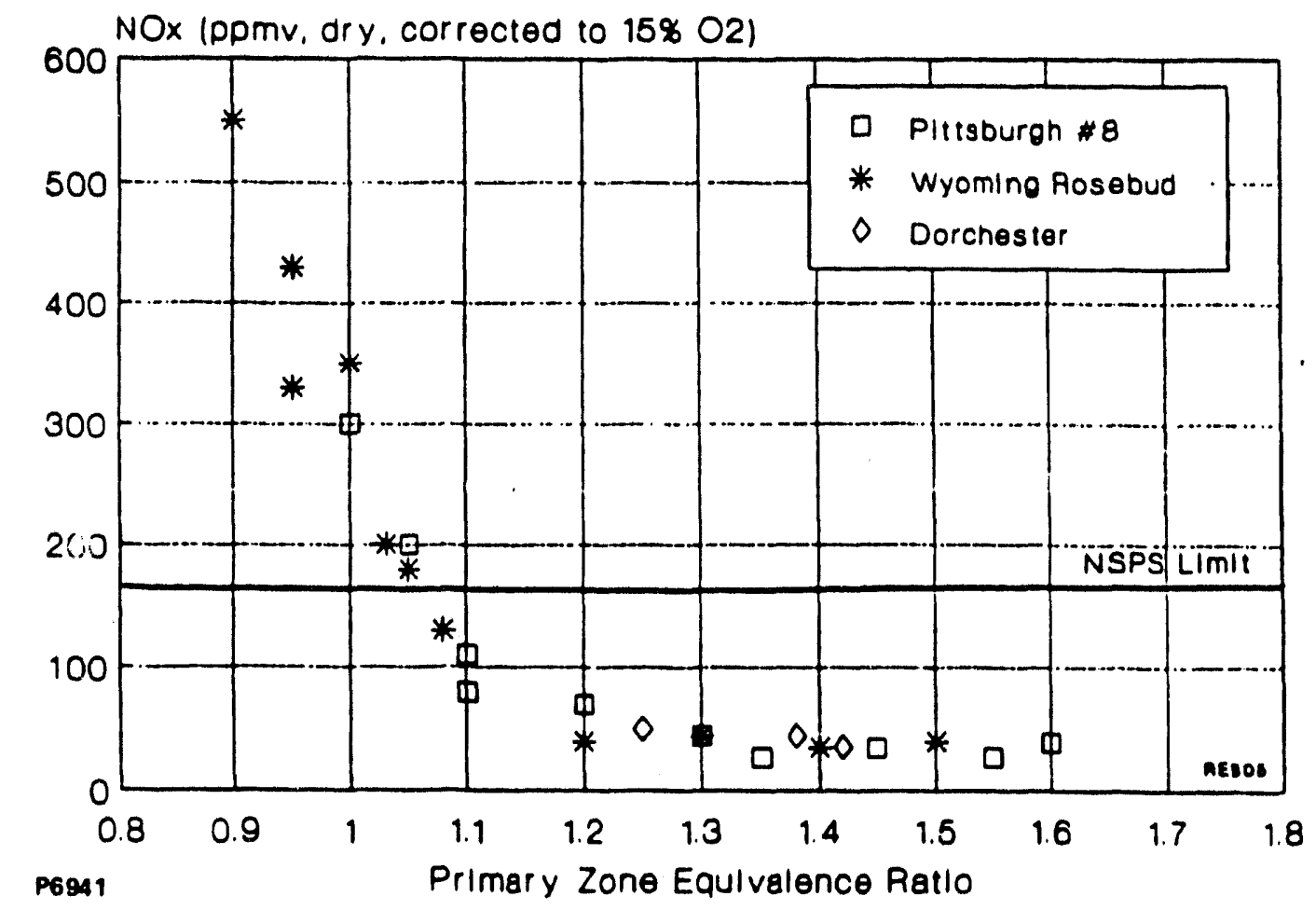

Fig. 5-5. Subscale Combustor NO, Emissions for Bituminous (Dorchester \& Pittsburgh No. 8 and Sibbituminous (Wyoming Rosebud) Pulverized Coals

In sulfur capture, while the major players are $\mathrm{SO}_{2}$ and $\mathrm{H}_{2} \mathrm{~S}$, a number of minor players (COS, $\mathrm{SH}, \mathrm{SO}$, $\left.S_{2}, S\right)$ may account for as much as $30 \%$ of the total sulfur gas species at certain conditions in the fuelrich regime. The exact composition is strongly temperature dependent. Fig. 5-6 shows the total measured $\mathrm{SO}_{2}+\mathrm{H}_{2} \mathrm{~S}$ obtained during a test as a function of equivalence ratio. Also plotted is the predicted equilibrium concentration of $\mathrm{SO}_{2}+\mathrm{H}_{2} \mathrm{~S}$ at a temperature close to that measured at the primary zone exit. Though there is a discrepancy between the two curves, these differences can be accounted for by the presence of minor sulfur gas species in concentrations somewhat different from those predicted at equilibrium conditions.

The sulfur reduction data from the primary zone exit shows a monotonic decrease with increasing equivalence ratios greater than approximately 1.2 (Fig. 5-7). The decrease in sulfur capture can be explained in terms of two phenomena: the lower flame temperature at higher equivalence ratios causes the injected limestone to be heated less rapidly, hereby producing $\mathrm{CaO}$ of less specific surface area, and hence less reactivity, and the increasing amount of $\mathrm{H}_{2} \mathrm{~S}$ present at richer conditions. The bench-scale bomb reactor experiments at TDS, performed under a METC contract modification, showed that under rapid-heating conditions, such as prevail in the combustor, limestone was much more reactive with $\mathrm{SO}_{2}$ than with $\mathrm{H}_{2} \mathrm{~S}$. A significant effect of temperature on capture was observed. Thus, this downward trend agrees with the trends seen in the data from the bench scale experiments.

The reasons for the rapid decrease in sulfur reduction, at times greater than the time of the peak, were thought to be due to one or both of the following processes. First the captured sulfur is being released from the slag and sorbent mixture in the slag trap. (Slag analyses show low sulfur contents.) Second, sulfur may be being released from the reacted sorbent before the particle hits the impact separator centerbody. 


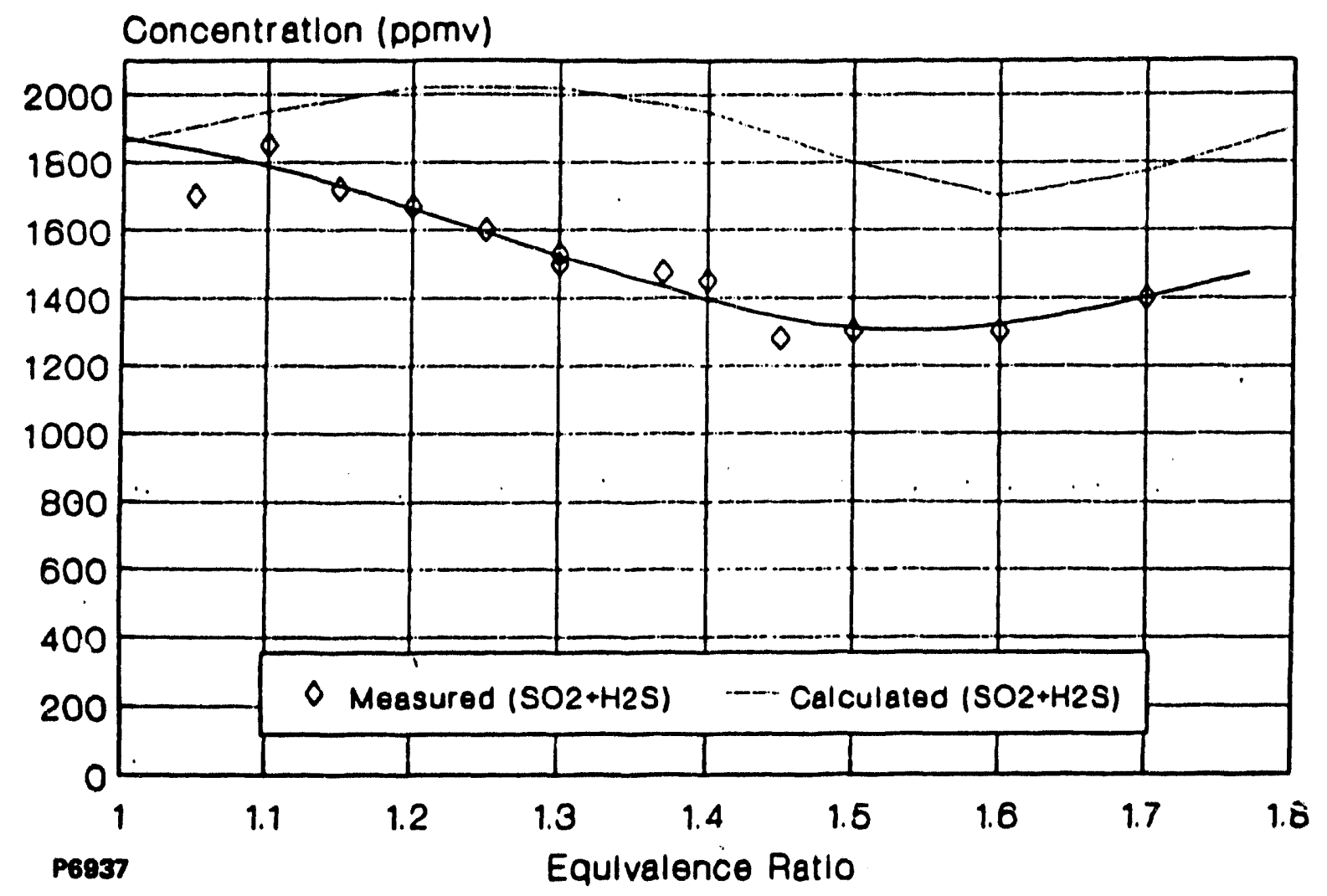

Fig. 5-6. Measured and Predicted Primary Zone Concentrations of $\mathrm{SO}_{2} \mathrm{Plus}_{2} \mathrm{H}_{2} \mathrm{~S}$ in the Products of Combustion for Pittsburgh No. \&-No Sorbent Injection; Wet Basis, not Corrected to $15 \% \mathrm{O}_{2}$

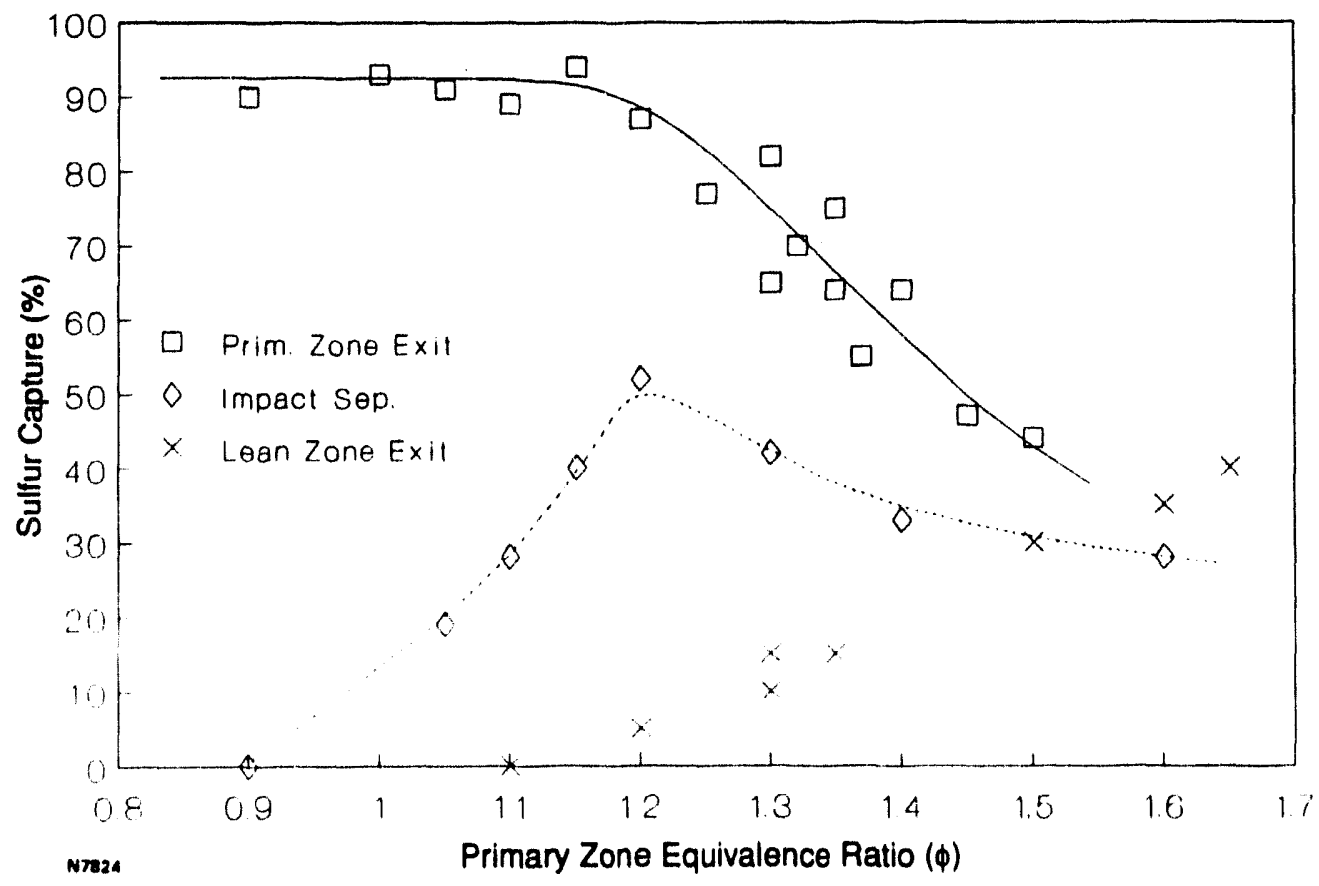

Fig. 5-7. Measured Sulfur Reduction at Three Locations in Subscale Slagging Combustor, -325 Mesh Limestone Sorbent, $\mathrm{Ca} / \mathrm{S}=2-4$ 
Three calcium - based sorbents were evaluated during this program. The majority of the work was done with calcium carbonate (limestone), but brief tests were also made with calcium hydroxide (hydrated lime), and calcium acetate. Calcium-to-sulfur ratios for all three sorbents ranged from 2 to 4 . No significant difference is seen between calcium carbonate and the calcium hydroxide test. With calcium acetate, substantially poorer sulfur reduction was seen.

The trends measured at the combustor exhaust, and confirmed by slag analysis data, give an insight into the sulfur capture mechanisms occurring in the subscale slagging combustor when calcia-based sorbents are injected. In general, the principal sulfur gas species present in the rich zone are $\mathrm{SO}_{2}$ and $\mathrm{H}_{2} \mathrm{~S}$, with the predominant specie for moderatelv rich conditions being $\mathrm{SO}_{2}$ and that for highly fuel-rich conditions being $\mathrm{H}_{2} \mathrm{~S}$. The injected limestone calcines rapidly to form highly reactive $\mathrm{CaO}$, which then reacts to form a mixture of $\mathrm{CaSO}_{4}, \mathrm{CaSO}_{3}$ and $\mathrm{CaS}$, the composition of the mixture depending on the relative amounts of $\mathrm{SO}_{2}$ and $\mathrm{H}_{2} \mathrm{~S}$. $\mathrm{CaSO}_{4}$ and $\mathrm{CaSO}_{3}$ are unstable at primary zone conditions and decompose rapidly, whereas $\mathrm{CaS}$ is stable. Thus, the sulfur reductions measured by gas analysis at the combustor exhaust and those inferred from the slag sulfur content reflect only $\mathrm{CaS}$ formation.

Examination of the sulfur reduction data tended to indicate twu potential methods for improving the overall sulfur removal from the slagging combustor. These are either to stabilize the $\mathrm{CaSO}_{4}$ product or slag, (i.e., by quench of reacted sorbent with air or water) or by forcing either globally or locally very fuel-rich conditions.

Iron oxide based sorbents were also tested for sulfur capture and compared to the calcium-based sorbents. Two compounds were evaluated: hematite, $\mathrm{Fe}_{2} \mathrm{O}_{3}$, and magnetite, $\mathrm{Fe}_{3} \mathrm{O}_{4}$. The iron oxide based sorbents differ from those based on calcia in that sulfur capture is not limited by the surface properties of the solid particles, sulfur capture is an equilibrium process, and high levels of these sorbents actually improve slag fluidity. In addition, the product of the capture process is a stable sulfide.

The $\mathrm{SO}_{2}$ reductions obtained at the combustor exhaust indicated that both iron oxide sorbents perform considerably better than the calcia based sorbents. In particular, the magnetite results show reductions as high as $70 \%$, at an equivalence ratio of 1.5 . Both sorbents show an increase in effectiveness as the primary zone equivalence ratio is increased.

Slag was removed both by centrifugal separation from the toroidal vortex in the primary zone dome and by inertial separation in the impact separator. Overall slag rejection is determined both by measurement of particulate emissions downstream of the lean-bum zone and by measurement of the weight change of the slag bucket during the run. The two measurements generally agreed to within $5 \%$, with the slag bucket giving a slightly lower slag rejection result. This was to be expected, as the bucket measurement did not always account for all material separated on to the combustor walls. Measured slag/sorbent rejection had been excellent at $90 \%$, plus or minus $5 \%$. No significant difference in slag rejection with and without sorbent injection has been observed, as shown in Fig. 5-8.

Detailed fly ash size analyses were made of fly ash samples obtained by isokinetic probing at the combustor exit, downstream of the lean-burn zone. Analyses were made for combustor tests with and without sorbent injection. Fig. 5-9 shorvs measured loadings as a function of particle size measurements of the as-fired coal show it to be typically $95 \%$ below 200 mesh, with a top size of approximately 110 microns. The pulverized limestone sorbent used is $100 \%$ below 325 mesh. The loadings with sorbent are for a calcium to sulfur molar ratio of 2:1. At lower ratios, the loadings will decrease. The highest loadings were measured for the higher ash coal when used with sorbent, as would intuitively be expected. 


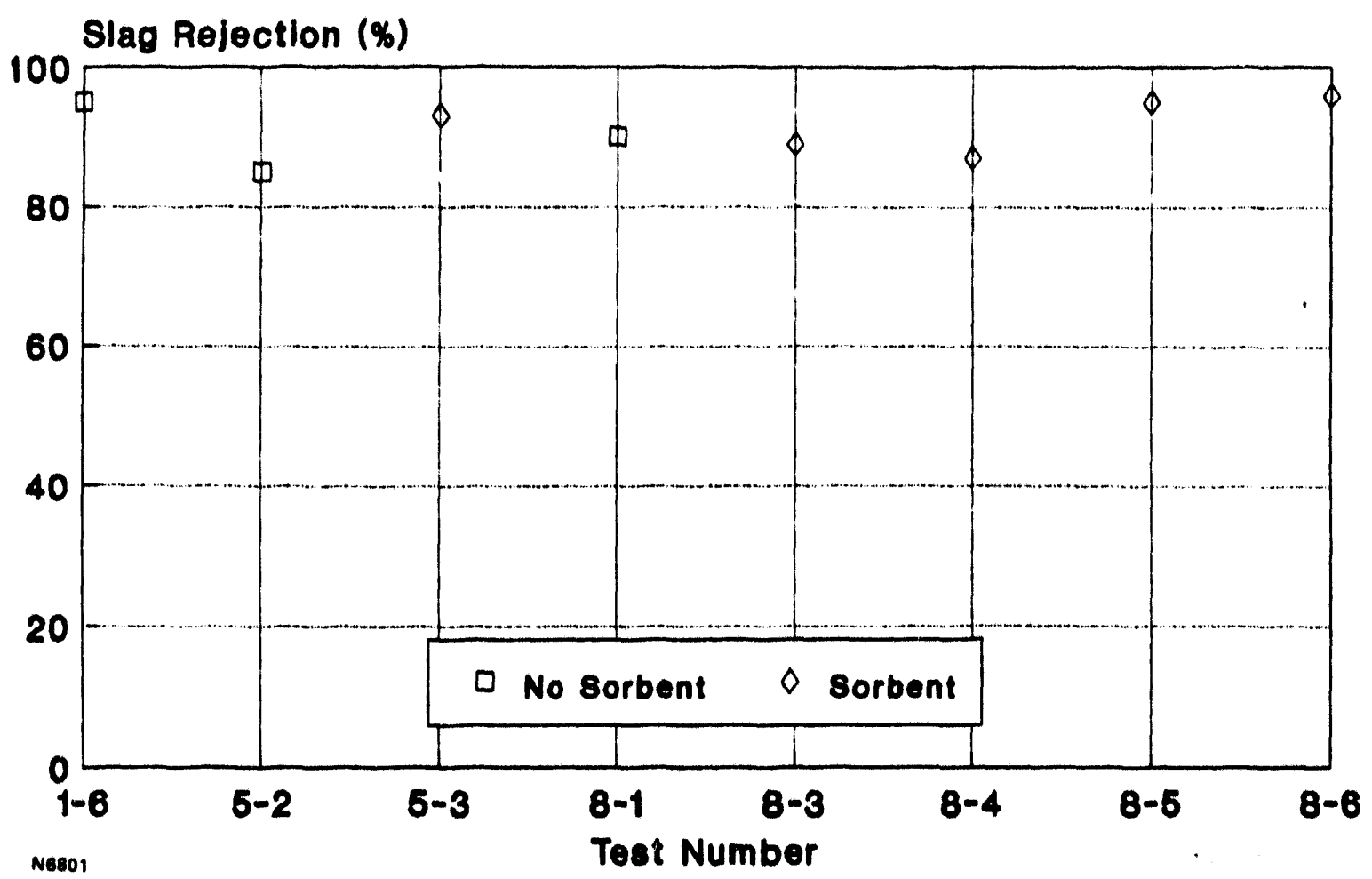

Fig. 5-8. Slag Rejection Data for Subscale Slagging Combustor Test

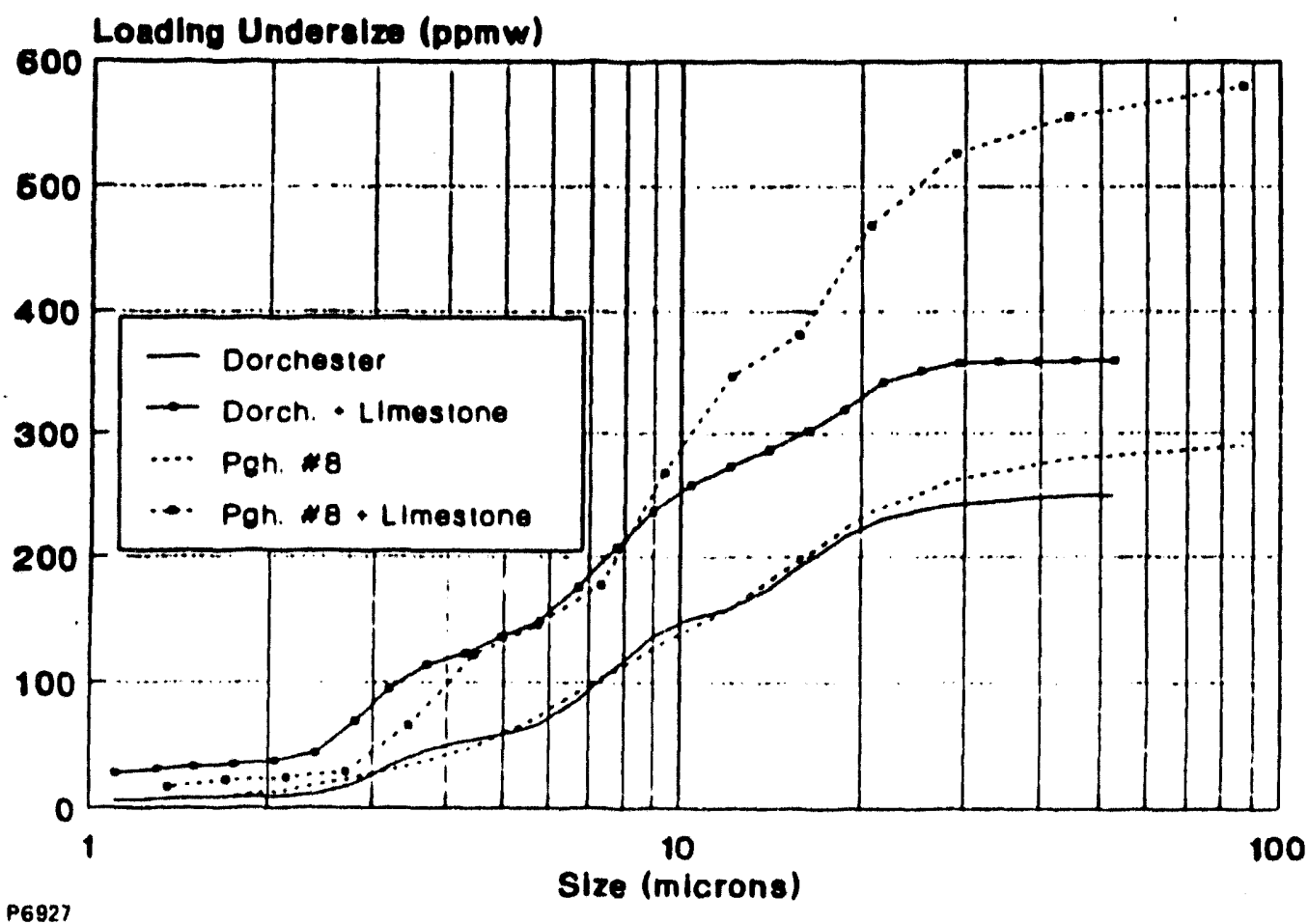

Fig. 5-9. Measured Exhaust Gas Particulate Loadings as a Function of Particle Size for Dorchester \& Pittsburgh No. 8 Pulverized Coal with and without Limestone Sorbent 
There was no substantial difference in the size distribution for samples with or without sorbent injection, and in general the mass mean diameter of the fly ash was measured to be 8 to 9 microns. It should be recognized that this is above the 5 micron size considered acceptable for turbines. Additionally, a small number of particles are in the range of 20 to 80 microns in diameter. Because of their size, they represent a large percentage of the mass in the exhaust, and are also potentially quite erosive. The appearance of these particles in scanning electron microscope photographs indicates that they are entrained slag droplets. Measures to reduce re-entrainment in the impact separator or to provide additional cleanup stages may be needed.

The initial particulate goal of this program has been to meet or better NSPS particulate limits, which for the subscale slagging combustor is 13 ppmw. Without a slagging cyclone, third-stage exit measurements showed particulate loadings of 250 to $500 \mathrm{ppmw}$.

A Westinghouse alkali probe was provided for measurement of particulate alkali and vapor alkali loadings in the hot gases exiting the lean/quench combustor. The major problem with most alkali sampling is that alkali vapor species inevitably condense somewhere in the sampling line and system, often escaping detection. Other problems have been: failure to measure the alkali (especially soluble alkali) in collected particulates, (most insoluble alkali poses no problem to the turbine), and condensation of vapor-phase alkali on particulates in the sampling lines and system. The latter problem results in underestimation of the alkali vapor content of the process gas, or leads to the erroneous conclusion that good particulate cleanup alone can protect the combustion turbine from alkali-induced hot corrosion.

The Westinghouse probe avoids these problems. Rather than using the probe to withdraw a gas stream for external separation of particulates and alkali, these are collected in the probe itself. The probe is inserted into the gas stream and a sample of gas is withdrawn through the probe continuously.

The measured alkali levels corresponded to between 1 and $2 \%$ of the total alkali in the coal. This represented a good reduction in alkali through the action of the impact separator, but it is not low enough to prevent corrosive attack in the expander of the gas turbine. Experience with traces of alkali in oil-fired combustion turbines has resulted in the widely accepted guideline that sodium plus potassium may not exceed 0.02 ppmw on an exhaust flow basis. Thus, the 0.42 to 0.71 ppmw found in the coal burner exhaust is an order of magnitude too high. Combustion turbine oil fuel specifications currently limit the sodium plus potassium level in the fuel oil to $1 \mathrm{ppmw}$. Since the weight ratio of oil fuel mass flow rate to turbine inlet hot gas mass flow rate is approximately 1:50, the 1 ppmw limit in the oil is equivalent to a limit of $0.02 \mathrm{ppmw}$ in the turbine inlet gas.

For PC-firing, measured flame temperatures in the primary zone are plotted as a function of equivalence ratio in Fig. 5-10. These measurements are made with a two-color optical pyrometer focused at the center of the dome region in the primary zone. The peak flame temperature $\left(2400^{\circ} \mathrm{K} / 3860^{\circ} \mathrm{F}\right)$ was measured at an equivalence ratio of approximately 1.05 . The flame temperature at the nominal operating point of the primary zone is on the order of $2000^{\circ}$ to $2100^{\circ} \mathrm{K}\left(3140^{\circ}\right.$ to $\left.3320^{\circ} \mathrm{F}\right)$.

For CWM-firing, flame temperatures on the order of 1900 to $2000^{\circ} \mathrm{K}\left(2960^{\circ}\right.$ to $\left.3140^{\circ} \mathrm{F}\right)$ were measured at equivalence ratios in the range 1.2. to 1.4. These flame temperatures are some $150^{\circ}$ to $200^{\circ} \mathrm{K}$ below the measured flame temperatures for PC firing at the same equivalence ratios. 


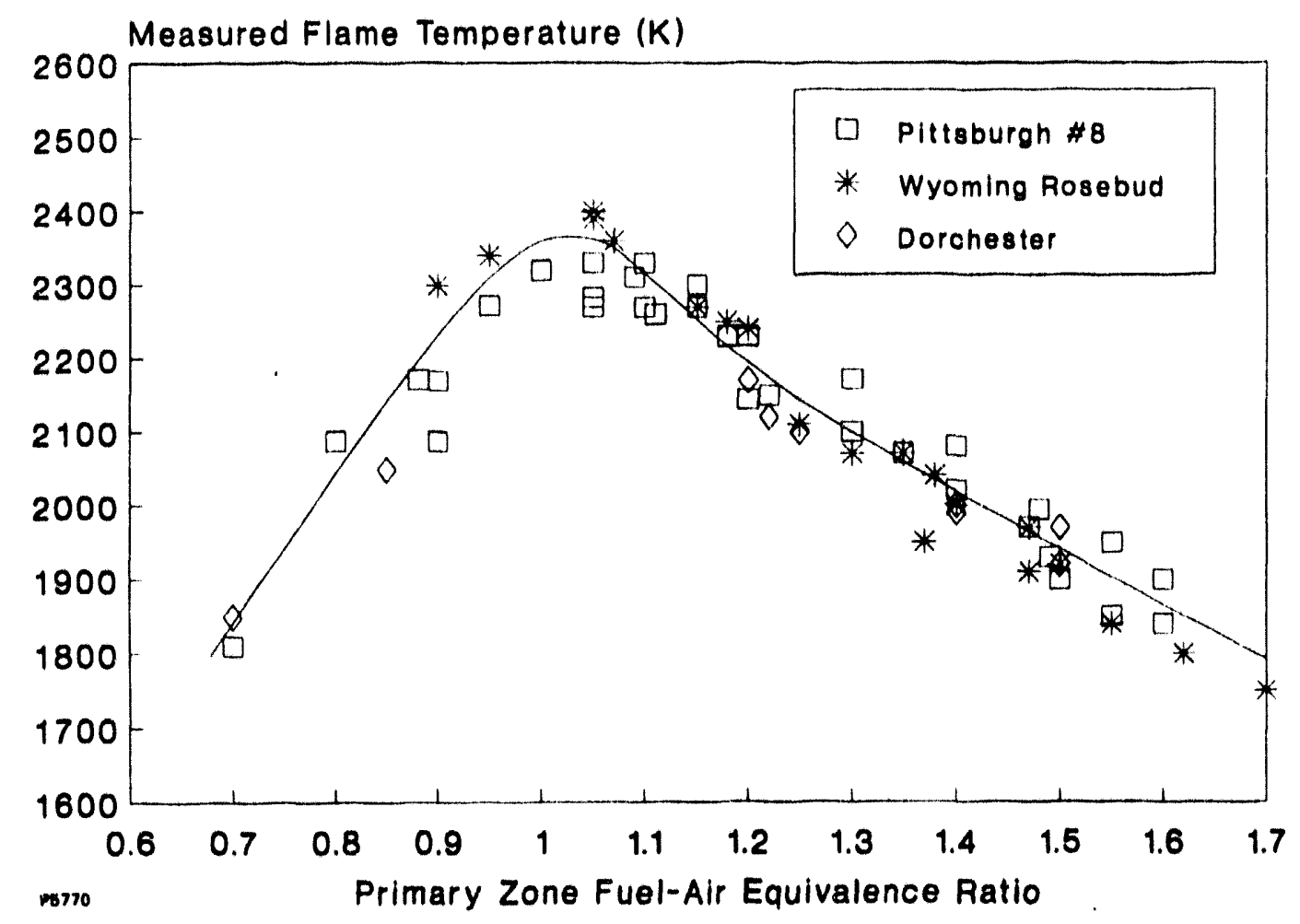

Fig. 5-10. Primary Zone Flame Tempernture as a Function of Equivalence Ratio

A thermocouple rake was installed at the combustor third-stage exit in order to provide an indication of the temperature profile. This probe employed six (6) thermocouples, spaced at one-inch intervals, to cover the exit stream from the wall to the centerline. Symmetry is assumed in describing the temperature profile.

Exit profile curves for six (6) different average outlet temperatures are shown in Fig. 5-11. They represent a wide range of combustor primary equivalence ratios, 1.2 to 1.6, and dilution airflows. These yield average exit temperatures of $1600^{\circ}$ to $2000^{\circ} \mathrm{F}$. At the project design point exit temperature of $1850^{\circ} \mathrm{F}$, the calculated pattem factor is $14 \%$, which is well within the project goal, to achieve a pattern factor of $20 \%$ or less.

All components of the subscale slagging combustor were water-cooled to assure no local overheating occurred. Although no attempt was made to tailor the water fluxes to minimize heat loss, the watercooling system is designed to enable accurate measurement of system heat losses. Thus, measured heat losses from the subscale combustor during testing were higher than they would be for a full-scale unit. The heat loss is a function also of primary zone temperanure, particulate loading, and combustor wall refractory condition. The best results, a $12 \%$ loss, were obtained with a completely intact refractory coating. The combustor has experienced refractory loss, particularly on convex surfaces in the impact separator, due to repeated thermal cycling, and the constantly changing operating conditions that are experienced in a research program. It is estimated that heat losses could be cut to less than half those found pres :ntly, when a large, high-pressure full-scale unit is designed. 


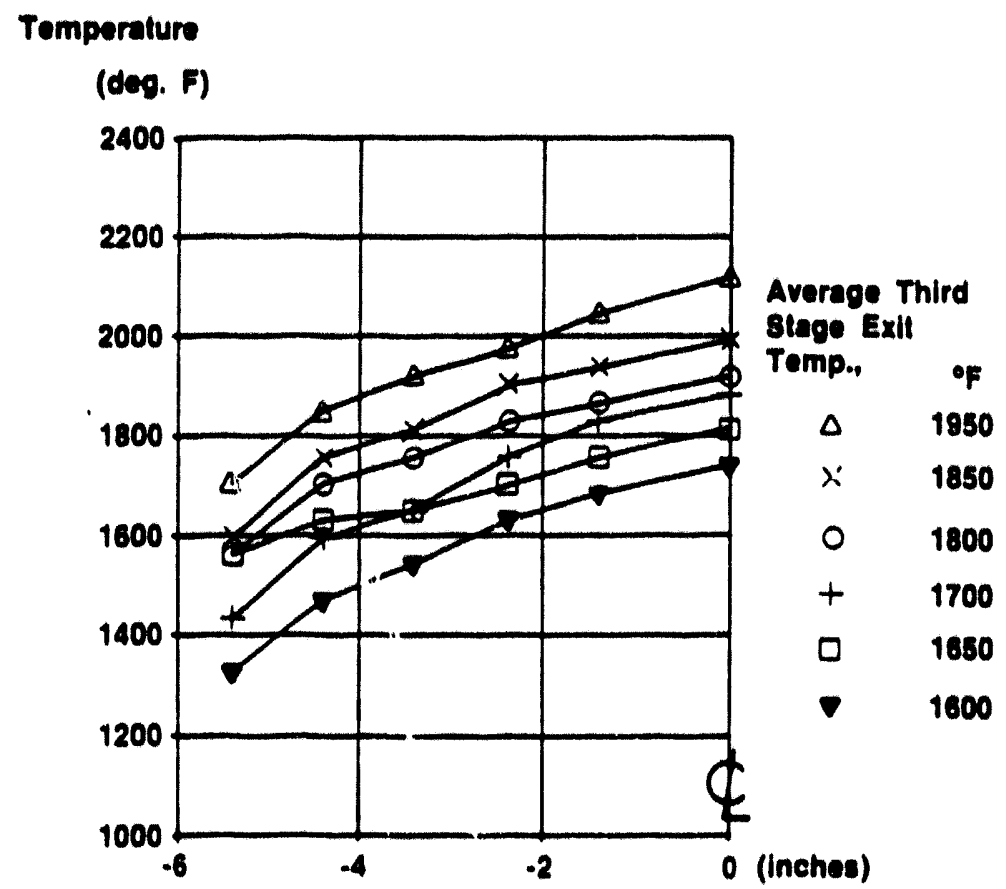

P6025

Distenes Irom Duet Center

\section{Fig. 5-11. Subscale Slageing Combustor Third Stage Extt Temperature Profiles at Several Average Exit Temperatures}

The measured overall combustor total pressure loss declined from $8 \%$, which had been considered normal, to approximately 5 to $6 \%$. It was discovered that this resulted from erosion of the primary zone exit nozzle ceramic lining. This lowered the gas velocity approsching the impact separator, but there is no evidence that slag separation was adversely afiected by the lower velocity. It should be remembered, however, that the various trade-ofis between overall pressure loss and particle collection efficiency are by no means complete at this point, since additional cleanup is required.

\section{DISCUSSION OF ORIOINAL TVC RESULTS}

During the period of time in which the original design of the TVC was tested, the subscale $12 \mathrm{MM}$ Btw/hr combustor became operational for the first time and demonstrated excellent coal-fired operation at $6 \mathrm{~atm}$. All three coal fuel types were burnod successfully. As a result of this active testing the following conclusions may be drawn:

- It was possible to achieve the full design thermal capacity of $12 \mathrm{MM}$ Btu/hr with the subscale slagging combustor, while burning $100 \%$ pulverized coal and operating at the design pressure of $6 \mathrm{~atm}$.

- Because of the separate-chamber, rich-lean design of the subscale slagging combustor, NOx emissions that easily meet the NSPS limits are readily achieved. 
- Because of its refractory-lined, toroidal-vortex design, the subscale slagging combustor readily achieves in excess of $99 \%$ carbon bumout efficiency when $100 \%$ coal-fired.

- $90 \%$ of the ash can be captured as slag in the impact separator.

- Objectives for third-stage exit temperature $\left(1850^{\circ} \mathrm{F}\right)$, and exit temperature pattern factor $(14 \%)$ were readily achieved.

- Sulfur reductions in the third stage exhaust of up to $45 \%$ with calcia and $85 \%$ with iron oxide have been achieved. The NSPS goal is 70 to $90 \%$ reduction, depending on coal sulfur content.

- Feeding pulverized coal into the combustor against 6 atm pressure is achievable, but doing the same with sorbent is more difficult, due to the small flow rates needed.

- The demands of NSPS in the area of particulate removal indicate an additional cleanup stage, over-and-above the impact separator is needed. A slagging cyclone, the prime candidate to meet these requirements was designed, fabricated, and tested, as described next.

In fall of 1990, a slagging cyclone separator was installed between the rich-burn primary and lean-burn secondary combustors. An oil-fired run was made in order to complete curing of the newly installed refractory layers in the combustor and cyclone separator. The system was allowed to come up to preheated air temperature $\left(650^{\circ} \mathrm{F}\right)$ before lighting off a fuel oil flame. The oil flow was progressively increased over a period of several hours in order to increase the bulk gas temperature in the combustor and cyclone and allow the refractory to cure. The slagsing cyclone testing was nun from November 1990 through January 1991. The objective of this period was to determine the collection efficiency of the slagging cyclone separator. Table 5-1 shows these estimates for the tests Cl-1 through Cl-6.

Table 5-1.

Fly Ash Loading and Overall Slag Colloction Efficlenoy Eatimates wtth Slagging Cyolone

$\begin{array}{lcc}\text { Test Number } & \begin{array}{c}\text { Estimated Total Slag } \\ \text { Collection }\end{array} & \begin{array}{c}\text { Estimated Exhaust Fly Ash } \\ \text { Loading }\end{array} \\ \text { C1-1 } & (\%) & (\text { ppmw) } \\ \text { C } 1-2 & 99.7 & 7 \\ \text { C } 1-3 & 99.6 & 9 \\ \text { C } 1-4 & 99.2 & 18 \\ \text { C } 1-5 & 97.2 & 64 \\ \text { C } 1-6 & 98.9 & 25 \\ & 98.4 & 37\end{array}$

For these test conditions, the NSPS emissions limit of $0.03 \mathrm{lb} / \mathrm{MM}$ Btu would correspond to approximately $15 \mathrm{ppmw}$. These estimates confirm that the cyclone is operating at approximately $90 \%$ collection efficiency and definitely shows the potential for meeting the turbine inlet particulate loading requirements and possibly the NSPS requirements. 
Fig. 5-12 shows mezsured size distributions for particle samples collected by isokinetic sampling dovnnstream of the cyclone separator. The Fig. shows the size distribution of a cyclone bucket powder saniple, a sample of black powder from the particle filter and a sample of fly ash removed ftom unclemeath the black powder on the same particle filter. The unburned coal carried over from the cyclone bucket to the isokinetic particle sampler is somewhat smaller than that remaining in the bucket, but is still relatively large. The fly ash collected on the filter, however, is extremely fine, with a mean size of around 3 microns. Some $90 \%$ of the fly ash is contained in particles of diameter 5 microns or less.

At the conclusion of slagging cyclone testing, the combustor was tom down and installation of the revised impact separator and slag tap hardware commenced. The primary zone components were first removed from the test assembly to allow the upper housing of the old slag separator to be removed. The new slag separator upper housing was aligned with the cyclone separator inlet. The primary zone cornponents were then re-installed, along with the new slag separator nozzle. Subsequently, the new impect separntor/centerbody assembly was set in place. A quartz window was installed to provide a view

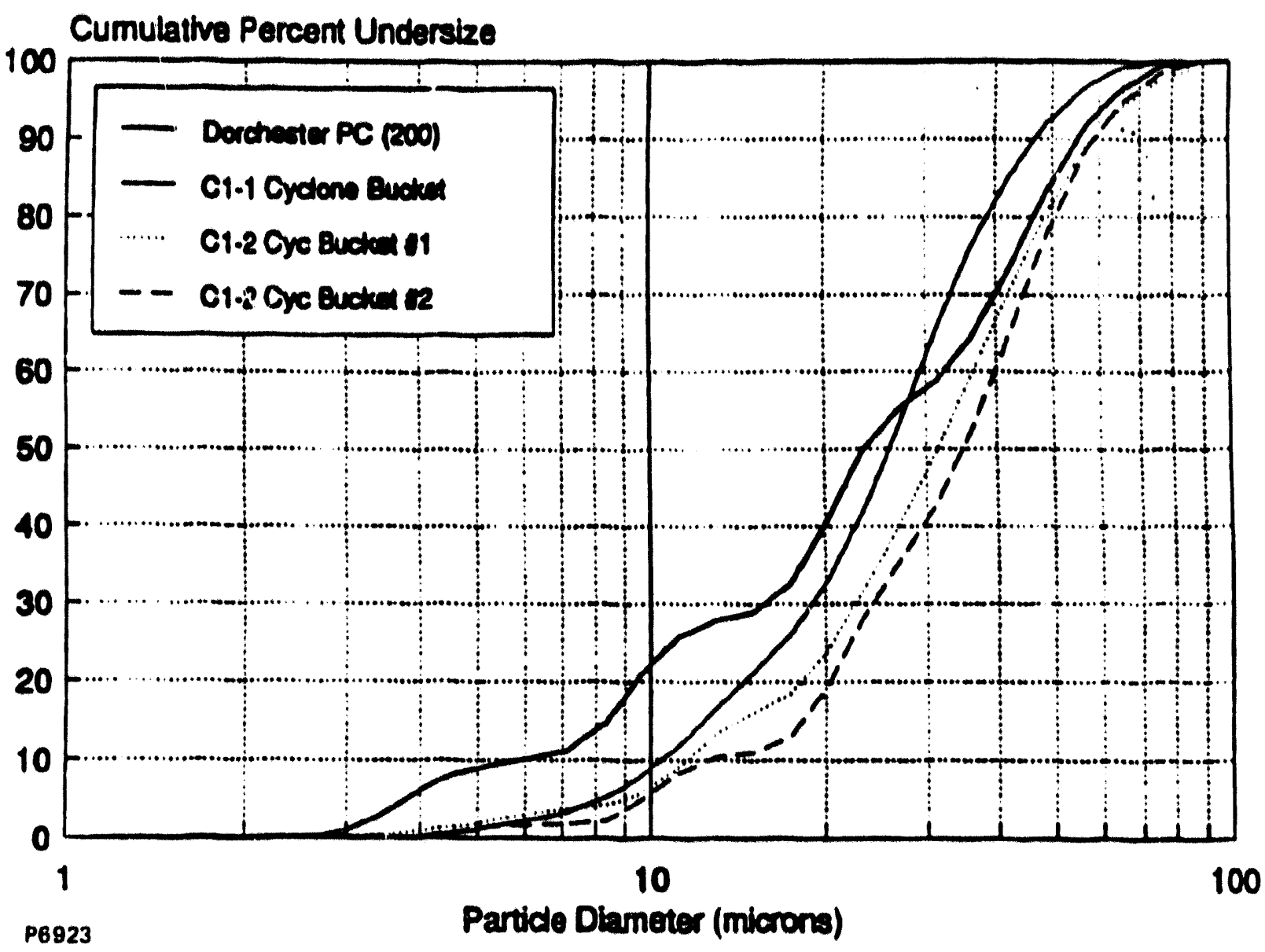

Fig. 5-12. Particle Size Distributions from Cyclont Bucketh Mensured Size Distributlons for: (1) 200 Mesh Dorchester Coal;

(2) Sample from Cyclone Bucket, C1-1; (3) Sample No. 1 Test from Cyclone Bucket, Test C1-2; (4) Snmple No. 2 from Cyclone Bucket, Test C1-2 
of the top of the new separator surface. The water supply, water level controls and the pneumatically actuated slag ram were installed in the slag bucket. The cooling water system was modified to provide cooling to the new components. Additional gas and water instrumentation systems were installed and calibrated. The slag ram system was tested. Movement of the ram was relatively slow, the limitation being the airflow capacity of the actuating solenoid valve. A solenoid valve of larger airflow capacity was procured. The automatic level control system for the slag water-bath was checked and worked well.

The PC-firing tests with the slag tap in place began in April 1991. Several test runs were completed focusing just on the tapping of slag. The video monitor viewing the slag tap showed molten slag descending trom the tap and freezing as it hit the water. A slag ram was occasionally used to free frozen slag from the tap aree

The addition of the redeaigned impact separator stage with the curved centerbody lowered the heat loss about $3 \%$.

Results from sorbent Injection experiments with the slag tap/quench are plotted in Fig. 5-13. Although the very high captivail previously observed at the exit of the primary zone were not duplicated, the sulfur cepture at the exit from the lean zone (1.e. the combustor emissions reduction) his been increased dramatically. At a tuel/air equivalence natio of 1.2 and a $\mathrm{Ca} / \mathrm{S}$ molar natlo of 3, the lean-zone exit sulfur capture bes been increased from 10 to $50 \%$ by adding the slag tap. This confirmed thet the reacted sorbent has been prevented from decomposing by removing it trom the high temperature slag bucket and quenching it in water.

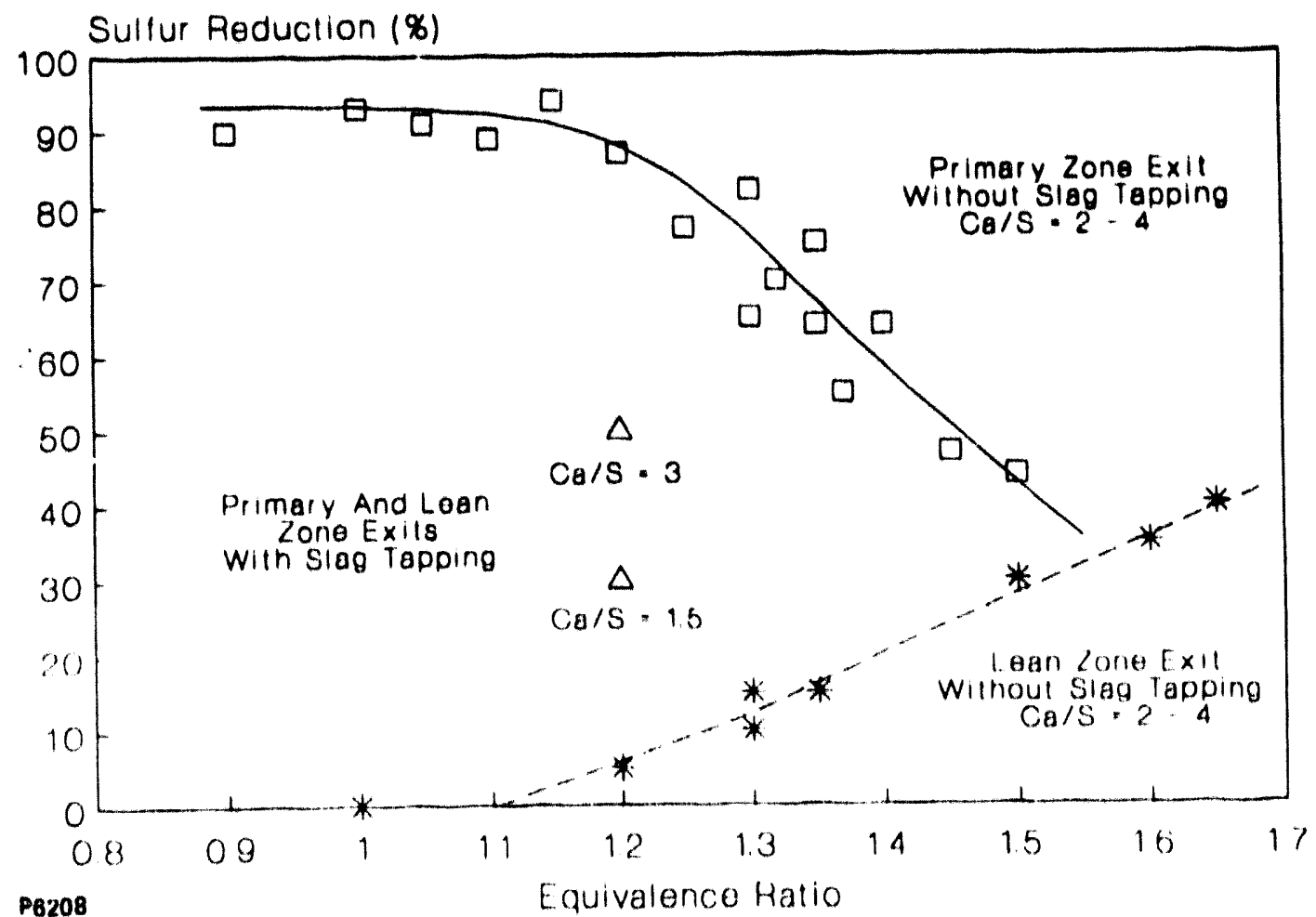

Fig. 5-13. Sulfur Capture with Pittsburgh No. 8 Coal 
The TDS Toroidal Vortex Combustor used as the primary combustor in Westinghouse's proposed DCFOT system has proved to be reliable and effective during the subscale testing. The latest conflguration has proven out that slag tapping can be accomplished successfully while effecting high carbon gasification levels in the primary zone. Measured CO levels at the exit to the lean-quench combustor varied between 10 to $70 \mathrm{ppm}$ at $1.1 \geq \leq 1.6$. NOx levels are controllable to $\leq 0.2 \mathrm{lb} /$ MMBtu lovel at $\approx \geq 1.05$, which is significently below current NSPS.

Inclusion of the slagging cyclone sepanator reduced emission levels significently so that turbine blade erosion is unlikely, plus the alkall levels may not produce significant corrosion. The particulate loading levels at the turbine inlet will still be above the NSPS limits of $0.03 \mathrm{lb} / \mathrm{MM}$ Btu, but this could be handled by back end cleanup.

Sulfur capture results have only been mildly encounging. With the introduction of the she tapping system, it hes been possible to increase sulfur reductions to $50 \%$ at a Ca/S molar matio of three with 323 meeph limertone.

In the last year of this project, the tendency hes been to consider more tual-rich conditions in the primary 2000 ( $>1.4) 80$ as to inoresse the caloric value of the low Btu ges being burned in the lean-quench comburtor. This would tend to lend in the direction of the iron oxide sorbents which are more effective a lower flame temperntures and higher $\mathrm{H}_{2} \mathrm{~S}$ coscentrations. One of the last experimental nuns on the subecale combustor verified the up to $70 \%$ sulfur cepture could be obtained at higher Fe/S moler natios. The iron oxides produce a stable iron oxysulfide matte which is stable and soluble in the molten siag. Since iron oxides are also fluxing azents this may be the direction to 80 if in combustor sulfur capture is required. To meet the new EPA sulfur requirements it will take additional sulfur capture to get to the 90 to $95 \%$ needed for the future. 


\section{ANCILLARY STUDIES}

\subsection{COLD-FLOW CYCLONE TESTS}

The inclusion of a high efficiency cyclone separator in the second combustor stage was proposed during the conception of this project to enhance the possibility of meeting the NSPS particulate emissions requirements at the combustor exit. The proposed cyclone would have to operate at high temperature $\left(3200^{\circ} \mathrm{F}\right)$ and 6 atm. Particulates in the gas would be in the form of fine molten fly ash. Because of the lack of experience with cyclones at these conditions, operation of the cyclone at this high gas temperature posed uncertainties and risks.

To obtain information on cyclone operation and performance at the novel operating conditions involved, Iaboratory scale cold-flow cyclone modeling experiments were performed. The cold-flow experimental reaults had to be ecalable to the subscale comburtor conditions in order to allow an assessment of predicted performance it those conditions. This was eccomplished by modeling of the following principa non-dimensional panmeters in the laboratory scale experiments:

$$
\begin{array}{lll}
\text { Reynolds Number } R_{0}=\frac{\rho U D}{\mu} & \text { Weber Number } & W_{0}=\frac{\rho U L^{2}}{\sigma} \\
\text { Stokes Number } & \text { Stk }=\frac{P_{D} u d_{D}^{2}}{18 \mu D} & \text { Swirl Number } \quad S w=\frac{O_{e}}{R O_{X}}=\frac{\pi D_{e} D}{4 a b}
\end{array}
$$

where $p$ is the eas density, $u$ is the inlet velocity, $D$ is the cyclone barrel diameter, $\mu$ is the gas viscosity, $P_{p}$ is the particle density, $d_{p}$ is the mass median diameter of the inlet particle flux, $L$ is a characteristic length of the liquid layer, $\sigma$ is the liquid surface tension, $D_{e}$ is the cyclone exit diameter, $a$ is the cyclone inlet height, $b$ is the cyclone inler width, $R$ is a characteristic radius, and $O_{\phi}$ and $O_{x}$ are the tangential and axial momentum fluxes, respectively. Re-entrinment offects are correlated by the liquid layer Reynolds Number ReL, expressed as

$$
R e_{L}=\frac{4 Q_{L}}{v_{L^{a}}}
$$

where QL is the liquid yolume flow rate and VL is the liquid kinematic viscosity. Aerosols of glycerine were generated in the inlet gas stream to simulate molten ash particle viscosity and surface tension in the subscale combustor model cyclone, as the values at ambient conditions are comparable to those of molten ash at gas turbine combustor conditions. 
A schematic diagram of the experinental apparatus is shown in Fig. 6.1. The dimensions of the model cyclone, fabricated from Plexiglas, are given in Fig. 6-2. Air from the main facility compressor provided the test gas. The mass flow rate was controlled by flow regulating valves, and measured using a standard sharp-edged orifice plate. A heat exchanger was installed to lower the $260^{\circ} \mathrm{F}$ air temperature from the compressor to $70^{\circ} \mathrm{F}$.

An aerosol was generated by atomization of glycerine using an air-blast atomizer which produced droplets up to several bundred microns in diameter. In order to determine overall cyclone collection efficiencies, the cyclone exit flow was filtered allowing measurement of glycerine passed through the cyclone. The filter material used was rated at 95 to $98 \%$ collection for particles above 0.2 microns. The langer aerosol particles were removed by an impact separator before the glycerine droplet-laden test gas entered the cyclone model.

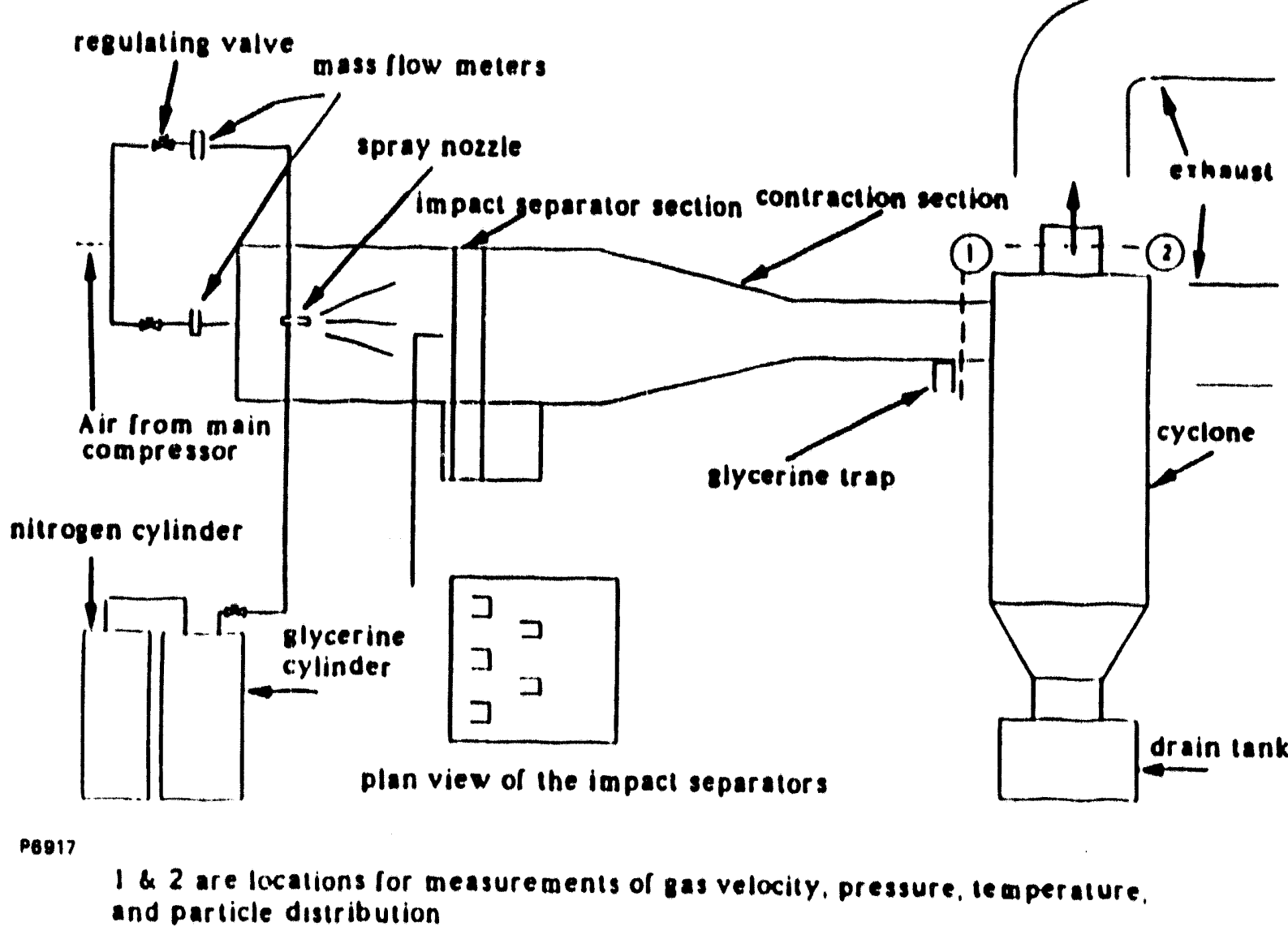

Fig. 6-1. Cyclone Separator Experimental Arrangement 


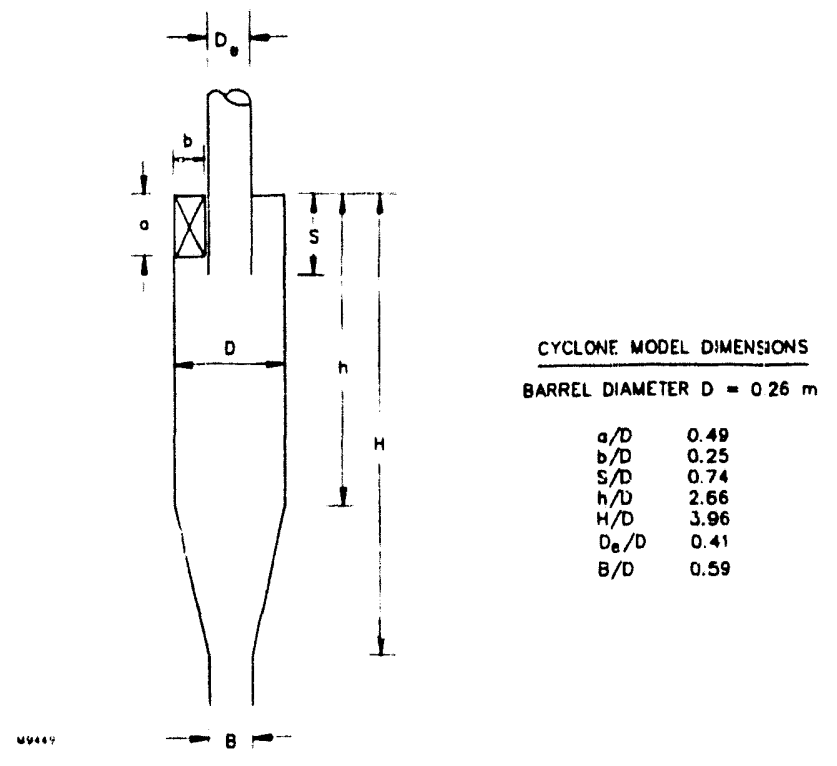

Fig. 6-2. Model Cyclone Dimensions

The cyclone collection efficiency required in order to meet the NSPS nequirements upstream of the turbine will be a function of the ash content of the coal, the sorbent loading, and the collection efficiency of the impact separator. Based on the measured combustor fly ash loadings and size distributions with the original subscale combustor configuration and the cyclone grade efficiency curves obtained in the model tests, it is possible to estimate the fly ash loadings and size distributions at the cyclone exit. These estimates are illustrated in Fig. 6-3, for two coals (Dorchester 6\% ash, 1\% sulfur) and Pittsburgh No. 8 (7.6\% ash, 2.4\% sulfur), with and without sorbent and for two cyclone inlet velocities ( $50 \%$ and $100 \%$ of design velocity). Except for one case (Pittsburgh No. 8 with sorbent at $50 \%$ velocity), there are predicted to be no particles present in the exhaust which are greater than 5 microns in diameter. Indications are that at the design velocity, the NSPS limit can be met, particularly for the lower ash, low sulfur coal. The current industry limit consensus is sketched in Fig. 6-3.

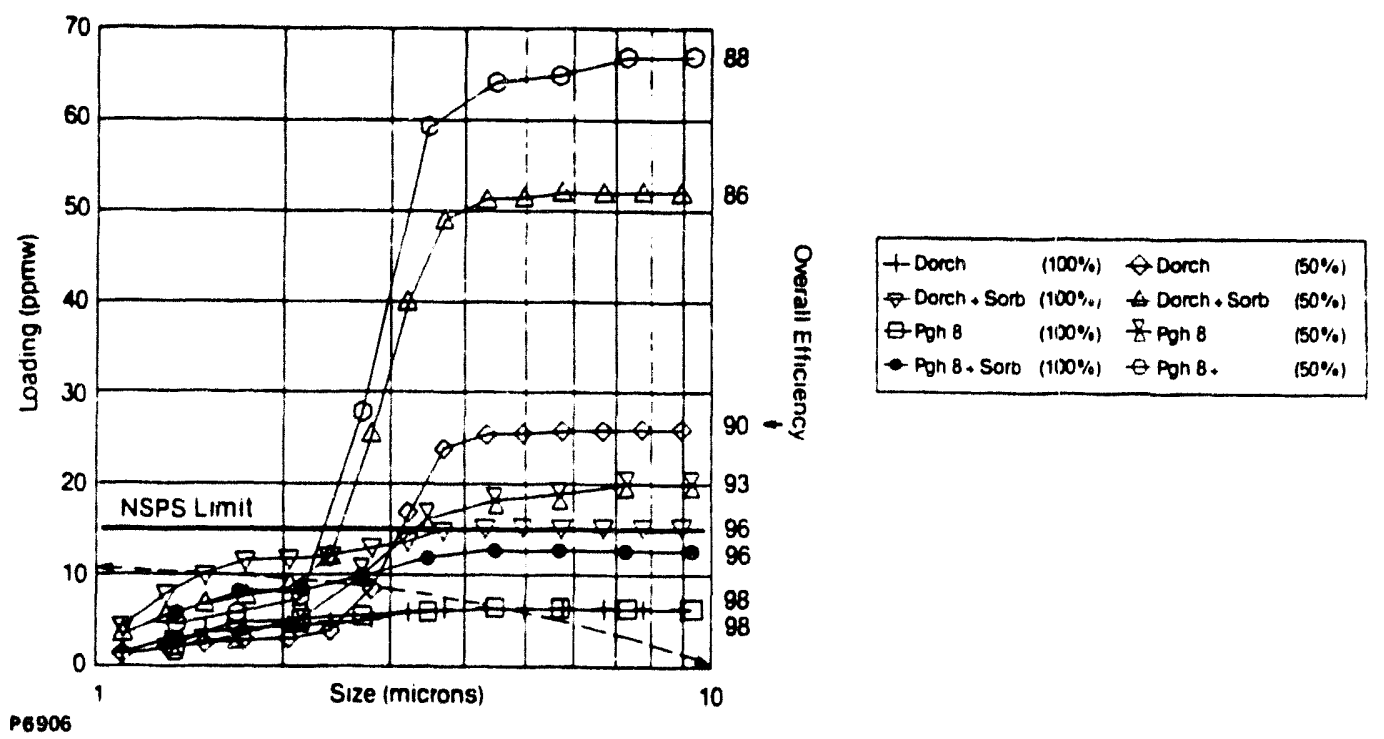

Fig. 6-3. Predicted Cyclone Exit Particulate Size Distributions 
In order for the high pressure, high temperature cyclone to reproduce the high efficiencies measured in the bench scale experiments, the inlet gas stream must be at a high enough temperature for the mineral matter to be molten and the cyclone walls must be maintained at a high temperature in order to obtain good separated slag flow. The fluxing effects of iron oxides may well be of great benefit in ensuring highly efficient slagging cyclone separation.

Results from the bench scale experiments indicated that a slagging cyclone, operated at subscale slagging combustor conditions, would provide sufficient cleanup to meet the turbine requirements, and provide sufficient cleanup to meet the NSPS goals for some coals, provided that the mineral matter to be separated is molten and sticky at the inlet.

\subsection{SUBSCALE CASCADE DESIGN}

A critical factor in the successful development of a direct coal-fuel gas turbine is the delivery of a suitably clean combustion product gas that is compatible with the turbine components. Under the original contract the second phase of the Basic Program included evaluating the effect of combustor exit gas on turbine materials. Two 30-hour subscale combustor tests were to be conducted at the TDS facility to determine turbine vane erosion, corrosion, and deposition trends. A sketch of how the cascade was to be installed is illustrated in Fig. 6-4. A now set of turbine vanes would have been installed for each test. The vanes and the test rig conditions were designed to simulate the conditions within the first stage of the Westinghouse W501, utility size (100 MW nominal), combustion turbine.

In the cascade, exhaust gas flow from the lean-burn stage of the TVC passes into the left end of the cascade rig, a 10.75-in. I.D. water cooled circular duct. It then transitions from the circular cross section to rectangular, in an air-cooled sheet metal section. Flow leaves the sheet metal section at approximately $550 \mathrm{ft} / \mathrm{s}$ and enters five (5) air-cooled vanes. It expands through a pressure ratio of two in the vanes, passes through a short diffuser, and then will be quenched to $400^{\circ} \mathrm{F}$ by an array of wide-angle water spray nozzles. Two sheet metal curved ducts return the flow to the original centerline, where it passes to the let-down valve and exhaust stack.

Vane cooling was designei to maintain surface metal temperatures at the WS0: level, with airfoil boundary conditions scaled from the original W501 calculations. Allowance was tride for differences in Reynolds Number, size, and fluid properties. Calculations showed that sufficiev: cooling would be achieved using a series of spanwise holes drilled through the airfoil. There are eight holes on the camber line. A total of $0.5 \mathrm{lb} / \mathrm{s}$ of air is consumed when all five (5) vanes are added together.

\subsection{SULFUR STUDIES}

During this program, two parallel experimental programs were conducted at TDS in addition to the main subscale slagging combustor program. These efforts, neither of which spanned more than a fraction of a year, were Spent Sorbent Stability in Molten Slag, and Basic Sulfur Capture Studies.

The objective of the Spent Sorbent Stability in Molten Slag task, was to support the subscale component development by characterizing the chemical kinetics related to the release of sulfur oxides from spent sorbent in slag. The study concluded that retention of the sulfur in the slag would be adequate, provided the slag residence time in the impact separator, is one minute or less. If sorbent can be removed with the slag quickly enough, there will be too little time for the sulfur to escape back into the exhaust stream. It was felt necessary to quantify the rate at whicls captured sulfur is evolved from hot sorbent/slag mixtures. A series of experiments were performed using a small apparatus, in which sulfur-containing sorbent was immersed in molten slag, and the evolved gases messured as a function of time. 


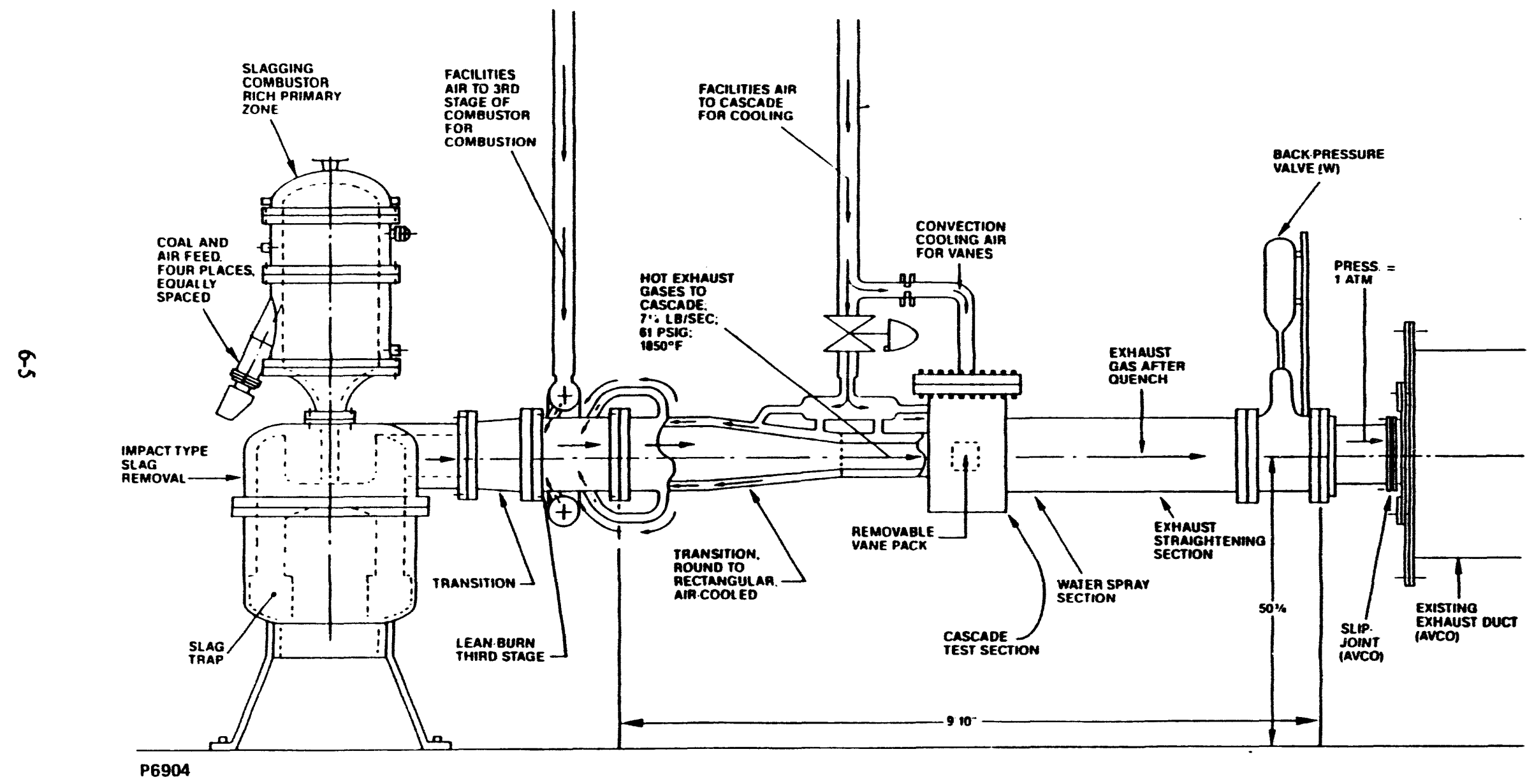

Fig. 64. Sketch of Cascade Rig for Installation in Erhanat of Slagging Combustor 
The key results are summarized in Fig. 6-5. for spent sorbent by itself, a sorbent/slag mixture, and spent sorbent injected into molten slag. This latter case, the most realistic, shows the quickest evolution of sulfur. However, even in this last case, it appeared to take nearly 6 minutes for all the sulfur to escape. If the sorbert/slag mixture can be separated from the combustor gas stream completely in some small fraction of 5 minutes, improved permanent sulfur capture should result.

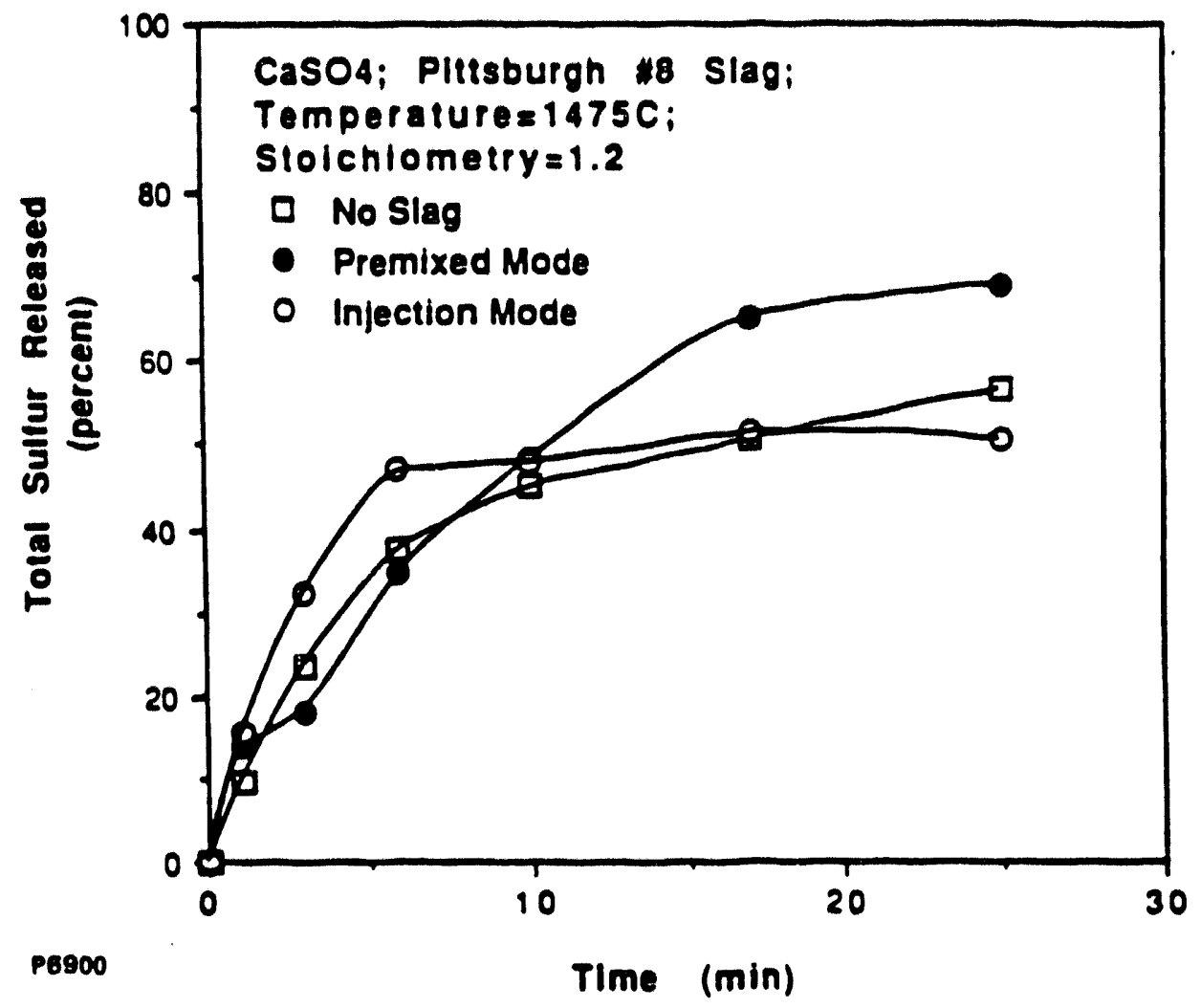

Fig. 6-5. Time History of Spent Sorbent Decomposition in Bench-Scale Apparatus

As a parallel effort to the subscale slagging combustor studies, a hot flow rig was assembled and used for sulfur capture studies. The overall objective of this study was to understand the effects of operating variables (temperature, residence time, sorbent type, and sorbeut feed rate) on sulfur capture from a gas mixture which simulated coal combustion products. This was undertaken in order to improve sulfur capture in the subscale slagging combustor.

The overall sulfur capture measured in the Hot Flow Facility was considerably below the levels achieved in the subscale combustor. The reason for the discrepancy between sulfur capture from the two units was traced to difficulties in achieving a high heating rate and temperature for the limestone particles. The lo' $\mathrm{W}$ particle heating rates and temperatures were due to high heat losses from the small flow reactor, and an excess of sorbent sarrier gas required to maintain a continuous flow of sorbent to the reactor. However, the measured sulfur captures are consistent with the actual thermal history of the limestone particles. These experimental difficulties emphasized the sensitivity of the transient capture processes to the combustor operating conditions. 
Limestone, magnetite, and a mixture of limestone and magnetite were used as sorbents. Within the limitations of the experimental conditions, the following conclusions were made:

- Limestone and the mixtures of limestone and magnetite resulted in higher sulfur captures than magnetite.

- In limestone tests, a peak in sulfur capture was detected in the time interval $20-40 \mathrm{~ms}$.

- Limestone is a more efficient sortent for sulfur dioxide $\left(\mathrm{SO}_{2}\right)$ than for hydrogen sulfide $\left(\mathrm{H}_{2} \mathrm{~S}\right)$.

- The spent sorbent sulfur species were calcium sulfate and calcium sulfite. Calcium sulfide was not detected.

It should be noted that although magnetite by itself is a poor sulfur getter under combustor conditions, it will reduce the slag viscosity and improve the impact separator efficiency. This is especially true at flame stoichiometries greater than 1.4 where the slag viscosity is high, due to the lower flame temperatures and the presence of lime. The presence of iron in the slag might also help stabilize the reacted lime in the very stable iron/calcium oxysulfide matte. The reduced slag viscosity should permit faster slag tapping which would help retain the high transient sulfur captures obtained in the first stage.

\subsection{AMES ALKALI MEASUREMENTS}

During two subscale combustion tests run on October 19,1992, exhaust alkali measurements (vapor phase and solids bound) were made using the Ames Alkali Monitor by a representative of Ames National Laboratory. During the first test the sampling probe was facing into the flue gas flow and operated isokinetically. Ingested solids tends to effect the stability of the flow rate through the instrument. The vapor phase alkali concentrations in the exhaust of the slagging combustor were nominally 20-30 ppbw sodium and much less for potassium. The solid bound alkali levels, as measured by the Ames monitor were orders of magnitude higher.

During the second test, the sampling probe for the Ames monitor was installed facing downwind and was not operating isokinetically. The Ames monitor worked well during this test. Hence, only the vapor phase alkali levels were quantifiable. This should be satisfactory since it is the vapor alkali that troubles gas turbine components. The solid bound alkali can be determined via chemical analysis of the collected flyash.

After data analyses, it was concluded that during coal combustion the sodium vapor phase levels varied between 20 and 25 ppbw and the potassium vapor levels between 8 and 20 ppbw. The vapor alkali levels for combustion turbines are considered by Westinghouse to be 20 to $50 \mathrm{ppbw}$.

\subsection{GENERIC TURBINE DESIGN STUDY}

The purpose of the Generic Turbine Design Study was to develop a conceptual design of a combustion turbine that would perform in a pressurized fluidized bed combustion (PFBC) application. For the purposes of this study the pressurized circulating fluidized bed (PCFB) system designed by Pyropower was the reference bed application. To develop a reference plant configuration, the study was further refined by using the current demonstration project under development for the Des Moines Energy Center (DMEC-1), Pleasant Hills lowa. DMEC-1 is an 80-megawatt project (selected by DOE under Round 3 of the Clean Coal Technology Program) to demonstrate feasibility of a PFBC system. 
A series of tasks were accomplished to develop the combustion turbine system design for the PFBC application chosen. These taski included:

- Turbine and plant performance

- Blading and cooling arrangements

- Casing arrangement with an off-engine startup combustor

- Turbine system analysis (including controls, fuel handling, and inlet and exhaust systems)

- Off-engine startup combustor

- Interconnecting piping

The "Generic Turbine Design Study" final report, dated June 1993, contains an introduction or overview of each task; review of the analysis performed; and any results, conclusions, or recommended design approsches. Also included in the report is a summary of the design evolution and, piping and sizing calculations.

The Westinghouse 251B12 Combustion Turbine, shown in Fig. 6-6, was used as the baseline engine for the PFBC application. The standard 25IB 12 combustion turbine performance for ISO conditions, natural gas, no injection and 4" $\mathrm{H}_{2} \mathrm{O}$ inlet and exhausi loss includes:

- Power Output - $48 \mathrm{MW}$ (nominal)

- Pressure Ratio - 15.5:1

- Total Air Flow - $382 \mathrm{lb} / \mathrm{s}$

- Heat Rate - 10,600 Btu/kWh (LHV)

- Thermal Efficiency - $32.2 \%$.

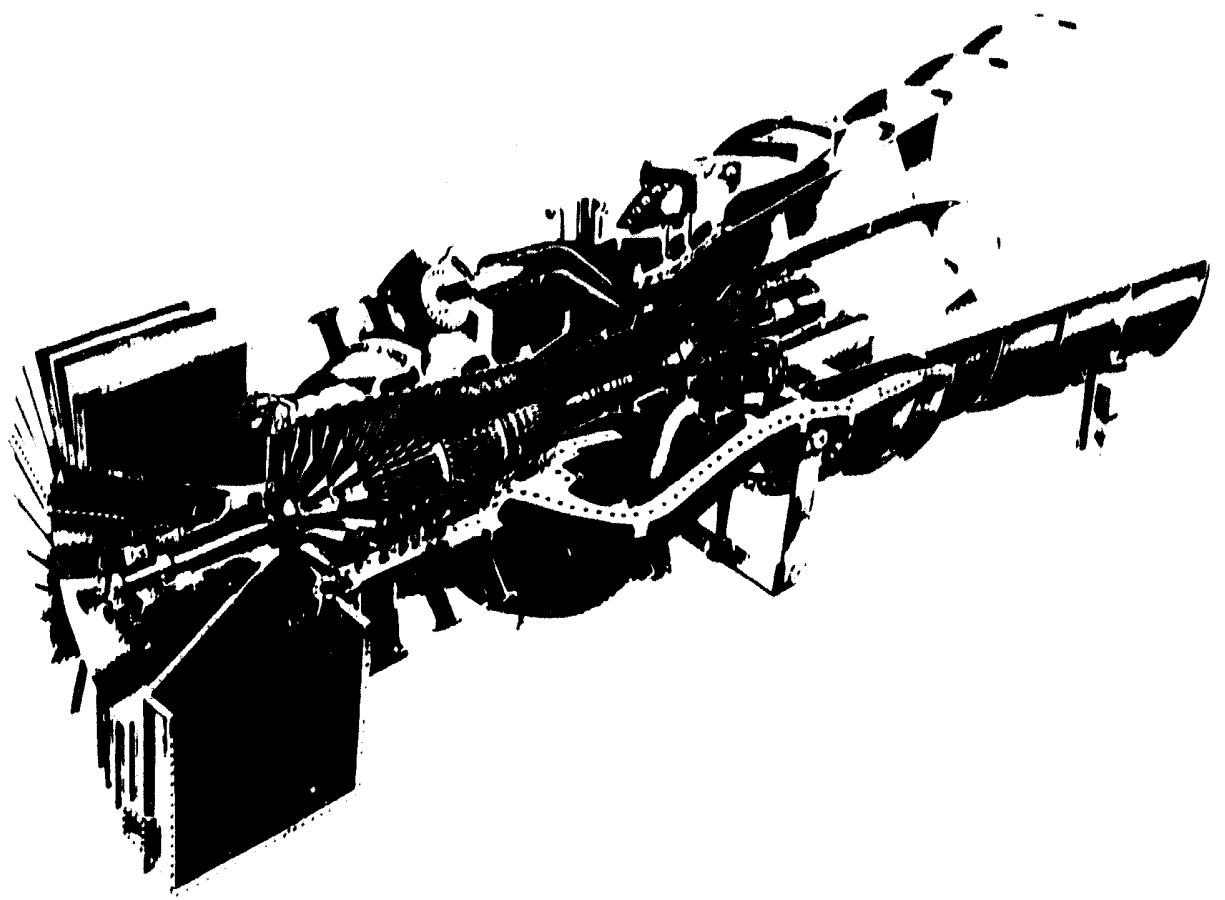

Fig. 6-6 Westinghouse 251B12 Combustion Turbine 
The 251B 12 combustion turbine is a single shaft, two-bearing, solid coupling, simple cycle unit containing:

- Multi-stage (19 stages) axial-flow air compressor featuring

- Variable inlet guide vanes

- Horizontally split casing giving access to internal parts

- Individually removable stainiess steel blading

- Accessible pressure-lubricated, pivoted-pad journal bearing

- Double-acting Kingsbury-type thrust bearing

- Cold-end drive with solid coupling to main reduction gear

- Combustion system including

- Eight can-type combustors in a circular array

- Combustors removable with cylinder cover in place

- Optional multiple fuels capability

- Ignition system with retractable ignitors

- Three-stage reaction-type turbine fearuring

- Horizontally split casing giving access to internal parts

- Individually removable alloy turbine blades

- Cooled by air-to-air cooler with cooling air filtered

- Individual first-stage vanes removable with cylinder cover in place

- Accessible pressure-lubricated, pivoted-pad journal bearing

- Low loss axial-exhaust system ideal for waste heat applications

Several modifications were required to this engine to enable it to perform as a prime mover in a PFBC system. These modifications are described in the Generic Turbine Design Study Report.

The 251B 12 combustion turbine is typically sold as a packaged unit called the ECONOPAC. The 251B 12 ECONOPAC, shown in Fig. 6-7, is a complete pre-engineered packaged generating system, designed for ease of operation and maintenance. All components and subsystems are carefully selected and optimized to form a compact, housed combustion turbine system within enclosures, designed to comply with environmental requirements as well as showing Westinghouse's increasing concern for aesthetics. The basic ECONOPAC system includes:

- 25IB 12 Combustion Turbine on bedplate assembly

- Generator

- Exciter

- Auxiliaries

- Starting package

- Inlet air system including filter (2-stage pad)

- Exhaust system 
- Electrical/control package

- Compressor water wash system

- Fuel-gas/steam injection skid

- Cooler assemblies

- Generator switchgear

- Medium voltage motor starter

- Fire protection

The ECONOPAC package will need to be modified slightly for PFBC applications. Along with the 25IB 12 combustion turbine modifications, the inlet air system, the exhaust system, and the fuel gas and sterm injection skids must be redesigned.

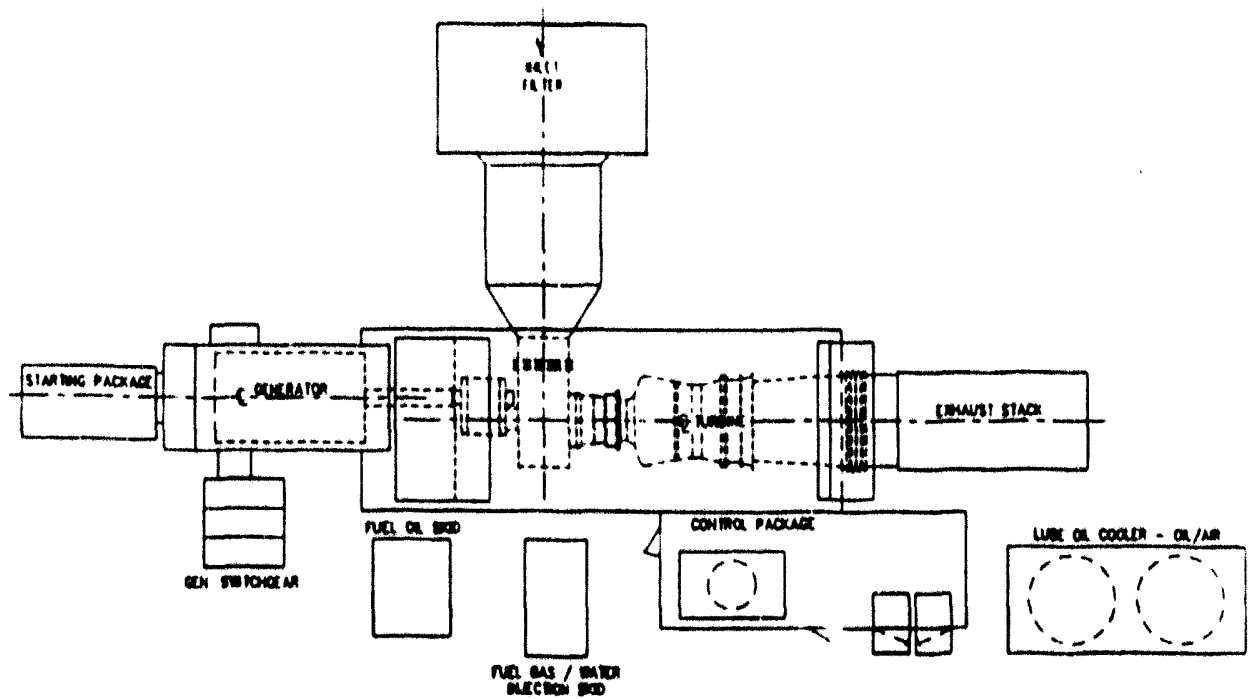

Fig. 67. Typleal 251B12 ECONOPAC

The result of this successful study was a verautle conceptual design capable of meeting PFBC requirements. Performance calculations were determined by varying the following parameters:

- Inlet temperature - Analysis shows that the necessary modifications to the 251B12 limit the lower inlet to approximately $55^{\circ} \mathrm{F}$. The new power outpur expected, at a $59^{\circ} \mathrm{F}$ inlet temperature, is $20,250 \mathrm{~kW}$.

- Pressure drop in the system - As the PFBC system jressure drop increases, power output level decreases. A detail design objective should be to clesign the bed, piping, valves, and turbine casing to minimize system pressure drop.

- Composition of vitiated air- As expected, the composition of the fuel affects the power output. A fuel with products of combustion higher in moisture content and less carbon dioxide produced more power. 
- Vitiated air temperature into the turbine - From a new power perspective, the system should operate at the highest temperature it can accommodate, but is limited by the operating temperature of the ceramic filters.

For the selected PFBC application, removing the first two stages of compressor blading, reshaping the inlet scroll, modifying the blade design and repositioning the inlet guide vanes (IOV) is a feasible design approach to obtaining the reduced (from the standard 251B12 19-stage compressor) inlet mass flow. Analysis results showed a reduction in mass fluw from $375 \mathrm{lb} / \mathrm{sec}$ to $229 \mathrm{lb} / \mathrm{sec}$, a reduction in pressure ratio from 15.5 to 11.6 and a revised compressor map and an increased sensitivity to inlet air temperatures, especially at the lower part of the range. If a compressor was required for a PFBC application with mass flow similar to the standard 251B 12, these modifications would not be necessary.

Analysis of the reduced flow PFBC turbine showed that the existing vane setting angle is approximately correct. The compressible flow function for the reduced flow PFBC is 77.8 compared to 81.1 for the baseline 251B12. Incidence angles were acceptable following current Westinghouse design practices. the match of incidence angles and turbine efficiency can be modestly improved by closing the row 1 vane by approximately 1 degree, but is not recommended due to the additional manufacturing cost involved.

Several alternative casing concepts were developed and analyzed. The concentric inlet/outlet design was eliminated because of the very large casing penetrations required and the potential for the inlet liner to creep or buckle at elevated temperatures when subjected to extemal pressure. The single inlet/outlet design with the piping located on the lower right-hand side of the casing, as shown in Fig. 6-8, was selecied as the conceptual design choice because it used the existing bedplate design, allowed floor space on one side of the turbine for laydown, and kept the upper half of the turbine free of major piping connections for ease of maintenance.

The total pressure loss from the compressor diffuser exit to the pipe leading to the fluidized-bed combustor is approximately 2.9 psi, which compares favorably to the 2.2 psi loss to the combustor inlet for the unmodified gas turbine without the fluidized-bed combustor.

Advantages:

- One inlet and outlet on lower side (not top or bottom) improves access for maintenance

- Better external piping arrangement

Disadvantages:

- Larger pipe

- Limited room for flange

- Higher inlet velocity

- Larger casing required (-144" wide)

- Plenum design to resist $\Delta \mathrm{P}$ at high temperature

The separate pipe casing penetrations were located to minimize interference with existing gas turbine piping and support structures. An area reinforcement analysis, in accordance with the American Society for Mechanical Engineering (ASME) Boiler and Pressure Vessel Code, was performed, and the inlet and outlet was located and sized to satisfy the rules. 
In order to develop a control system conceptual design, normal openation and emergency shutdown sequences were developed. The current Westinghouse Distributed Processing Family (WDPF) control system offored by Westinghouse for the 251B 12 is acceptable for the PFBC application. The combustion turbine startup combustor must operate on either fuel oil or natural gas. Westinghouse has provided skidmounted systems for each of these fuels and supplies them for conventional combustion turbine applications. Modified versions of these fuel skids will be required for the PFBC plant.

The inlet and exhaust system for this PFBC applications wili be slightly different from the typical Westinghouse ECONOPAC offering. The modified 17-stage compressor requires inlet air temperature control so a combination heating and cooling system must be installed in the intake system. The exhaust system will contain a heat recovery steam generator.

Combustion performance calculations were performed and a conceptual design for an off-engine startup combustor was developed along with a detalled bill of materials. Many of the current combustor components can be used in this application, including the combustor basket, fuel nozales, ignites, and steam or water injection system (if necessary).

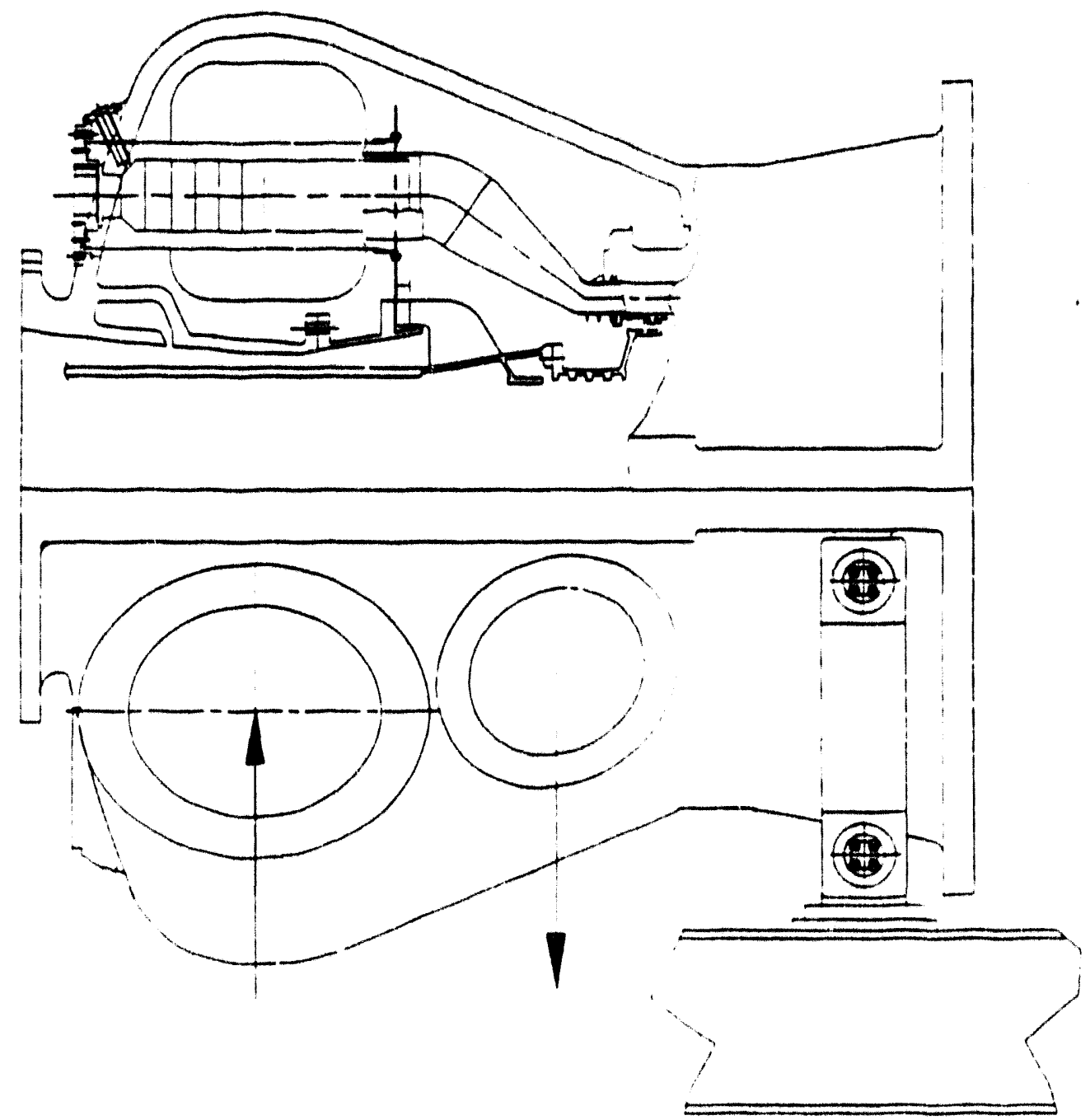

Fig. 6-8. Single Inlet Concept (Preferred) 
Definition of the plant cycle arrangement and the fluid state points of that arrangement were developed in order to conceptually design the piping system. The pipe sizes defined are reasonable for power plant piping. The velocities for most of the runs are in the 5,000 to 8,000 fpm range, which is reasonable for this application. The pressure drops through the pipes are not excessive and are acceptable. A total of $18.5 \mathrm{in} . \mathrm{H}_{2} \mathrm{O}$ in the hot pipe. The cold pipe can be made of standard piping materials. The two sizes of clean hot gas pipes will require a design that includes an internal stainless steel liner, castable refractory inner-liner, and seamless carbon steel pipe. Piping and insulation material recommendations are based on temperature proffle and pipe wall stress analyses and are acceptable based on prior successful operating experience and ASME B31-1. Flexible expansion joints are shown in both the compressed air and clisen hot gas piping systems and turbine/compressor valve chancteristics were developed and are specifiud.

\subsection{SUBBITUMINOUS COAL TESTING FOR NORTHERN STATES POWER COMPANY}

Subbituminous coal testing at TDS' Haverhill facility was done as a cooperative activity between Northern States Power (NSP), Westinghouse and Textron; this was independent of the work sponsored by DOEMETC. NSP provided two different Wyoming subbituminous coals, which were burned in the pressurized slagging combuntor over a series of soven test runs.

The Antelope and Rochelle seam coals were found to burn easily and completely. Carbon burnouts based on the amount of carbon in the quenched slag and the flyash were $\geq 99.99 \%$. Lean-zone CO levels were found to be between 60 to $70 \mathrm{ppm}$ at a primary $20 \mathrm{ne}$ fuel to air equivalence ratio equal to 1.2 .

NOx emissions were controlled to $<0.2 \mathrm{lb} / \mathrm{MMBth}$, which is significantly below the $0.6 \mathrm{lb} / \mathrm{MMB}$ Mtu NSPS limit, by staging combustion and nuning the primary zone $\geq 1.1$.

The limestone sorbent injected seemed to have little effect on sulfur capture. Unllke the DOE sponsored work at a $=1.2$ on the eastern bituminous coalo, where $\mathrm{SO}_{2}$ wus the dominant selfur specie, these tects on the NSP westem subbituminous coals showed the $\mathrm{H}_{2} \mathrm{~S}$ to be the domineat specie. This can be understood by the fet that the peak flame temperatures in the primary zone should be significantly lower with these weatern cosls wtth high moisture content.

Interestingly, the sorbent injected seemed to have little effect on sulfur capture. With or without sorbent addition the sulfur capture in the primery 200 wes 45 to $65 \%$ and the lean/quench amiasions levels showed a $30 \%$ reduction. This is not very suprising because as the sulfur gas composition decreases in the gas phnse, it becomes more difficult for it to react with the limestone; plus provious nonequilibrium sulfur capture work showed lower ceptures wtth $\mathrm{H}_{2} \mathrm{~S}$ then with $\mathrm{SO}_{2}$. It appeared that the inherent $\mathrm{Ca}$ found in these coals was causing the sulfur capture. The reaulting concentration of the $\mathrm{H}_{2} \mathrm{~S}$ seems to be too low to aliow for further significant reaction with the limertone sorbent fed.

Although particulate emissions exceeded NSP limits of $0.03 \mathrm{lb} / \mathrm{MMBtu}$, the mean size of the particles passed through the slagging cyclone separator was 2 microns with a top size $\leq 5$ microns. Based on these results, it appears that the loading of particulates, although greater than NSPS lovels, are quite smoll in size and unlikely to cause erosion damage to the turbine blades.

Weatinghouse's alkali probe measurements were taken during each run and gave vapor alkali levels $<100$ ppbw. Ames alkali probe measurements, taken on only one nun, indicated that the vapor alkali had an upper limit of 100 ppbw. 
Table 6-1.

Analyses for Coals Tested

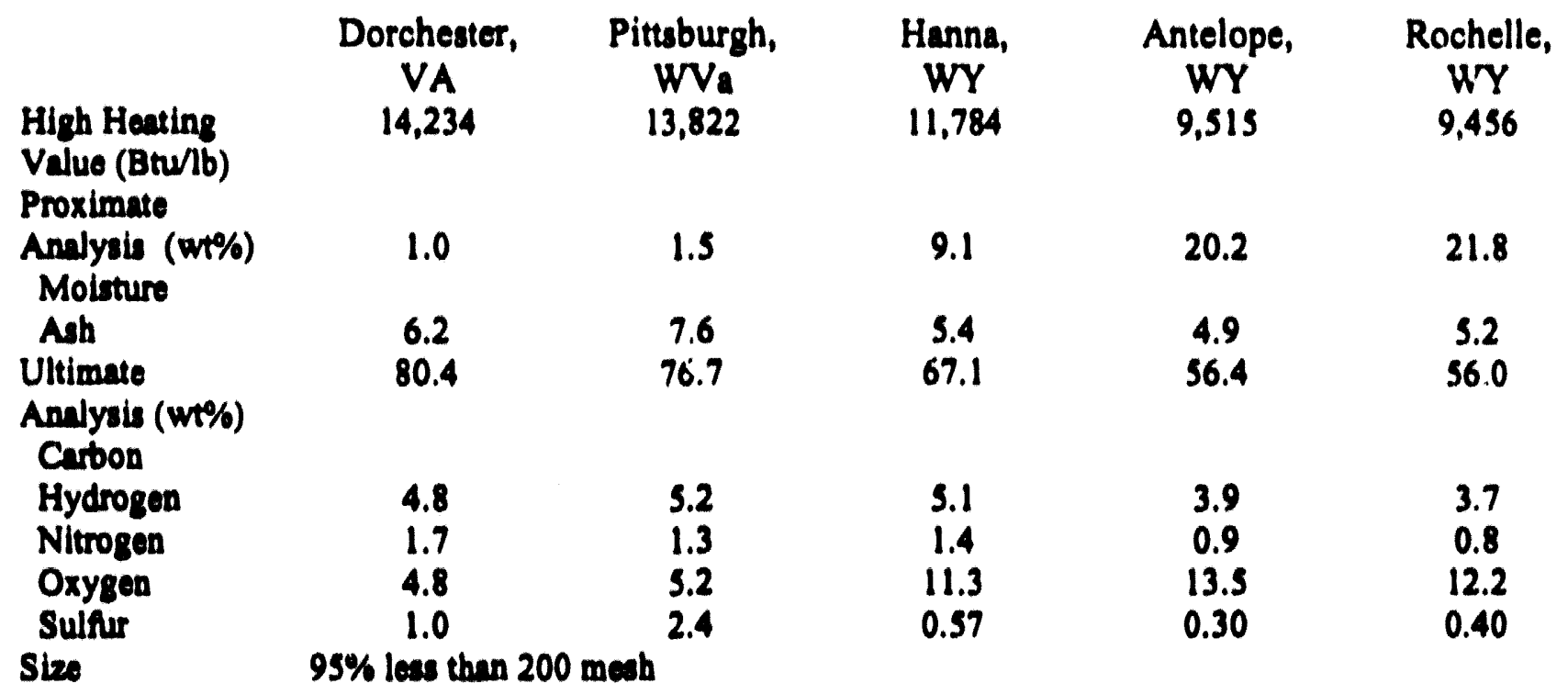

Table 6-1 gives the analysis of the Rochelle and Antelope coals. Along with these coals are also included the analyses for the previous cosls studied in the DOE work.

\subsection{Advanced Turbine syctems - 8coping and Feaslbillty Studies}

The Nationd Energy Strutegy (NES) calls for a belanced progrum of greater energy efficiency, use of alternative fuols, and the eavironmentally reponible dovolopment of all U.S. enersy resources. Consistent with the NES, a DOE progran was created to develop Advanced Turbine Systems (ATS). The objective of this 8-yeur progrum, is to develop natural gas fired base load power plants that will have cycle efticiencie greater then $60 \%$ (LHV), be environmentally euperior to current technolosy, and also be cost competitive. The progrem will include work to trunser advanced technology to the cond-and biomese-fueled systems being developed is other DOE progenms.

This section of the find report summarizes the response of Weatinghouse to Phase $\mathrm{l}$, Program Definition/Plnnning Studies of the Innovative Cycle Studies Element of the ATS progmen.

It should be noted that today, with a turbine inlet temperature of about $2460^{\circ} \mathrm{F}\left(2300^{\circ} \mathrm{F}\right.$ rotor inlet temperature), natural gas combined cycles are in the nnge of 54 to $35 \%$. The target of $60 \%$ combined cycle efficiency by the year 2000 seems beyond reach if the inlet temperature is raised, and the combined cycle configuration is basically unchanged. In the Westinghouse study, innovative changes to the combined cycle were investigated to 800 if the $60 \%$ plant cycle efficiently can be attained.

Intercooling between compressor stages to reduce compression power has long been a feature of centrifugal compressor installations. Thus, inclusion of intercooling by splitting the single axial compressor into a low pressure (LP) and a high pressure (HP) section is an obvious suggestion. Since HP compressor delivery temperature is greatly decreased with intercooling, additional benefits accrue to the cooling air system. The lower compressor delivery temperarure led logically into another idea, that of exhaust gas recuperation. Westinghouse has a long history of recuperative turbine installations. 
The intercooled, recuperative combined cycle (ICRCC), shown in Fig. 6-9, was analyzed and compared to the base cycle in Fig. 6-10. At the same rotor inlet temperature, and the same turbine expansion ratio (- 18:1), combined cycle efficiency was found to increase a very significant 1.5 to 2.0 percentage points. The turbomachinery for the ICRCC is directly coupled to form a single shaft operating at 3600 RPM. The HP compressor and gas turbine would be a two bearing rotor in a single housing. The LP compressor, generator and steam sabine would have individual rotors in separate housings. The generutor rotor would be double ended 80 that it can be driven from both ends.

Within the basic intercooled, recuperative combined cycle configuration, the broad question of water vapor addition to the Brayton cycle and its effect on efficiency was also investigated. Evaporative cooling of inlet air has long been a technique employed to increase gas turbine and combined cycle power when inlet air is hot and dry. Steam injection into compressor delivery air for power augumentation has be incorporated into many gas turbines over the years.

The first alternative considered added an evaporative aftercooler within the basic ICRCC. HP compressor delivery air was cooled as it evaponted prebeated intercooler water, thus allowing more heat trinsfor from turbine exhaust ges into aftercooler exit air through the recuperator. Gas turbine power increased considerably since additiond mass (water vapor) is now avaliable for expansion through the turbine while the compressor's mase flow bas not chnnged.

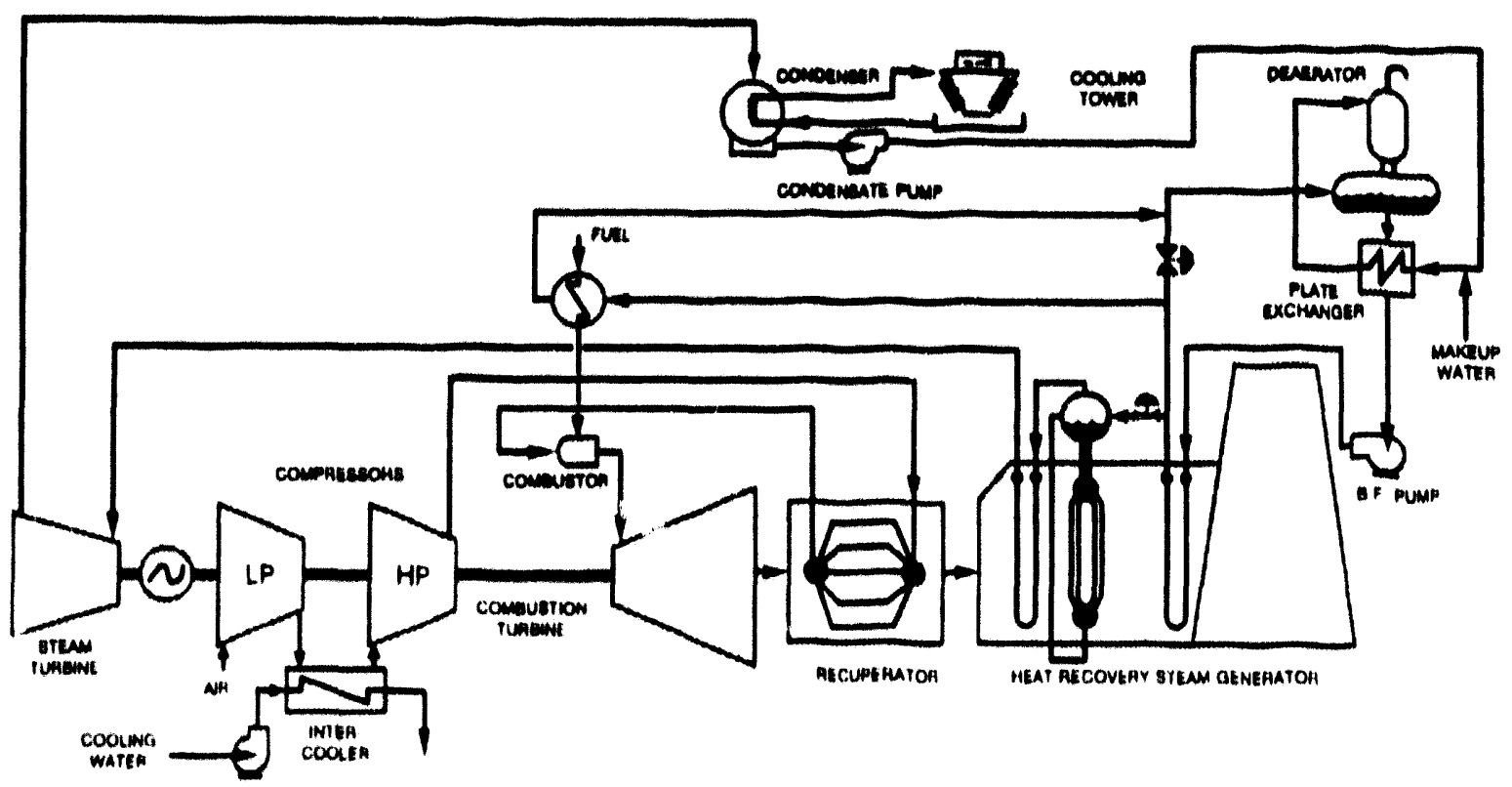

Fig. 6-9. Intercooled, Recuperattve Combined Cycle 


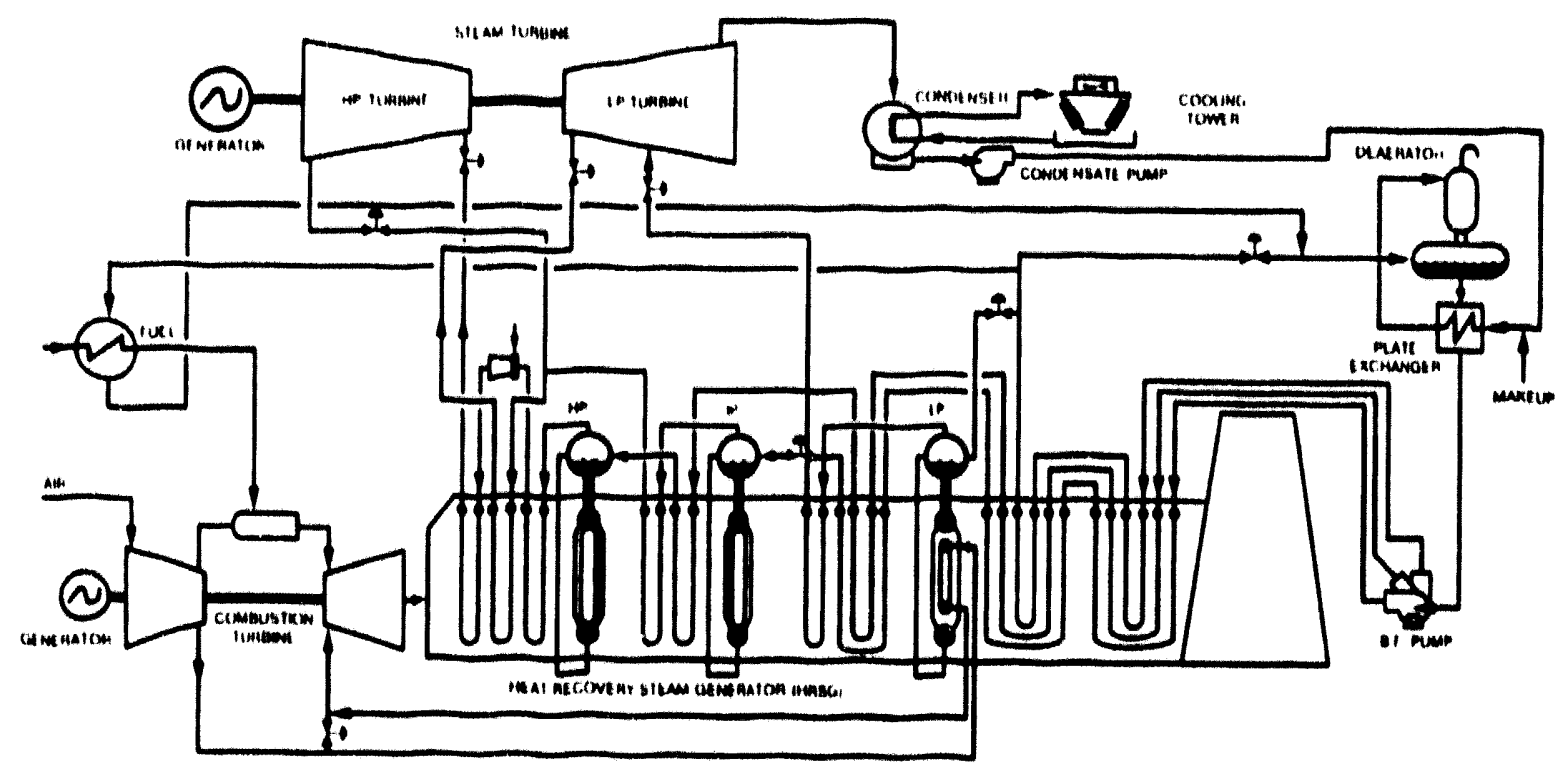

Fig. 6-10. 501F Based, Natural Gas Fired, Comblaed Cycle Plant

The ultimate form of intercooling is continual evaporative cooling of the compression process through the introduction of a fine water mist into each compressor stage. Preheated water droplets about 5 microns in diameter would possibly evaporate in each stage providing a continuous reduction in the beat of compression. Continual or staged evaporation of water into the recuperntor air stream is yet another iden investigated in the preliminary phase. Recuperntor gas side exit temperature will be lowered by this technique leaving leas enersy for the lower efficiency bottoming cycle.

Another concept considered was closed loop steam cooling. Closed loop steam cooling involves directing a portion of the dry steam rised in the heat recovery steam generator (HRSO) through the walls of stationary hot end components, such as combustor baskets, transitions, and vanes, prior to expanding it through the steam turbine. The steam, which is superheated as it removes heat radiated and converted from the hot gas path, is supplied to the steam turbine.

Thermochemical recuperation of gas turbine exhaust energy, as shown in Fig. 6-11, was also considered. Here only the combustion turbine would produce power (no longer a combined cycle) by burning reformed, recuperated fuel. Methane and sufficient steam in the presence of a catalyst, and at appropriate temperature, will reform into a low Btu fuel consisting of $\mathrm{H}_{2}$ and $\mathrm{CO}$. None of the latent heat of vaporization of steam generated in the HRSG is lost to the cycle, and so the potential exists for efficient exhaust energy recuperation. In current reforming technology, methane conversion efficiency is a function of pressure, temperature and excess steam/methane ratio.

One final reconfiguration of the combined cycle with the turbine split to allow reheat after partial expansion, was studied. At a cycle pressure ratio of approximately 20:1, it was found that combined cycle efficiency dropped about 4.0 percentage points when compared to the ICRCC. 


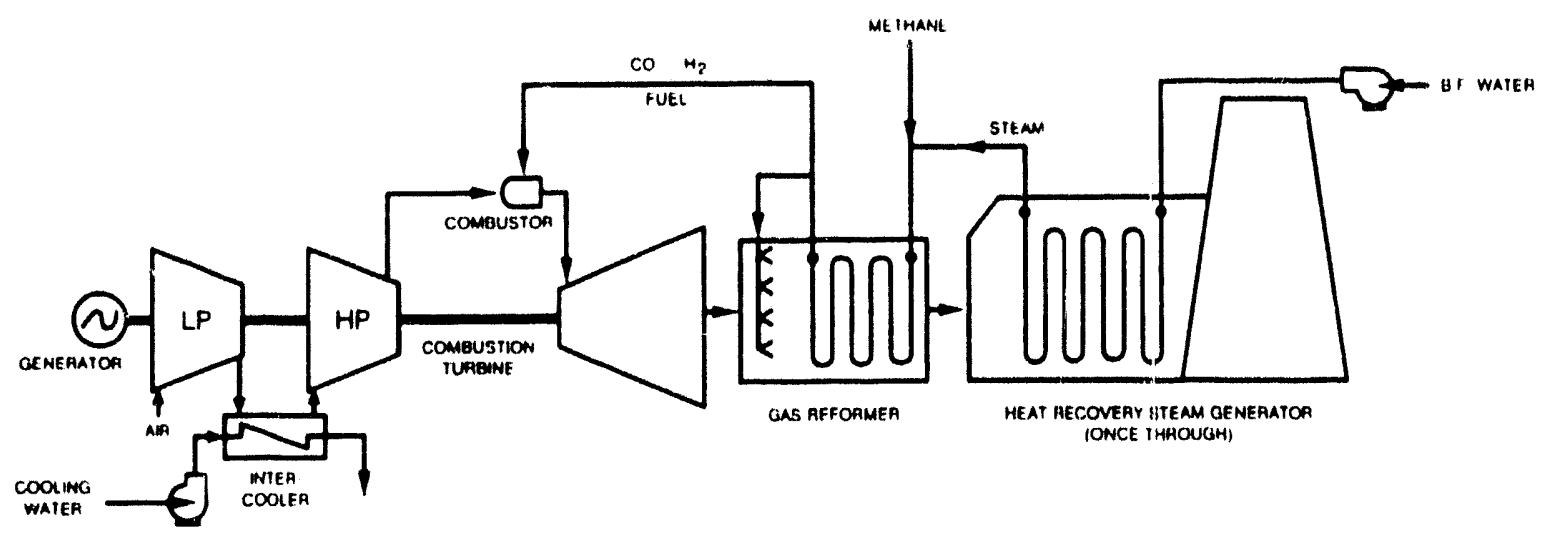

Fig. 6-11. Thermo Chemical Recuperntion Cycle

The conclusion reached from Phase I cycle studies was that compressor intercooling, combined with exhaust recuperation and closed loop steam cooling should be considered as the reference cycle for ATS in Phase I. The optimal types of intercooling and recuperation could not be determined, however, due to the preliminary nature of the studies.

Within the framework of the ICRCC, cycle efficiency will be further increased by:

- Raising firing temperature

- Reducing cooling air requirement

- Increasing component aerodynamic efficiencies, and

- Recucing clearances and leakages

Raising the rotor inlet temperature from its current, $2300^{\circ} \mathrm{F}$ level in the Westinghouse $501 \mathrm{~F}$ engine is necessary for the advanced turbine system to achieve its $60 \%$ (LHV) target. If turbine inlet temperature increase on its own is considered, while holding metal temperatures in the hot gas path components constant through the use of additional quantities of cooling air, the increase in cycle efficiency of only 1.2 percentage points is all than can be expected for a $200^{\circ} \mathrm{F}$ increase in the rotor inlet temperature.

As rotor inlet temperature increases, the cooling air quantity required to hold metal temperature also increases significantly. Reducing this cooling air requirement is an extremely effective method for increasing cycle efficiency, since more of the air which has absorbed work in the compressor can now be brought to the turbine and expanded through all four stages of the turbine. Because exhaust temperature increases, heat transfer through the recuperator into the compressor air stream is enhanced, requiring less fuel/lb of air, and more heat is available to the bottoming cycle. At ATS conditions, each reduction in 
cooling air requirement of $1 \%$ of compressor inlet flow would increase cycle efficiency approximately 0.2 percentage points.

As discussed previously, closed loop steam cooling of stationary vanes is the most effective method of eliminating cooling air, since cooling air is replaced by steam (which doesn't enter the gas path).

The application of thermal barrier coatings ( 10 to 30 mils) to the outside aerofoil surfaces will reduce conduction of heat from the hot gas path into the cooled aerofoil, and thus reduce the amount of cooling air required. Ensuing good bonding to the substrate, fatigue resistance, and surface smoothness will be prerequisites to this method of cooling air reduction.

Currently the last 3 (of 4) stages in the 501F are cooled. First stage vane cooling is accomplished by a combination of impingement, film and convective cooling. First stage blade cooling incorporates serpentine, ribbed, pin fin passages with external film. Both of these highly complex cooling schemes may be further refined, but potential gains are small. Alternatively, several approaches which have been investigated in the past may be reconsidered.

One of the most promising of these is shell/spar construction. Shell/spar vanes and blades may be formed by bonding a thin non-porous aerofoil shaped metal sheet (the shell) to an inner hollow cast support member (the spar), or by casting. Cooling air for the assembly is supplied from alternate cavities within the spar (the supply cavities). It flows along chordwise convection cooling channels between the spar and the shell and returns to the remaining spar cavities (the discharge cavities). The heated or spent cooling air is then routed from the discharge cavities to the main gas stream through exit holes in the shrouds or areofoil.

In the later stages, spanwise holes which taper from hub to mid-height represent an improvement over the constant diameter holes used in rotor blade cooling. With this technique, increased cooling in the critical mid-height region is obtained by reducing overcooling in the hub region, resulting from the lower coolant temperature as cooling air enters the hub region. Increased hub region flow area obtained by tapering reduces heat transfer in that region, thus reducing temperature rise in the coolant as it flows radially outward.

Another variation in cooling hole geometry is to integrally cast circumferential ribs periodically spaced along the length of each cooling hole. These ribs act as flow turbulators to produce turbulent rather than laminar heat transfer for the cooling air. Field tests have been run on a 501 engine comparing smooth and turbulated holes that verified that the heat transfer coefficient was doubled by the use of the turbulators.

Cooling flow could also be reduced if higher temperature material/coating systems could be incorporated. Higher creep strength vane and blade alloys, which when processed to form directionally solidified (DS) or single crystal (SC) structures, should offer temperature advantages of $75^{\circ}$ to $200^{\circ} \mathrm{F}$ over conventionally cast alloys.

Uncooled blade path components would obviously greatly increase advanced turbine system efficiency. Ceramics and ceramic composites will be considered during the ATS program for application in stationary components (baskets, transitions, row 1 vane).

Better utilization of the cooling flow is another potentially beneficial area. In the 501F engine, some $60 \%$ of the cooling air is used for aerofoil cooling. Most of the remainder leaks into the turbine hot gas 
path through clearances in the parts which bound the coolant flow path as it proceeds through the engine. Cooling air flowing through inner and outer shroud cavities prevents hot gas ingress, and maintains the casing and rotor at required temperatures. Cascading some of this flow before finally allowing it to escape to gas path (instead of exhausting immediately into the gas path), will reduce considerably the total quantity of air used for cooling.

Within the ICRCC configuration, improving the aerodynamic efficiencies of the compressors to reduce compression work, and the turbine to increase expansion work will enhance overall efficiency. The 501F compressor with an average polytropic efficiency of $92 \%$ is very efficient, and was designed based on Westinghouse's 20 years of accumulated 501AA to DS design experience. However, it has not yet reached the limit of aerodynamic efficiency. Aero technology, now available to Westinghouse through a 15-year technology agreement with Rolls-Royce, will enable the ATS compressors to be designed to optimize loading with minimum loss for each row of aerofoils.

Likewise the 501F's highly efficient 4-stage turbine which already incorporates the results of 3dimensional, viscous, aerodynamic computations will be further refined using sophisticated aero engine procedures integrating through flow, blade-to-blade, boundary layer and 3-D viscous calculations.

Configurations of all diffusers in the engine will be carefully designed to maximize efficiency and all pressure losses through ducting, piping, manifolding, and components such as inter (and after) coolers and recuperators, will be minimized to reduce compression work and maximize expansion potential.

Diaphragm/vane segment seal clearances will be minimized and leakage further reduced through the extensive use of abradable material or filled honeycomb structures in combination with knife edge seals. Innovative seals such as brush seals, which have had aero application, will be investigated.

The requirement for single digit NOx $\left(15 \% \mathrm{O}_{2}\right)$ with CO and UHC less than 20 ppmvd each, to be achieved without any post-combustion emissions control devices, is a serious challenge which will require significant $R \& D$ effort. Currently, premix, lean burn combustion systems are receiving the focus of attention, and it is predicted that these will eventually reach the required emissions levels. An alternative which is gaining attractiveness is the use of a catalytic metal or a ceramic matrix reactor within the combustor.

Both of these systems will benefit from the higher (when compared to compressor delivery temperature in the 501F) air temperature entering from the recuperator of the ATS. For catalytic combustion, the higher temperature air will enhance the reactivity threshold of the catalyst for natural gas fuel. In the case of the lean premixed combustor, the flammability range should be broadened, thus reducing pilot burner fuel. In both cases, no additional temperature rise will be needed across the combustor (compared to the base cycle) since both combustor outlet and combustor inlet temperatures increase in the ATS.

A key feature of the ICRCC chosen as the reference natural gas fired ATS is the combustor shell design. The shell will not be structural, but will contain only pressurized compressor delivery and recuperator return air. The structural connection between HP compressor and turbine cylinders will be through radial-axial struts. This leaves the shell free to be reconfigured for compressor air take-off to the coal fuel processing system, and return from the recuperator. .

The coal-fired system is an integrated system bleeding air from the compressor and returning low Btu fuel. The increase in volume flow to the turbine when compared to a natural gas fired (dry) system is small, and can usually be accommodated without turbine modifications. However, if large amounts of moisture are evaporated into the air stream in the gas fired ATS, then by comparison, turbine flow would 
be much reduced in the coal-fired case. To match compressor and turbine flows, compressor flow may be increased by the addition of inlet stages to the LP compressor, and/or by the use of variable compressor geometry.

The feasibility of achieving 60\% (LHV) efficiency in a natural gas fired cycle within a 8-year time frame was established. Cycle innovations, increased firing, reduced cooling air usage, improved component efficiencies and improved material/coating systems will all be needed to accomplish this ambitious goal. The resulting advanced turbine system will be environmentally superior, as well as adaptable to coalderived fuel systems. 


\section{CONCLUSIONS AND RECOMMENDATIONS}

The subscale $12 \mathrm{MM} \mathrm{Btu/hr}$ toroidal vortex combustor demonstrated excellent coal-fired operation at 6 atm. All five fuel types were burned successfully. As a result of this active testing the following conclusions may be drawn:

- It was possible to achieve the full design thermal capacity of $12 \mathrm{MMBtw} / \mathrm{hr}$ with the subscale slagging combustor, while burning $100 \%$ pulverized coal and operating at the design pressure of 6 atm.

- Because of the separate-chamber, rich-lean design of the subscale slagging combustor, $\mathrm{NO}_{\mathbf{x}}$ emissions that easily meet the NSPS limits are readily achieved.

- Carbon burnout efficiency in excess of $99 \%$ was achieved when $100 \%$ coal-fired.

- Ninety percent of the ash can be separated as slag in the impact separator, and 98 to $99 \%$ removed with the addition of a slagging cyclone separator.

- Objectives for third-stage exit temperature (1850 F), and exit temperature pattern factor (14\%) were readily achieved.

- Overall pressure loss is 5 to $6 \%$ without cyclone separator and 7 to $9 \%$ with the cyclone.

- Feeding pulverized coal or sorbent into the combustor against 6 atm pressure was achieved.

- Sulfur reductions in the third stage exhaust of up to $50 \%$ have been achieved.

- Vapor alkali measurements made with the Ames monitor showed that sodium vapor levels varied between 20 to $25 \mathrm{ppbw}$ ind the potassium vapor levels are in the range of 8 to $20 \mathrm{ppbw}$.

Based upon the technical accomplishments within this program, the development of a direct coal-fired combustion system that could be integrated into a combined cycle is feasible. Advantages of the TVC concept include:

- Its small size-to-Btu heat-release ratio.

- The production of an inert high-density of glass-type slag, which results from the melting of the mineral matter.

- The production of trace quantities of very fine relatively nonabrasive ash particulates.

- The potential for minimum $\mathrm{NO}_{\mathrm{x}}$ emissions through the destruction of fuel $\mathrm{NO}_{\mathrm{x}}$, and the prevention of thermal $\mathrm{NO}_{\mathbf{x}}$ generation.

- The nonequilibrium capture of sulfur, approximately $90 \%$, with calcia-based sorbents. 


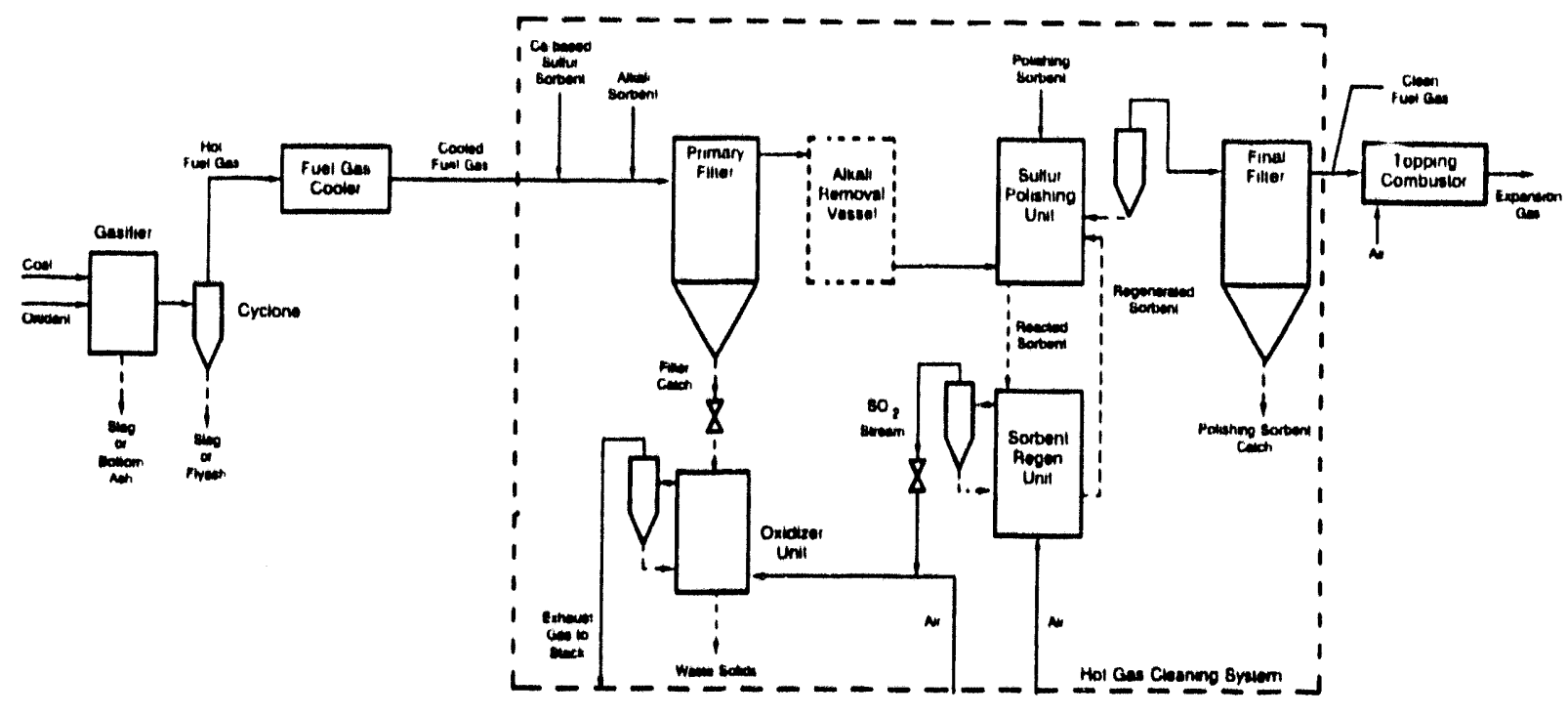

Fig. 7-1. Direct Coal-Fired Combined Cycle Plant

Various components of a direct coal-fired combined cycle have been the subject of investigations under several development programs over the last several years. These components, however, need to be integrated into an operating cycle as illustrated in Fig. 7-1.

As a next step, it would be prudent to prove operation and performance of the cycle components, individually and as a whole, before committing significant resources to a base load or repowering combined cycle project. For example, current data indicates that additional sulfur capture is required downstream of the slagging combustor. In order to reach an appropriate temperature region for equilibrium sulfur capture by limestone sorbents, the gas must first be cooled in a heat exchanger. Additional components to be evaluated include: hot-gas cleanup filter, sulfur capture polishing system, and topping combustion system (which is part of the TVC). In step 2, a $50 \mathrm{MMBtu} / \mathrm{hr}$ combustor would be installed in a component verification facility and operated at 6 and 14 atms.

A direct coal-fired combined cycle would have a combination of cycle simplicity, low emissions, high efficiency, fuel flexibility and competitive costs. In addition, the plant footprint would be relatively small. The combination of thermal and economic performance with reasonable space requirements makes this power generation concept attractive for either repowering or new capacity additions.

From other tasks completed within project, additional conclusions are:

- The current design of the CFCTCC is more economically competitive than a PC-FGD plant and would become more economically competitive than the gas and oil-fired CTCC if gas and oil fuel costs should become $>\$ 4.00 / \mathrm{MMBtu}$.

- The design of a 251B12 can be modified to meet the operational requirements of a PFBC.

- $60 \%$ efficient combined cycle plants fired with natural gas are possible. 
To support the attainment of a $60 \%$ plant cycle efficiency target, Westinghouse has defined an intercooled, recuperative combined cycle that has the combustion and steam turbines directly coupled to form a single shaft operating at 3600 RPM. To support the advanced combined cycle efficiency goal, cycle innovations, increased gas firing temperature, reduced cooling air usage, improved component efficiencies and improved material/coating systems will be needed. 
(This page intentionally loft blank.) 


\section{PROJECT BIBLIOGRAPHY}

\section{TECHNICAL PAPERS}

Abichandani, J. S., Loftus, P. J., Diehl, R. C., Woodroffe, J. A., and Holcombe, N. T., 1989, "NonEquillbrium Sulfur Removal for High Temperature Gases," 6th Annual Pittsburgh Coal Conference, Pittsburgh, PA.

Bannister, R. L., Newby, R. A., Wiant, B. C., Diehl, R. C., Eppich, H. M., Horazak, D. A., 1993, "A Direct Coal-Fired Advanced Combined Cycle for Repowering and New Base Load Generation," presented at EPRI International Symposium on Improved Technology for Fossil Power Plants - New and Retrofit Applications, March 1-3. Washington, D. C.

Bannister, R. L., Newby, R. A., Diehl, R. C., 1992, "Developing a Direct Coal-Fired Combined Cycle," Mechanical Engineering, Vol. 114, No. 12, pp. 64-70.

Bannister, R. L., Wiant, B. C., Jensen, A. R., Mach, F. V., Claeson, E. U., Raatika, L. M., Diehl, R. C., Eppich, H. M., and Newby, R. A., 1992, "Development of a Direct Coa-Fired Combined Cycle for Commercial Application", ASME Peper 92-OT-258.

Bannister, R. L., Pillsbury, P. W., Diehl, R. C., and Loftus, P. J., 1990, Recent Test Results in the Direct Coal-Fired 80 MW Combustion Turbine Program", ASME Paper 90-OT-58.

Diehl, R. C., Stickler, D. B., Loftus, P. J., Bannister, R. L., and Pillsbury, P. W., 1989, "A Direct CoalFired 80 MW Utility Combustion Turbine-Status Report", ASME Paper 89-GT-116.

Horazak, D. A., Buchanan, T. L., 1990, "Economic Evaluation of Process Alternatives for Direct CoalFueled Combustion Turbine Combined Cycle," EACT - Yol 2. Adranced in Solid Euels, pp. 39-46.

Hura, H. S., Loftus, P. J. and Dichl, R. C., 1991, "Cold Flow Modeling of a Cyclone for Particulate Removal in Direct Coal-Fired Gas Turbines, 8th Annual Pittsburgh Coal Conference, Pittsburgh, PA.

Jensen, A. R., Mach, F. V., Claeson, E. U., Rantikka, L. M., Mataczynskd, C. A., Bannister, R. L., Newby, R. A., Scalzo, A. J., Wiant, B. C., Diehl, R. C., Eppich, H. M., Krippene, B. C. and Wilbur, J. T. 1992. "Development of a Direct Coal-Fired Advanced Combined Cycle Concept for Repowering and Now Base Load Generation", ASME Paper 92-JPGC-OT-4.

Little, D. A., Bannister, R. L., Wiant, B. C., 1992, "Development of Advanced Gas Turbine Systems," to be presented at ASME Cogen Turbo Power Conference, September 21-23, Bournemouth, U.K.

Lottus, P. J., Diehl, R. C., Bannister, R. L., and Pillsbury, P. W., 1991, "NOx Control in a Slagging Combustor for a Direct Coal-Fuel Utility Gas Turbine," EPAEPRI Conference on Stationary Combustion $\mathrm{NO}_{x}$ Control, Washington, D.C.

Lottus, P. J., Diehl, R. C., Stickler, D. B. and Bannister, R. L., 1991, "Slag Utilization and Behavior in a Pressurized Gas Turbine Coal Combustor," Engineering Foundation Conference on Inorganic Transformations and Ash Deposition During Combustion, Palm Coast, FL. 
Lottus, P. J., Chatwanl, A. U., Turan, A. and Stickler, D. B., 1988, "The Use of 3-D Numerical Modeling in the Design of a Gas Turbine Coal Combustor," "Heat Tmasfor in Gas Tumbine Engines and Three-Dimensional Elows ASME HTDD. Vol. 103, pp 95-105.

Pillsbury, P. W., Bannister, R. L., Diebl, R. C., and Loftus, P. J., 1989, "Direct Coal Firing for Large Combustion Turbines: What Do Economic Projects and Subscale Combustor Tests Show?", ASME Paper 89.JPOC/OT 4.

Thoman, R. J., Horazak, D. A., Hals, F. A., 1987, "Development of Coal-Fueled Gas Turbine Systems for Electric Utility Applications, "ASME Paper 87-0T-271.

\section{DOE REPORTS}

Advanced Coal-Fueled Gas Turbine Systems, Topical Report, June 1993, "Generic Turbine Deaign Study," DOE Report No. DOE/MC/23167-?.

Advanced Coal-Fueled Oas Turbine Systems, Topical Report, May 1993, "Subscale Combustion Testing," DOE Report No. DOE/MC/23167-?.

Advanced Coal-Fueled Gas Turbine Systems, Quarterly Report, Jan. - Mar. 1992, DOE Report No. DOEMC/23167-3099, NTIS-DE92018939.

Advanced Coal-Fueled Gas Turbine Systems, Quarterly Report, July - Sept 1992, DOE Report No. DOEMC/23167-3215.

Advanced Coal-Fueled Oes Turbine Syatems, Qunrterly Roport, Oct. - Dec. 1992, DOE Report No. DOE/MC/23167-3297.

Advanced Coal-Fueled Gas Turbine Systems, Annunl Report, July 1991 - June 1992, DOE Report No. DOEMMC/23167-3321, NTIS-DE93000257.

Advanced Con-Fuoled Oas Turbine Systems, Annual Report, July 1990 - June 1991, DOE Report No. DOE/MC/23167-3065, NTIS-DE92001145.

Advanced Coal-Fueled Gas Turbine Syrtems, "Reference System Definition Update," Topical Report, Sept. 1991, DOE Report No. DOE/MC/23167-3056, NTIS-DE92001119.

Advanced Coal-Fueled Gas Turbine Systems, Quarterly, Jan.-Mar. 1990, DOE Report No. DOE/MC/23167-2874, NTIS-DE90009695.

Advanced Coal-Fueled Gas Turbine Systems, Annual Report, July 1989 - June 1990, DOE Report No. DOE/MC/23167-2920, NTIS-DE91002013.

Advanced Coal-Fueled Gas Turbine Systems, Quarterly Report, Oct. - Dec. 1989, DOE Report No. DOE/MC/23167-2812, NTIS-DE90010052.

Advanced Coal-Fueled Gas Turbine Systems, Annual Report, July 1988 - June 1989, DOE Report No. DOEMC/23167-2836, NTIS-DE90009669. 
Advanced Coal-Fueled Gas Turbine Systems, Annual Report, Vol. 1, July 1987 - June 1988, DOE Report No. DOE/MC/23167 - 2678, NTIS-DE89000953.

Advanced Coal-Fueled Gas Turbine Systems, 1988, Annual Report, Vol. 2, July 1987 - June 1988, DOE Report No. DOE/MC/23167-2678, NTIS-DE89000954.

Advanced Coal-Fueled Oas Turbine Systems, Semiannual Report, Jan. - June 1987, DOE Report No. DOE/MC/23167-2400, NTIS-DE8700651S.

Advanced Coal-Fueled Oas Turbine Systems, Semiannual Report, July - Dec. 1986, DOE Report No. DOE/MC/23167-2277, NTIS-DE87001066. 

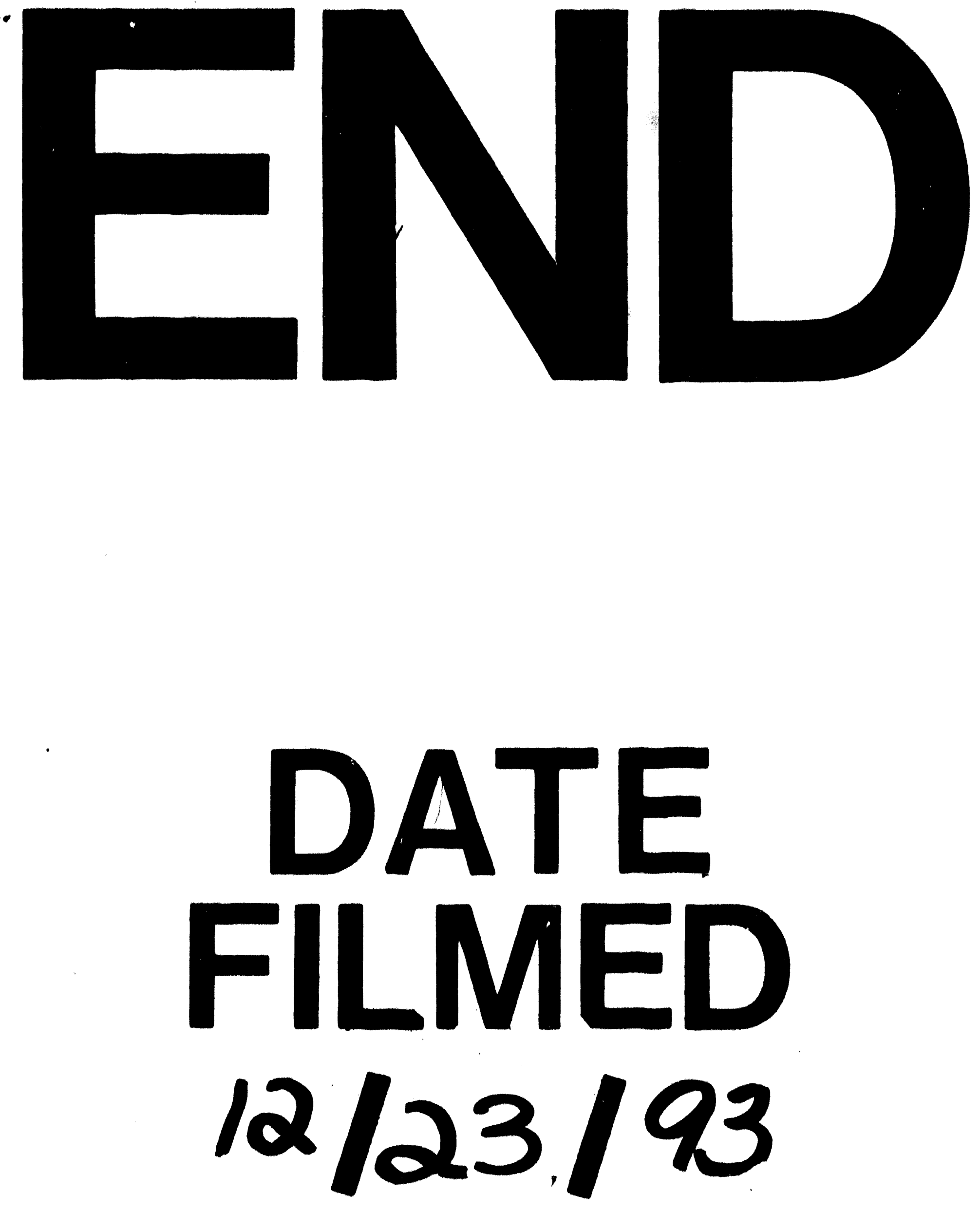

1 
